NBER WORKING PAPER SERIES

\title{
WHAT DETERMINES CONSUMER FINANCIAL DISTRESS? PLACE- AND PERSON-BASED FACTORS
}

\author{
Benjamin J. Keys \\ Neale Mahoney \\ Hanbin Yang \\ Working Paper 26808 \\ http://www.nber.org/papers/w26808
NATIONAL BUREAU OF ECONOMIC RESEARCH
1050 Massachusetts Avenue
Cambridge, MA 02138
February 2020

The results in this paper were calculated (or derived) based on credit data provided by TransUnion, a global information solutions company, through a relationship with the Kilts Center for Marketing at The University of Chicago Booth School of Business. All views expressed and any errors contained in this paper are solely those of the authors. We thank Bruno Escobar Izquierdo and Xuyang Xia for excellent research assistance and seminar audiences at the Bank of England, the Central Bank of Ireland, Dartmouth, Georgetown, Imperial College London, the J.P. Morgan Chase Institute, Kellogg, NYU-Stern, Washington University, and the Wharton School for helpful comments. Keys thanks the Research Sponsors Program of the Zell/Lurie Real Estate Center. Mahoney acknowledges support from the Initiative on Global Markets at the University of Chicago Booth School of Business. The views expressed herein are those of the authors and do not necessarily reflect the views of the National Bureau of Economic Research.

NBER working papers are circulated for discussion and comment purposes. They have not been peer-reviewed or been subject to the review by the NBER Board of Directors that accompanies official NBER publications.

(C) 2020 by Benjamin J. Keys, Neale Mahoney, and Hanbin Yang. All rights reserved. Short sections of text, not to exceed two paragraphs, may be quoted without explicit permission provided that full credit, including $(\subset$ notice, is given to the source. 
What Determines Consumer Financial Distress? Place- and Person-Based Factors

Benjamin J. Keys, Neale Mahoney, and Hanbin Yang

NBER Working Paper No. 26808

February 2020

JEL No. G5,G51,K35

\title{
ABSTRACT
}

We use credit report data to study consumer financial distress in America. We show there are large, persistent disparities in financial distress across regions. To understand these patterns, we conduct a "movers" analysis. For collections and default, there is only weak convergence following a move, suggesting these types of distress are not primarily caused by place-based factors (e.g., local economic conditions and state laws) but instead reflect person-based characteristics (e.g., financial literacy and risk preferences). In contrast, for personal bankruptcy, we find a sizable place-based effect, which is consistent with anecdotal evidence on how local legal factors influence personal bankruptcy.

\author{
Benjamin J. Keys \\ Department of Real Estate \\ The Wharton School \\ University of Pennsylvania \\ 432 Vance Hall \\ 3733 Spruce Street \\ Philadelphia, PA 19104 \\ and NBER \\ benkeys@wharton.upenn.edu \\ Neale Mahoney \\ Department of Economics \\ Stanford University \\ 579 Jane Stanford Way \\ Stanford, CA 94305 \\ and NBER \\ nmahoney@stanford.edu
}

Hanbin Yang

Harvard University

hanbin.v.yang@gmail.com 


\section{Introduction}

Consumer financial distress in the United States is high in both absolute and relative terms. In credit report data, one-third of individuals have at least one debt in collections and nearly $5 \%$ have declared bankruptcy in the last 7 years. ${ }^{1}$ While there is no perfect data for relative comparisons, the available data indicate that financial distress is much higher in the U.S. than in Europe. ${ }^{2}$

In this paper, we aim to advance our understanding of consumer financial distress in the U.S. by examining patterns of financial distress across geographic areas. We measure financial distress using a nationally representative panel of TransUnion credit report data that tracks approximately 35 million individuals on a monthly basis over 2000-2016. We focus our analysis on three common metrics of financial distress - debt in collections, credit card delinquency, and personal bankruptcy. We emphasize these metrics because our aim is to observe financial distress for the broadest possible segment of the population. Other financial products - such as home loans and auto loans - are held by a smaller and less representative sample of the population, and thus provide us with a narrower window on people at risk of default.

The first part of our paper documents large and persistent geographic disparities in financial distress between the Upper Midwest and Deep South regions of the country. ${ }^{3}$ In the Deep South, $44 \%$ of people with a credit report have unpaid debt in collections versus $24 \%$ in the Upper Midwest. Similarly, measures of credit card delinquency and bankruptcy are $40 \%$ to $50 \%$ higher in the Deep South than in the Upper Midwest.

The main part of the paper aims to better understand what determines these persistent geographic disparities. As we show in a variance decomposition, roughly three-quarters of the variation in financial distress over 2000-2016 occurs across geographic areas, as op-

\footnotetext{
${ }^{1}$ Authors' calculations using credit bureau data from June 2015. See Section 2 for more details.

${ }^{2}$ For the sake of comparability, it is useful to rely on survey data from similar years. According to the 2007 Survey of Consumer Finances, 20.8\% of U.S. households are late on their debt payments (https://www.federalreserve.gov/pubs/bulletin/2014/articles/scf/scf.htm). In contrast, the EU-SILC (Statistics on Income and Living Conditions) 2008 ad hoc module indicates a median rate of arrears across E.U. countries of $3.2 \%$ on mortgage loans and $1.2 \%$ on non-mortgage loans (http:/ / ec.europa.eu/eurostat/web/income-and-living-conditions/data/ad-hoc-modules).

${ }^{3}$ We define the Upper Midwest as Iowa, Minnesota, North Dakota, South Dakota, Wisconsin, and the Upper Peninsula of Michigan and the Deep South as Alabama, Arkansas, Georgia, Louisiana, Mississippi, and South Carolina.
} 
posed to within geographic areas over time. Our goal is to understand the sources of these cross-sectional differences. We do not attempt to uncover the drivers of over-time variation in financial distress that is often the focus of macroeconomic analysis.

Much of the existing research on the sources of financial distress can be separated into two categories. One category emphasizes local institutional and economic factors, such as state-level bankruptcy laws (e.g., Fay, Hurst and White, 2002; Auclert, Dobbie and Goldsmith-Pinkham, 2019) and local economic conditions (e.g., Agarwal and Liu, 2003). A second category emphasizes individual characteristics, such as preference parameters (e.g., discount rates, risk preference, default stigma, social capital) and behavioral factors (e.g., inattention, financial literacy). ${ }^{4}$

We quantify the relative importance of these categories using a "movers" research design that examines how financial distress evolves when individuals move to places with different levels of financial distress. If local institutional and economic factors are important, we would expect outcomes to converge to those in the new location. If financial distress is determined by individual characteristics, we would not expect any convergence. In keeping with the movers design literature, we will sometimes refer to local institutional and economic factors as "place effects" and individual characteristics as "person effects" (e.g., Finkelstein, Gentzkow and Williams, 2016). ${ }^{5}$

We operationalize this movers research design by estimating event-study regressions of a given outcome on the "size of the move," defined as the average difference in that outcome between the origin and destination areas, controlling for individual and time fixed effects. We show robustness to defining the size of the move using narrower and broader levels of geographic aggregation and to estimating two-way fixed effects models that relax assumptions implicit in the event-study design.

The identifying assumption for the movers research design is the standard parallel

\footnotetext{
${ }^{4}$ See e.g. Gross and Souleles (2002) on default stigma, Agarwal, Chomsisengphet and Liu (2011) on "individual social capital," and Gerardi, Goette and Meier (2013) on financial literacy.

${ }^{5}$ As noted in the prior literature, individual characteristics may be shaped by the local environment, especially at young ages (e.g., Bronnenberg, Dube and Gentzkow, 2012; Finkelstein, Gentzkow and Williams, 2016). As such, the person effects we estimate may partially embed the place effects of where people grew up. That being said, we think it is appropriate in most contexts to refer to these characteristics as person effects, since they are persistent features of individual behavior that are not affected over the medium run by local institutional or cultural factors.
} 
trends assumption - conditional on controls, the size of the move is uncorrelated with differential changes in the outcome not caused by the move. A natural concern is that people move to less expensive and potentially more distressed locations in response to persistent negative shocks to their economic circumstances (e.g., job loss) or conversely move to economically vibrant locations in response to persistent positive shocks. We provide two sets of evidence in support of our identifying assumption.

First, we show there is no correlation between the size of the move and the pre-move trend in our outcomes. For instance, in our event study plots, there is no evidence of an effect prior to the move, and an effect that occurs fairly precisely, though gradually, after the move takes place. ${ }^{6}$

Second, we show that we obtain similar results when we exclude potentially problematic variation. To address concerns about bias from origin-specific shocks, we isolate variation from individuals who move "from the same origin" to destinations with different financial distress. To address concerns about bias from destination-specific shocks, we isolate the complementary variation from individuals who move "to the same destination" from origins with different financial distress.

We address the concern that financial distress experienced shortly after a move may reflect place effects from the prior location by focusing on outcomes 6 years after the move. Bronnenberg, Dube and Gentzkow (2012) show that in a Becker and Murphy (1988) type model - where behavior today depends on the depreciated sum of past behavior - place effects asymptote to their true value as the stock of "preference capital" depreciates. For our outcomes, place effects reach their steady states within 6 years, indicating that these results no longer embed the effects of the prior location. ${ }^{7}$

We find that credit card delinquency and debt in collections converge by less than $10 \%$ at 6 years post move. In other words, the place-based component accounts for less than one-tenth of the geographic variation in financial distress between areas, while the

\footnotetext{
${ }^{6}$ With monthly updates of zip code based on the mailing address of the individual, the depersonalized credit report data allows us to closely track household location.

${ }^{7}$ For our movers analysis, we also focus on "flow" measures of financial distress that reflect recent changes to the credit report, which eliminate any mechanical relationship between current financial distress and financial distress that was incurred at the prior location. However, since virtually all items must be removed from credit reports at 7 years, and in practice most items fall off credit reports in less than 6 years, the results using "stock" measures are very similar.
} 
person-based component accounts for the remaining nine-tenths.

The small convergence for debt in collections masks a substantially larger place-based component of roughly $20 \%$ for medical debt in collections. This finding is consistent with local medical providers (e.g., doctors offices and hospitals) having a meaningful impact on overall debt in collections through heterogeneous collection practices. However, taken together, these results imply that for collections and default, individual characteristics are the dominant force.

In stark contrast to the results discussed above, we find a sizable place-based component for the likelihood of filing for bankruptcy. At 6 years after a move, bankruptcy filing rates converge by roughly one-quarter of the origin-destination difference for Chapter 7 and one-third of the difference for Chapter 13.

Chapter 13 results, to some extent, reflect an underlying informational theory of geographic variation. Under an informational theory, when individuals move to a place with higher Chapter 13 filing rates, they learn about Chapter 13 and there is an increase in the rate of filing. However, when individuals move to locations with lower Chapter 13 filing rates, they do not unlearn what they previously knew, and so there is not a symmetric decrease in filing. We find that Chapter 13 effects are more than twice as large for moves to places with higher Chapter 13 filing rates than moves to places with lower filing rates. This type of informational theory is supported by previous anecdotal evidence on the importance of lawyer networks and legal traditions in the Chapter 13 filing decision (Sullivan, Warren and Westbrook, 1994; Jacoby, 2014) and parallels a finding in Chetty, Friedman and Saez (2013), who document a similar asymmetry in take-up of the earned income tax credit. $^{8}$

We also find larger place effects for across-state moves than for within-state moves, especially for Chapter 13 filings. Since bankruptcy laws vary at the state level, the larger place effects for across-state moves are consistent with an important role for state-level bankruptcy laws in determining bankruptcy filings.

To summarize our findings in one sentence: Individual characteristics determine whether

\footnotetext{
${ }^{8}$ Unlike prior work, we do not find any persistent correlation between our place effects and local or economic factors. We discuss these results and their interpretation in Section 5.
} 
you get into financial distress, while place-based factors determine whether you use bankruptcy to get out.

While we believe our research design is valid, the most likely violation of our identifying assumption would bias upwards our place-based effects. This violation would occur if moves to more distressed areas were precipitated by negative shocks, such as job loss, that directly cause financial distress. To the extent it exists, upward bias works against our finding of small place-based effects for debt in collections and credit card non-payment, and it would preserve our finding of relatively larger place-based effects for personal bankruptcy.

Taken together, this set of facts helps prioritize competing theories of financial distress, and is thus useful for guiding future research and policy discussions. A large literature in economics and finance - including work by ourselves - has examined the effects of local institutional factors (e.g., state laws, local lending practices) on credit market outcomes. ${ }^{9}$ Our finding of statistically significant place-based effects is consistent with the results from this literature. However, with the exception of bankruptcy, our finding that place-based factors only account for a small share of the geographic differences suggests that these factors are only of limited quantitative importance for understanding the substantial geographic variation in financial distress we document. ${ }^{10}$

Conversely, the large person-based components for these outcomes suggest an important role for persistent individual characteristics in explaining the observed geographic variation in financial distress. Such characteristics may include financial literacy and human capital; household wealth and intergenerational transfers; and risk preferences, default stigma, or discount rates. These findings are consistent with new evidence on the origins and persistence of financial distress at the individual level (Athreya, Mustre-del Río and Sánchez, 2019; Brown, Cookson and Heimer, 2019) and are germane to the broader discussion on the determinants of consumer financial distress (Dynan, 2009; Porter, 2012).

Finally, our research adds a new finance-related dimension to a rapidly growing literature that seeks to separate geographic and institutional factors from individual character-

\footnotetext{
${ }^{9}$ See, for instance, Gropp, Scholz and White (1997); Pence (2006); Dick and Lehnert (2010); Mahoney (2015); Han, Keys and Li (2017).

${ }^{10}$ Note that our results do not suggest that place-based effects are not important. Many place-based factors, such as peer effects in Agarwal, Mikhed and Scholnick (2020) and Kalda (2020), can have a significant influence on individual financial outcomes, but do not explain the geographic variation in financial distress.
} 
istics using movers designs. This literature includes research on brand preferences (Bronnenberg, Dube and Gentzkow, 2012), health care costs, behavior, and outcomes (Finkelstein, Gentzkow and Williams, 2016, 2018, 2019; Hinnosaar and Liu, 2020), and intergenerational mobility (Chetty and Hendren, 2018a,b), among other topics.

The remainder of the paper proceeds as follows. Section 2 describes our data and presents summary statistics on our measures of financial distress. Section 3 documents the geographic variation in financial distress. Section 4 provides the econometric methodology of our movers approach. Section 5 conducts the analysis that decomposes the variation in financial distress into person- and place-based components. Section 6 concludes.

\section{Data}

\subsection{Credit Report Data}

We measure financial distress using a monthly panel of credit reports over 2000-2016 from TransUnion, one of the three national credit reporting agencies. ${ }^{11}$ The panel is based on a random 10\% sample of individuals with TransUnion credit records in 2000. In each month, a small percentage of individuals leave the panel (e.g., due to death). To maintain a representative sample, each month a random $10 \%$ sample of individuals with new credit reports is added to the panel.

In the average month, we observe data for 35.6 million individuals. We drop individuals if they have missing age information; most of these individuals have very little credit utilization. We also drop individuals who are older than 80 or younger than 20 . In the average month, the resulting sample has 30.1 million individuals.

For each individual $\times$ month observation, we observe two types of data. First, we observe individual-level information, such as zip code, age, credit score, and aggregated data on loans (e.g., aggregate credit card balances). ${ }^{12}$ Second, we observe line-item information on trades (e.g., specific credit cards), debts in collection, and public records (e.g,

\footnotetext{
${ }^{11}$ TransUnion approved a proposal for this project and then reviewed the working paper to ensure compliance with the project proposal.

${ }^{12}$ TransUnion receives updated addresses from data furnishers (e.g., lenders) on a monthly basis. Individuals typically provide their new address to their lenders, who in turn will supply that information to TransUnion. The majority of address updates occur through this channel; individuals sometimes also contact TransUnion Consumer Relations to update their address information.
} 
bankruptcies). We use these data to construct our primary measures of financial distress. More detail on variable construction is provided in Appendix Section A.

Bankruptcy: Filing for bankruptcy allows individuals to discharge their debts, stop foreclosure or repossession of property, and prevent wage garnishment. Bankruptcy is often considered a "last resort" and thus serves as an indicator for serious financial distress. We construct an indicator for whether the individual has declared bankruptcy in the last 3 years, and separate indicators for whether they have filed under Chapter 7 or Chapter 13 of the bankruptcy code in the last 3 years. We use a 3-year window to smooth over noise in more high-frequency measures, since bankruptcy is a rare outcome.

Credit card delinquency: Credit card delinquency occurs when an individual is 30 days or more past due (30+ DPD) on their required monthly payments. Compared to bankruptcy, delinquency is an early indicator of financial distress. To align with our bankruptcy measure, we construct an indicator for whether an individual has become delinquent on any credit card during the last 3 years, for all individuals with a credit report and conditional on those with a credit card.

Debt in collections: Debt in collections is debt reported to TransUnion by third-party debt collectors. Third-party collectors acquire debt from primary creditors, such as health care providers, financial institutions, and utilities (Appendix Table A1 provides a breakdown of collections by creditor). For instance, health care providers typically sell accounts to collectors after 180 days and credit card issuers usually write off accounts and sell their debt when borrowers are 180 days past due. Depending on state laws, debt collectors may contact debtors by letter or phone about outstanding debts, and can also attempt to collect through wage garnishment. Debt collectors may cease reporting for a variety of reasons, including when the debtor agrees to a repayment plan or when the account is paid in full. Debts in collection cannot be reported more than 7 years after the initiating event. See CFPB $(2016,2021)$ for more details.

To align with our bankruptcy and credit card delinquency measures, we construct an indicator for whether an individual has received at least one new collection account during the past 3 years and a measure of total collections balances accrued in the past 3 years.

Debt collections that are more than 3 years old are still a liability for individuals and 
thus informative of financial distress. Hence, to complement the flow measure of debt accrued during the last 3 years, we also construct stock measures of whether the individual has at least one debt in collections and their total collection balance, regardless of when the collection was incurred. Since collection items are deleted from credit reports after 7 years, the stock variables can reflect collections accrued up to 7 years ago. ${ }^{13}$ For the stock measures, we are also able to separately identify medical and non-medical debt in collections, and we construct indictors for having at least one debt in collections and collections balances in each category. ${ }^{14}$

As mentioned in the introduction, we focus on these measures because they provide the broadest possible window into financial behavior. Other financial products - such as home loans - are held by a smaller and more affluent sample of the general population. Because of this, the set of individuals who are "at risk" for financial distress for this product is less broadly representative.

\subsection{Summary Statistics}

Table 1 shows summary statistics for our key measures of financial distress, and other measures we use in robustness analysis, as of June $2015 .^{15}$

The top two panels show statistics for debt in collections. Over the last 3 years, $28.4 \%$ of individuals have incurred new collections. Unconditional on incurring debt, individuals have accrued an average of $\$ 818$ in balances in the last 3 years, implying average balances of $\$ 2,880$ among those who have accrued debt. The stock measures are only modestly higher. Debt in collections (1+ debt in collections) are held by $34.1 \%$ of the sample, with $22.1 \%$ holding some medical debt and $24.2 \%$ holding some non-medical debt in collections. This pattern suggests that roughly four-fifths of those with debt in collections have accrued new collections items in in the last 3 years (28.4\% out of $34.1 \%)$. The unconditional stock

\footnotetext{
${ }^{13}$ As shown in Appendix Figure A1, most debt in collections reported to credit bureaus is fairly recent; for a given vintage of debt in collections, about $60 \%$ of collections items are no longer reported at a time horizon of 3 years.

${ }^{14}$ We are unable to separate flow measures into medical and non-medical debt due to data limitations. Specifically, prior to 2009, we are unable to separately identify medical debt in the line-item collections data, and therefore cannot observe the origination date separately for medical vs. non-medical debt in collections for the first part of our sample.

${ }^{15}$ We use the midpoint of 2015, rather than the start or end of the year, to avoid the unrepresentativeness of the holiday period.
} 
of collection balances are $\$ 1,351$ on average.

Our estimate of the percentage of individuals with debt in collections compares well to other sources. Using data from an unnamed major credit bureau, the Urban Institute reports that 33\% of individuals have at least one debt in collections in 2016 (Urban Institute, 2019), which is almost identical to our stock measure of $34.1 \%$. In a nationallyrepresentative survey conducted by the Kaiser Family Foundation / New York Times, 27\% percent of 18-to-64-year-olds report being contacted by a collection agency in the prior 12 months (Hamel et al., 2016).

The bottom two panels of Table 1 show statistics for credit card delinquency and bankruptcy. Our data indicate that $10.1 \%$ of individuals become delinquent on a credit card over the past 3 years. Conditional on having a credit card, 14.2\% become delinquent over the past 3 years. We estimate that 14.8 in 1,000 individuals have filed for bankruptcy over the last 3 years, with 10.5 in 1,000 filing under Chapter 7 and 4.5 in 1,000 filing under Chapter 13. The overall bankruptcy rate is identical to that reported in New York Fed's Consumer Credit Panel over this time period (NYFed, 2019). ${ }^{16}$

Accurate measurement of when individuals move is important for our movers analysis. To validate the measurement of moves in the TransUnion data, Appendix Table A2 reports the frequency of moves in the TransUnion data, Current Population Survey, and American Community Survey across different geographic units (any move, move across zip code, move across county, move across state), different time horizons (1 year and 5 years), and at different points in time (2005 and 2015). The table shows that for all the outcomes where there is overlap, the frequency of moves is quite similar in the TransUnion data to the rates reported in the CPS and ACS.

\section{Geographic Variation}

In this section, we discuss the sharp geographic disparities in financial distress across regions within the United States. To motivate our focus on cross sectional differences - in contrast with the time-series variation emphasized in macroeconomic analysis - we start

\footnotetext{
${ }^{16}$ The rate of Chapter 7 and Chapter 13 bankruptcies sum to greater than the combined bankruptcy rate because individuals sometimes file under Chapter 7 and Chapter 13 in close succession. This is colloquially known as filing under "Chapter 20."
} 
by presenting a variance decomposition of financial distress. In particular, for each measure of financial distress, Table 2 shows the decomposition of the pooled variation into the time-series and cross-sectional components, based on a panel dataset of average financial distress for each commuting zone $(\mathrm{CZ}) \times$ year. $^{17}$ For nearly all of the outcomes, more than half of the variation is cross-sectional, and for half of the outcomes more than three-quarters of the variation occurs across CZs rather than within CZs over time.

Figure 1 presents maps of our key measures of financial distress. The maps are based on June 2015 data aggregated to the CZ level. ${ }^{18}$ Table 3 shows summary statistics for these CZ-level data, also from June 2015. In this table, we weight the CZ-level data by the number of individual-level observations in each $\mathrm{CZ}$ so that the statistics are representative of the underlying individual-level data.

Panel A of Figure 1 shows the percentage of individuals with debt in collections (1+ debt in collections) in the past three years. The map shows strikingly high rates of financial distress in the Deep South and low rates in the Upper Midwest. ${ }^{19}$ Specifically, Table 3 indicates that the percentage of individuals with debt in collections is $87 \%$ higher in the Deep South than the Upper Midwest (37.3\% vs. 19.9\%). We think this large geographic difference is intrinsically interesting and focus our analysis on the comparison between these two regions in the remaining discussion in this section. We note, however, that Table 3 shows other measures of the variation in distress across CZs.

The sharp geographic differences are similar for the stock measure of debt in collections and also for medical and non-medical debt in collections (Appendix Figure A2). However, as shown in Table 3, the differences are larger for medical debt (31.6\% vs. 14.4\%)

\footnotetext{
${ }^{17}$ Let $x_{i t}$ be the average level of financial distress in CZ $i$ and year $t$. The overall variation can be decomposed according to

$$
\sum_{i=1}^{N} \sum_{t=1}^{T}\left(x_{i t}-\overline{\bar{x}}\right)^{2}=\underbrace{\sum_{i=1}^{N}\left(\sum_{t=1}^{T}\left(x_{i t}-\bar{x}_{i}\right)^{2}\right)}_{\text {over-time }}+\underbrace{\sum_{i=1}^{N} T\left(\bar{x}_{i}-\overline{\bar{x}}\right)^{2}}_{\text {cross-sectional }},
$$

where $\bar{x}_{i}$ is average over time within $\mathrm{CZ} i$ and $\overline{\bar{x}}$ is the pooled average across CZs and years.

${ }^{18}$ Commuting zones are clusters of counties characterized by strong within-cluster commuting ties. There are $741 \mathrm{CZs}$ in the United States. Unlike metropolitan statistical area (MSA) designations, CZs cover the entire landmass of the United States.

${ }^{19}$ As we mention in Section 1, we define the Deep South as Alabama, Arkansas, Georgia, Louisiana, Mississippi, and South Carolina, and the Upper Midwest as Iowa, Minnesota, North Dakota, South Dakota, Wiscon$\sin$, and the upper peninsula of Michigan.
} 
than for non-medical debt in collections $(29.1 \%$ vs. $17.4 \%)$. The differences in medical debt may reflect the initial impact of the ACA Medicaid expansions, which most Southern states did not take part in. However, there were large differences prior to the 2014 Medicaid expansions, and most of the impact of the expansions does not materialize in the stock of medical debt in collections until after June 2015. ${ }^{20}$ The differences between the Deep South and Upper Midwest are proportionally similar when we examine average collection balances, overall and separately for medical and non-medical debt. The maps for these outcomes are somewhat less crisp, partially due to the increased noisiness of these measures (Appendix Figure A3).

Panel B of Figure 1 shows the percentage of individuals with at least one credit card delinquency (30+ DPD) over the past three years. Like debt in collections, there is a sharp geographic disparity, with credit card delinquency rates $49 \%$ higher in the Deep South than in the Upper Midwest (10.7\% vs. $7.2 \%)$. We focus on credit cards because they are widely held (71\% of individuals in our data). However, as shown in Panel A of Appendix Figure A4, credit card holding rates are lower in the Deep South. Thus, if we condition on having a card, the difference in credit card delinquency grows to $84 \%$ (17.1\% vs. $9.3 \%)$.

We next turn to bankruptcy filings, which, as discussed in Section 2, are measured as filings over the last 3 years per 1,000 people. As shown in Table 3, overall bankruptcy filings are 37\% higher in the Deep South than in the Upper Midwest (19.8 vs. 14.5 per 1,000). ${ }^{21}$ However, as shown in Panels C and D of Figure 1, these overall numbers mask large differences by chapter. Chapter 13 filing rates are almost 4 times higher in the Deep South than in the Upper Midwest (10.8 vs. 2.8 per 1,000). Chapter 7 filings, on the other hand, are concentrated in a region that stretches from Michigan in the north through Indiana and Ohio to Kentucky and Tennessee in the south. This alternative pattern means that Chapter 7 rates are 23\% lower in the Deep South than in the Upper Midwest (9.2 vs. 11.9 per 1,000). Alternatively put, while Chapter 13 accounts for $30 \%$ of bankruptcies nationwide, Chapter 13 accounts for 55\% in the Deep South and only 19\% in the Upper Midwest.

\footnotetext{
${ }^{20}$ See Kluender et al. (2021) on how the Medicaid expansions reduced medical debt in collections and Argys et al. (2017) and Gallagher, Gopalan and Grinstein-Weiss (2019) on the broader link between health insurance and financial distress.

${ }^{21}$ A map of overall bankruptcy rates is shown in Panel B of Appendix Figure A5.
} 
These differences in the chapter of filing, which have been documented in prior studies, are thought to reflect lawyer networks and differences in legal traditions (Foohey et al., 2016).

The measures we construct are based on credit report data, and thus condition on individuals with a credit report. According to Brevoort, Grimm and Kambara (2016), 89\% of adults have a credit report, so the averages are roughly representative of the national population. Notably, the geographic disparities we document would be even greater as measured relative to the adult population in each region. Panel B of Appendix Figure A4 shows the number of individuals with a credit report in our data as a percentage of individuals aged 20-80 calculated from the 2015 American Community Survey. As expected, our $10 \%$ sample of credit bureau data covers roughly $10 \%$ of the adult population. However, our coverage rates are higher in the Deep South than in the Upper Midwest $(13.6 \%$ vs $12.2 \%){ }^{22}$ This implies that if we adjusted for the underlying population, our measures of financial distress would be relatively higher in the Deep South and relatively lower in the Upper Midwest, further increasing the disparities.

A natural question is whether these differences we document using July 2015 data are persistent features of these geographic areas or reflect more transitory or cyclical factors. For our key outcomes, Appendix Figure A6 plots the rank of each CZ in 2015 against the rank in 2001. For debt in collections and credit card delinquency, the slope coefficients are 0.89 and 0.69 respectively, indicating that a CZ ranked 100 places higher in 2001 is ranked 89 to 69 places higher in 2015. In other words, while there is variation in the absolute level of financial distress over the business cycle, the relative rank of geographic areas in the U.S. is remarkably stable over time. ${ }^{23}$

For Chapter 7 and Chapter 13 bankruptcy, rank stability ranges from 0.55 to 0.74 , which is strong but lower than the persistence of the collections and credit card measures. The lower persistence of the bankruptcy measures may reflect the 2005 bankruptcy re-

\footnotetext{
${ }^{22}$ The high coverage rates in the Deep South are driven by people who do not have credit activity, such as people who only have a credit report because they have medical debt in collections. To see this, Panel $\mathrm{C}$ of Figure A4 displays the percentage of the population with a credit report but no trade accounts (i.e., no loans). The higher rate in the Deep South vs. the Upper Midwest (2.3\% vs. $1.2 \%)$ explains virtually the entire gap in coverage rates.

${ }^{23}$ Appendix Figure A7 shows that the results are very similar when we examine the correlation in outcomes over time.
} 
form (BAPCPA), which changed the incentives on both the extensive and chapter-of-filing margins (Mitman, 2016; Gross et al., 2018). The differences may also reflect the fact that bankruptcy filings, and in particular Chapter 13, are more strongly related to negative housing market shocks, which have been less persistent over time.

\section{Econometric Framework}

In the prior section, we documented large, persistent differences in financial distress within the U.S. In this section, we present an econometric framework for a "movers" analysis that decomposes this variation in financial distress to place- and person-based components. The place-based component captures local institutional and economic factors - such as state level bankruptcy laws and local economic conditions - that have been emphasized by one branch of the literature. The person-based component captures individual characteristics - such as preference parameters (discount rates, risk preference) and behavioral factors (e.g., inattention, financial literacy) - that have been highlighted by other research.

For this analysis, we restrict our sample to individuals we observe for the entire sample window and who are between 30 and 80 years of age, inclusive, in the last period. Motivated by the CZ-level variation documented above, we also focus our analysis on individuals who move across CZs, rather than considering more local moves. Specifically, our baseline sample restricts to individuals who have exactly one across-CZ move, with the move occurring between 2004 and 2007, inclusive. For these individuals, we can observe at least 4 years of pre-move data, which is important for examining pre-existing trends, and we can observe at least 8 years of post-move outcomes.

The longer time horizon allows us to examine the dynamics of the place effects. For instance, in a Becker and Murphy (1988) type model, where behavior today depends on the depreciated sum of past behavior, place effects asymptote to their true value as the stock of "preference capital" acquired at the prior location depreciates. The longer time horizon also addresses concerns that short-run effects may be attenuated towards zero by measurement error in the exact timing of the move. Restricting the sample to moves that occur in 2007 or earlier also avoids moves that were precipitated by the financial crisis. We discuss robustness to including these movers below. The resulting sample consists of 
145,805 movers, with a roughly even number of moves across years. ${ }^{24}$

Let $y_{i t}$ indicate an outcome for individual $i$ in time period $t$, where time is measured in quarters. Let $r$ indicate "event time" or quarters relative to the move, with $r=-1$ indicating the last quarter in the origin and with $r=0$ indicating the first quarter in the destination location. For each outcome and individual $i$, we construct our measure of the size of the move, $\widehat{\delta}_{i}$, as the average difference in the outcome between non-movers in the destination and the origin. ${ }^{25}$ For instance, an individual moving from a very low to a very high average collections region would have a large, positive $\widehat{\delta}_{i}$. Since we restrict to individuals with one move, an individual is associated with a single value of $\widehat{\delta}_{i}$ for each outcome.

In our baseline specification, we construct $\widehat{\delta}_{i}$ as the average difference between the outcome for non-movers in the origin and destination zip codes. Among the moves, the median origin or destination has 3,224 non-movers. Appendix Figure A9 shows a histogram of our baseline measure of $\widehat{\delta}_{i}$. We discuss robustness to alternative measures of $\widehat{\delta}_{i}$ below.

Our baseline event-study specification is

$$
y_{i t}=\alpha_{i}+\alpha_{y}+\alpha_{q}+\alpha_{r}+\left[\sum_{r \neq-1} \theta_{r} \cdot \widehat{\delta}_{i}\right]+x_{i t} \beta+\epsilon_{i t}
$$

where $\alpha_{i}$ are individual fixed effects, $\alpha_{y}$ are calendar-year fixed effects, $\alpha_{q}$ are calendarquarter fixed effects, $\alpha_{r}$ are event-time fixed effects, and $x_{i t}$ are controls for 10-year age bins. $^{26}$

The coefficients of interest are the $\theta_{r}$ and are normalized to zero in the last quarter in the origin $\left(\theta_{-1}=0\right)$. Movers with $\widehat{\delta}_{i}=0$, who move across CZs with equivalent financial distress, can be thought of as the control group. The coefficient of interest $\theta_{r}$ captures the

\footnotetext{
${ }^{24}$ Appendix Figure A8 shows heat maps of origin and destination CZs for these movers. The locations where people move from and to are broadly representative of the underlying geographic distribution of people with credit reports, also shown in this figure.

${ }^{25}$ In parallel to movers, we define non-movers as individuals who we observe for the entire sample window, are between 30 and 80 years of age in the last period, and never move across zip codes.

${ }^{26}$ We are unable to control for fully interacted calendar-year and calendar-quarter fixed effects because of the collinearity between time fixed effects and the event-time fixed effects. This is a standard feature of these type of specifications (see, e.g., discussion in Dobbie et al. (2020)).
} 
degree to which the change in outcomes for movers reflect the average difference between the origin and the destination, relative to this control group and the control variables. An estimate of $\theta_{r}=1$ indicates that outcomes have fully converged to those in the destination location; an estimate of $\theta_{r}=0$ indicates no convergence. We calculate robust standard errors clustered by origin $\times$ destination $\mathrm{CZ}$.

The identifying assumption is that the size of the move, $\hat{\delta}_{i}$, is uncorrelated with any differential changes in the outcome not caused by the move, conditional on the controls. A natural concern is that people move to less expensive and potentially more distressed locations in response to persistent negative shocks to their economic circumstances (e.g., job loss) or conversely move to more economically vibrant locations in response to persistent positive shocks.

To support our identifying assumption, Figure 2 shows binned scatter plots of the pre-move change in the flow measures of financial distress against the size of the move. Specifically, in each plot the vertical axis shows average financial distress 1 year pre-move minus average financial distress 3 years pre-move, and the horizontal axis shows $\widehat{\delta}_{i}$. The data is split by ventiles of $\widehat{\delta}_{i}$ and each point shows the average in that bin. The plots also show the line of best fit, estimated using the underlying data, and its slope and standard error. The plots indicate that the size and direction of the move are uncorrelated with any trends in outcomes. In particular, the correlations are not statistically distinguishable from zero and are small in magnitude relative to the pre-post differences discussed below.

To provide some initial evidence for the movers effects, Figure 3 shows binned scatter plots of the pre-post change in the same flow measures of financial distress against the size of the move. The plots are constructed in the same manner as before, except that the vertical axis now shows average financial distress 3 years post-move minus average financial distress 3 years pre-move. Across the measures of financial distress, there is a positive and statistically significant relationship between the size of the move and the outcome; we defer our discussion of magnitudes to the next section. The plots indicate that a linear "dose-response" relationship between the size of the move and our outcomes is a reasonable first approximation, although we will explore sensitivity to this assumption below. 
We examine the robustness of our results to a number of modifications of our baseline specification. One set of robustness analysis isolates variation stemming from moves "from the same place" or moves "to the same place." For instance, the concern that effects are driven by a persistent origin-specific shock (e.g., mass layoff) can be addressed by conditioning on individuals who moved from the same origin to destinations with differential financial distress, thus generating different values of $\widehat{\delta}_{i}$. Similarly, the concern that effects are driven by a shock at the destination (e.g., commodity boom) can be addressed by focusing on individuals who arrived at the same destination from different origins.

Econometrically, we isolate variation stemming from moves "from the same place" by adding a full set of origin $\mathrm{CZ} \times$ event-time fixed effects to Equation 1. We similarly estimate effects for individuals who move "to the same place" by adding a full set of destination $\mathrm{CZ} \times$ event time fixed effects.

A second set of robustness analysis examines sensitivity to how we construct the size of the move, $\widehat{\delta}_{i}$. The construction of this variable involves a natural tradeoff. If we define the group of non-movers too broadly, they will not be a good proxy for the mover's experience in the origin and destination locations. If we define the group of non-movers too narrowly, we will not have enough sample to reliably estimate $\widehat{\delta}_{i}$. As discussed above, for our baseline specification we constructed $\widehat{\delta}_{i}$ using non-movers who reside in the mover's destination and origin zip codes. Appendix Table A3 shows that for this definition, the median origin or destination we use to construct $\widehat{\delta}_{i}$ is based on 3,224 non-movers. However, the 5th percentile has only 353 non-movers, raising concerns about measurement error, especially for low-frequency measures, such as Chapter 13 filings.

Thus, as a robustness check, we construct $\widehat{\delta}_{i}$ using broader geographic areas, which reduces concerns about statistical noise at the cost of having a more geographically disperse measure of place. ${ }^{27}$ Specifically, we construct a version of $\widehat{\delta}_{i}$ using non-movers in the mover's origin and destination county. For this measure, the 5th percentile of origin or destination locations has 3,664 non-movers (see Appendix Table A3). We also examine the sensitivity of our results to defining $\widehat{\delta}_{i}$ more narrowly than the baseline specification,

\footnotetext{
${ }^{27}$ For consistency, we continue to define non-movers as individuals who we observe for the entire sample window, are between 30 and 80 years of age in the last period, and never move across zip codes.
} 
constructing $\widehat{\delta}_{i}$ using non-movers in both the same zip code and same 10-year age group as the mover. Age is the only demographic variable available in our data, which limits our ability to construct even finer measures. For the zip code $\times$ age group measure, the median origin or destination has 748 non-movers, and the 5th percentile has 90 non-movers (see Appendix Table A3). ${ }^{28}$

Our third robustness exercise examines sensitivity to a two-way fixed effects specification, where we replace the $\sum_{r \neq-1} \theta_{r} \cdot \widehat{\delta}_{i}$ terms in Equation 1 with fixed effects for each $\mathrm{CZ}$. Under the assumption that there is minimal noise in $\widehat{\delta}_{i}$ and any heterogeneity in the place effects is orthogonal to the size of the move, the baseline specification will provide identical estimates of the place and person components to a two-way fixed effects specification (Finkelstein, Gentzkow and Williams, 2016). By allowing for fully non-parametric place effects, the two-way fixed effect model relaxes these assumptions.

As we discuss below, the two-way fixed effects model produces very similar estimates of the relative importance of place versus person effects, indicating that more restrictive assumptions of the baseline specification are not quantitively important. We prefer our baseline specification because it allows us to visually display the pre-trends and the timing of the response to the moves.

\section{Results}

In this section, we present the event-study estimates from the movers analysis. We then probe the robustness of these estimates to alternative specifications and explore heterogeneity to understand the underlying mechanisms.

\subsection{Event Study Estimates}

Figure 4 presents event-study plots of the coefficient of interest $\left(\theta_{r}\right)$ by event time $(r)$ for our main outcome variables. Table 4 shows parameter estimates and standard errors for $\theta_{r}$ at 6 years post-move for our baseline and alternative specifications.

Panels A and B of Figure 4 examine effects on debt in collections (1+ debt in collections) and credit card delinquency (30+ DPD) in the past 3 years. Prior to the move, there is

\footnotetext{
${ }^{28}$ Appendix Figures A10 and A11 show histograms of these measures of $\widehat{\delta}_{i}$.
} 
no evidence of an economically significant trend in $\theta_{r}$, providing further support for our identifying assumption. ${ }^{29}$ There is an inflection point at $r=0$, which is consistent with limited measurement error in the timing of the move. After the move, the estimates of $\theta_{r}$ gradually increase and then stabilize at less than $10 \%$ at 4 to 8 years.

The results imply that, for these outcomes, place-based factors account for a small fraction of the geographic variation in financial distress between areas. With our baseline specification, shown in column 1 of Table 4, we can reject a place-based component of zero but can also reject a place-based effect larger than $10 \%$ at 6 years post-move.

Figure 5 further probes these results with event study plots on the stock of debt in collections, medical debt in collections, and non-medical debt in collections. The effects for stocks are almost identical to those for flows, which as discussed above, is due to the fact that financial distress indicators decay rather quickly. The results in the bottom row show that medical debt in collections is the primary determinant of the effect on collections, with a place effect of approximately $20 \%$ versus $4 \%$ for non-medical collections. This pattern is consistent with the heterogeneous collection practices of local medical providers, and the debt collectors they contract with, having an important impact on overall debt in collections.

Panels C and D of Figure 4 examine effects on Chapter 7 and Chapter 13 bankruptcy filings. As before, the results show no evidence of pre-trends, providing support for our identifying assumption, and an inflection point at $r=0$. In contrast to the previously examined outcomes, we find economically large place-based effects for bankruptcy, with a place-based component of $27 \%$ for Chapter 7 and 33\% for Chapter 13 at 6 years post-move. These results are consistent with state level bankruptcy laws (e.g., Fay, Hurst and White, 2002; Agarwal, Liu and Mielnicki, 2003; Livshits, MacGee and Tertilt, 2007; Auclert, Dobbie and Goldsmith-Pinkham, 2019) and local lawyer networks and legal traditions (Sullivan, Warren and Westbrook, 1994; Jacoby, 2014) playing an important role in bankruptcy filings.

Appendix Figure A12 shows bankruptcy event study plots separately for across- versus within-state moves (among the baseline sample of individuals who move across CZs).

\footnotetext{
${ }^{29}$ For credit card delinquency, there is a marginally significant $\theta_{r}$ at some pre-period time horizons, but the effect is economically small. Adjusting for it by controlling for a pre-existing trend would make the placebased effect marginally smaller, strengthening our interpretation of the results.
} 
We find consistently larger place effects for across-state moves than for within-state moves, especially for Chapter 13. At 6 years, the Chapter 13 place effect is $43 \%$ for across-state movers versus $14 \%$ for within-state moves. The Chapter 7 place effect is $34 \%$ for acrossstate movers versus $17 \%$ for within-state movers. The larger effects for across-state moves are consistent with an important role for state-level bankruptcy laws in determining the place effects.

Appendix Figure A13 shows bankruptcy event studies separately by credit score tercile, where the tercile is based on the credit score in the quarter prior to the move. We observe very little effect for the highest credit score tercile (above 765). In contrast, the largest effects are found for the lowest credit score tercile. The results, in our view, are consistent with a "double trigger" model (e.g., Bhutta, Dokko and Shan, 2017) in which place impacts bankruptcy, but only for people who have enough debt for bankruptcy to have a non-negligible probability of occurring.

A threat to the validity of our research design is a shock that causes people to move from a given location and has a persistent impact on their probability of financial distress. The lack of pre-trends provides some evidence against this concern. To more directly rule out this threat, Column 2 of Table 4 shows estimates from a specification where we add origin $\mathrm{CZ} \times$ event-time controls to the baseline specification. With these controls, the estimates are identified off of individuals who move "from the same place" to locations with differential financial distress, eliminating any bias from persistent origin-specific shocks. Column 3 addresses the complementary concern about bias from destination-specific shocks by adding destination $\mathrm{CZ} \times$ event-time controls to the baseline specification. While the point estimates are not exactly the same, the patterns are very similar, with small place effects for the debt in collections and credit card delinquency measures, and larger effects for the bankruptcy outcomes.

Columns 4 and 5 of Table 4 examine sensitivity to constructing the size of the move at different levels of aggregation. Column 4 constructs $\widehat{\delta}_{i}$ more narrowly, using all nonmovers in the same zip code and same 10-year age group as the mover. Column 5 construct $\widehat{\delta}_{i}$ more broadly, using all non-movers in the same county. The estimates using the zip-by-age-group $\widehat{\delta}_{i}$ are typically smaller than the baseline estimates, and are substantially 
smaller for bankruptcy outcomes. This is consistent with the smaller sample size leading to measurement error in $\widehat{\delta}_{i}$, which attenuates the estimates toward zero, with greater measurement error and attenuation for the bankruptcy outcomes due to the low rate of filing. The county-level estimates tend to be modestly larger. As in the other robustness exercise, the results are qualitatively similar.

As mentioned earlier, we restrict the sample to moves that occur in 2007 or earlier, which provides us with a long enough post period to observe convergence in the outcome, and also avoids including moves that were precipitated by the financial crisis. Appendix Table A4 is based on a larger sample of moves between 2004 and 2012, and show parameter estimates and standard errors for $\theta_{r}$ at 4 years post-move. With a shorter post-move time horizon, there is somewhat less convergence, but the general patterns are similar.

As discussed in Section 4, we also examine the sensitivity of our results to a two-way fixed effects specification, which relaxes the assumptions that $\widehat{\delta}_{i}$ has limited measurement error and that any heterogeneity in the place effects is orthogonal to the size of the move. Appendix Table A5 presents estimates of the share of differences in outcomes across regions (e.g., above- versus below-median financial distress, Deep South versus Upper Midwest) explained by the place effects. For each outcome, we report the average difference, the average amount attributable to place, and the share of the difference attributable to place. With few exceptions, the share of variation explained by place is very similar across sets of regions. As in the event studies, the share of variation explained by place is much larger for bankruptcy than for the non-bankruptcy outcomes. The precise estimates for the share of variation explained by place are slightly larger, on average, than those from the baseline event study model but smaller than those from the event study model where $\widehat{\delta}_{i}$ is constructed at the CZ level. More details are provided in Appendix Section B.

Finally, we examine the sensitivity of the bankruptcy results to the 2005 bankruptcy reform (Bankruptcy Abuse Prevention and Consumer Protection Act, BAPCPA) that occurred during our time period. To do so, we construct an alternative measure of the size of the move, $\widehat{\delta_{i t}}$, that is allowed to vary before and after the reform. Specifically, we define the pre-BAPCPA size of the move using average outcomes for non-movers in the pre-BAPCA period and the post-move size of the move using average outcomes for non-movers in the 
post-BAPCA period. Appendix Figure A14 shows event study plots, which use this timevarying measure but are otherwise identical to our baseline specification. The place-based effects for Chapter 7 and Chapter 13 are similar to the baseline estimates. Thus, while BAPCPA had sharp short-run and more modest medium-run effects on bankruptcy filings (Gross et al., 2018), our estimates of the relative importance of place- and person-based factors are robust to this more nuanced treatment of bankruptcy law.

Taken together, this evidence reinforces the view that the general pattern of small place effects for collections and credit card delinquency and larger place effects for bankruptcy is robust.

\subsection{Heterogeneity and Correlates}

To shed light on underlying mechanisms, we examine heterogeneity and correlates of the place-based effects.

The first form of heterogeneity we examine is based on the direction of the move. We define a move as "positive" if an individual moves to a destination with higher financial distress $\left(\widehat{\delta}_{i}>0\right)$ and "negative" if an individual moves to a destination with lower financial distress $\left(\widehat{\delta}_{i}<0\right)$. Informational theories predict larger effects for positive $\widehat{\delta}_{i}$. If, for example, individuals learn about the benefits of filing for bankruptcy when they move to places with higher filing rates (e.g., from peers or advertisements) but do not unlearn the benefits if they move to places with lower filing rates, we would expect larger place-based effects for positive moves. ${ }^{30}$

Columns 2 and 3 of Appendix Table A6 show estimates of the place effect for positive and negative moves. The starkest difference, in absolute value, is for Chapter 13 filing, with a place-based effect of $45 \%$ for positive moves versus $19 \%$ for negative moves. This asymmetry is consistent with the type of informational effects highlighted by previous anecdotal evidence on the importance of lawyer networks and legal traditions in the Chapter 13 filing decision (see, e.g., Sullivan, Warren and Westbrook, 1994; Jacoby, 2014). ${ }^{31}$

\footnotetext{
${ }^{30}$ Similarly, debt trap models - under which it is easier to get into financial distress than get out of it suggest larger effects for moves to places with higher financial distress rates (positive moves). Supply driven models, on the other hand, predict larger effects for moves to places with lower financial distress. To the extent the places with lower financial distress have higher credit supply, moves to lower financial distress places raise mover's access to credit, which can lead to higher rates of default for these individuals.

${ }^{31}$ Note that this pattern is inconsistent with large local stigma effects (Gross and Souleles, 2002), as it is
} 
There are statistically significant asymmetries for some other variables but they tend to be economically smaller and are not always robust to alternative specifications, making us hesitant to strongly interpret them.

Research using movers designs in other contexts has found larger differences by the age of the mover. For example, Chetty and Hendren (2018a) find that children who moved between neighborhoods at younger ages experienced larger place-based effects, likely because they were exposed to the local schooling environment for longer. In our context, we would expect larger impacts for younger movers if younger people are more responsive to information, more influenced by peers, or more malleable in the preferences that may contribute to financial distress. To examine the effects by age, columns 4 and 5 of Appendix Table A6 estimate the baseline specification separately by whether the mover is less than 40-year-old at the time of the move. Across most of the outcomes, the estimates are statistically indistinguishable for older and younger movers, and the point estimates do not suggest any clear pattern.

A standard practice in movers designs is to examine correlates of place-based effects (e.g., Finkelstein, Gentzkow and Williams, 2016; Chetty and Hendren, 2018b). Because a number of the correlates vary at the state level (e.g., bankruptcy exemptions), we conduct this analysis at the state level. We recover state-level place-based effects by running twoway fixed effects regressions of our outcomes on individual and state fixed effects. We then project the state-level fixed effects on state-level legal factors (e.g., measures of the generosity of bankruptcy laws, wage garnishment levels), measures of state-level credit supply (e.g., credit score-adjusted credit limits, bank branches), and state-level economic factors (e.g., median income, house values, employment).

In Appendix Section $C$, we provide more details on the regression specification and the results. To summarize our findings, we do not find any consistent patterns in this correlational analysis. This might arise from the fact that many of our measures have theoretically ambiguous effects on financial distress. For instance, more consumer-friendly bankruptcy laws could increase bankruptcy filings, because they make bankruptcy more beneficial to filers, or reduce them, because lenders endogenously respond by reducing unlikely that the potentially stigmatizing aspects of filing for bankruptcy would differ by the chapter of filing. 
the supply of credit. Similarly, better economic conditions might directly reduce financial distress but also increase borrowing amounts, offsetting the direct effect. Indeed, in the cross section, bankruptcy filing rates are weakly inverse-U-shaped in zip code income (see Appendix Figure A21). The absence of any correlations may alternatively reflect the more standard critique that there may be unobserved factors that are correlated with these local characteristics, clouding the interpretation of the estimates.

\section{Conclusion}

In this paper, we use monthly credit report data for a representative $10 \%$ panel of individuals over 2000-2016 to examine financial distress in the United States. We document large, persistent geographic differences in financial distress across regions, with a particularly stark disparity between the Upper Midwest and the Deep South.

To better understand these patterns, we first decompose the variance in financial distress measures into cross-sectional and time-series components. We find that for nearly all of the outcomes, more than half of the variation is cross-sectional, and for half of the outcomes more than three-quarters of the variation occurs across CZs rather than within CZs over time. We then conduct a movers analysis to examine how financial distress evolves when people move to areas with different levels of financial distress. For debt in collection and our credit card outcomes, we find only weak convergence following a move, while for bankruptcy we find fairly large place-based effects.

These findings are helpful in weighing competing theories of financial distress. The small place-based component for debt in collections and credit card delinquency indicates that supply-side factors (e.g., state laws, local lending practices) are not a primary explanation for geographic variation in distress, and instead suggests an important role for persistent individual characteristics in explaining the geographic variation across regions. Such characteristics include financial literacy and human capital, household wealth and intergenerational transfers, and variation across individuals in risk preferences, default stigma, or discount rates. ${ }^{32}$

\footnotetext{
${ }^{32}$ These persistent individual characteristics may be affected by the places where people grow up and thus may embed place based effects. However, because these effects are persistent when people move, they are similarly unlikely to respond to changes in local institutional or cultural factors, at least over the medium run.
} 
In contrast, the larger place-based estimates for bankruptcy, and in particular the large place-based effects for positive moves for Chapter 13 filings, is consistent with an informational theory whereby individuals learn about Chapter 13 when they move to places with high filing rates but do not unlearn when they move to places with low rates. This evidence supports prior anecdotal evidence on the importance of local lawyer networks and legal traditions in driving Chapter 13 filing decisions.

Our movers analysis quantifies the determinants of persistent cross-sectional differences in financial distress between areas. Further decomposing the mechanisms underlying the person-based and place-based components, along with understanding the impact of over-time variation in financial distress (e.g, due to the business cycle or local labor markets shocks) remain fertile ground for future research. 


\section{References}

Agarwal, Sumit, and Chunlin Liu. 2003. "Determinants of credit card delinquency and bankruptcy: Macroeconomic factors." Journal of Economics and Finance, 27(1): 75-84.

Agarwal, Sumit, Chunlin Liu, and Lawrence Mielnicki. 2003. "Exemption laws and consumer delinquency and bankruptcy behavior: An empirical analysis of credit card data." The Quarterly Review of Economics and Finance, 43(2): 273-289.

Agarwal, Sumit, Souphala Chomsisengphet, and Chunlin Liu. 2011. "Consumer bankruptcy and default: The role of individual social capital." Journal of Economic Psychology, 32(4): 632-650.

Agarwal, Sumit, Vyacheslav Mikhed, and Barry Scholnick. 2020. "Peers' income and financial distress: Evidence from lottery winners and neighboring bankruptcies." The Review of Financial Studies, 33(1): 433-472.

Argys, Laura M, Andrew Friedson, M Melinda Pitts, and D Sebastian Tello-Trillo. 2017. "The impacts of losing health insurance." Working Paper.

Athreya, Kartik, José Mustre-del Río, and Juan M Sánchez. 2019. "The Persistence of Financial Distress." The Review of Financial Studies, 32(10): 3851-3883.

Auclert, Adrien, Will S Dobbie, and Paul Goldsmith-Pinkham. 2019. "Macroeconomic Effects of Debt Relief: Consumer Bankruptcy Protections in the Great Recession." National Bureau of Economic Research.

Becker, Gary S, and Kevin M Murphy. 1988. "A theory of rational addiction." Journal of political Economy, 96(4): 675-700.

Bhutta, Neil, Jane Dokko, and Hui Shan. 2017. "Consumer ruthlessness and mortgage default during the 2007 to 2009 housing bust." The Journal of Finance, 72(6): 2433-2466.

Brevoort, Kenneth P., Philipp Grimm, and Michelle Kambara. 2016. "Credit Invisibles and the Unscored." Cityscape, 18(2): 9-34.

Bronnenberg, Bart, Jean-Pierre Dube, and Matthew Gentzkow. 2012. "The Evolution of Brand Preferences: Evidence from Consumer Migration." American Economic Review, 102(6): 2472-2508.

Brown, James R, J Anthony Cookson, and Rawley Z Heimer. 2019. "Growing up without finance." Journal of Financial Economics, 134(3): 591-616.

CFPB. 2016. "Study of third-party debt collection operations." Consumer Financial Protection Bureau.

CFPB. 2021. "Fair Debt Collection Fair Debt Collection Practices Act." Consumer Financial Protection Bureau.

Chetty, Raj, and Nathaniel Hendren. 2018a. "The impacts of neighborhoods on intergenerational mobility I: Childhood exposure effects." The Quarterly Journal of Economics, 133(3): 1107-1162. 
Chetty, Raj, and Nathaniel Hendren. 2018b. "The impacts of neighborhoods on intergenerational mobility II: County-level estimates." The Quarterly Journal of Economics, 133(3): 1163-1228.

Chetty, Raj, John N. Friedman, and Emmanuel Saez. 2013. "Using Differences in Knowledge across Neighborhoods to Uncover the Impacts of the EITC on Earnings." American Economic Review, 103(7): 2683-2721.

Dick, Astrid A., and Andreas Lehnert. 2010. "Personal Bankruptcy and Credit Market Competition." The Journal of Finance, 65(2): 655-686.

Dobbie, Will, Paul Goldsmith-Pinkham, Neale Mahoney, and Jae Song. 2020. "Bad credit, no problem? Credit and labor market consequences of bad credit reports." Journal of Finance.

Dynan, Karen E. 2009. “Changing Household Financial Opportunities and Economic Security." Journal of Economic Perspectives, 23(4): 49-68.

Fay, Scott, Erik Hurst, and Michelle J White. 2002. "The household bankruptcy decision." American Economic Review, 92(3): 706-718.

Finkelstein, Amy, Matthew Gentzkow, and Heidi L. Williams. 2019. "Place-Based Drivers of Mortality: Evidence from Migration." National Bureau of Economic Research Working Paper No. 25975.

Finkelstein, Amy, Matthew Gentzkow, and Heidi Williams. 2016. "Sources of Geographic Variation in Health Care: Evidence from Patient Migration." Quarterly Journal of Economics, 131(4): 1681-1726.

Finkelstein, Amy, Matthew Gentzkow, and Heidi Williams. 2018. "What Drives Prescription Opioid Abuse? Evidence from Migration." SIEPR Working Paper 18-028, August 2018.

Foohey, Pamela, Robert M. Lawless, Katherine Porter, and Deborah Thorne. 2016. "“No Money Down" Bankruptcy." Southern California Law Review, 90: 1055.

Gallagher, Emily A, Radhakrishnan Gopalan, and Michal Grinstein-Weiss. 2019. "The effect of health insurance on home payment delinquency: Evidence from ACA Marketplace subsidies." Journal of Public Economics, 172: 67-83.

Gerardi, Kristopher, Lorenz Goette, and Stephan Meier. 2013. “Numerical ability predicts mortgage default." Proceedings of the National Academy of Sciences, 110(28): 11267-11271.

Gropp, Reint, John Karl Scholz, and Michelle J. White. 1997. “Personal Bankruptcy and Credit Supply and Demand." The Quarterly Journal of Economics, 112(1): 217-251.

Gross, David B, and Nicholas S Souleles. 2002. "An empirical analysis of personal bankruptcy and delinquency." The Review of Financial Studies, 15(1): 319-347.

Gross, Tal, Raymond Kluender, Feng Liu, Matthew J. Notowidigdo, and Jialan Wang. 2018. "The Economic Consequences of Bankruptcy Reform." MIT Working Paper. 
Hamel, Liz, Mira Norton, Karen Pollitz, Larry Levitt, Gary Glaxton, and Mollyann Brodle. 2016. "The Burden of Medical Debt: Results from the Kaiser Family Foundation/New York Times Medical Bills Survey." Kaiser Family Foundation.

Han, Song, Benjamin J. Keys, and Geng Li. 2017. "Unsecured Credit Supply, Credit Cycles, and Regulation." The Review of Financial Studies, 31(3): 1184-1217.

Hinnosaar, Marit, and Elaine Liu. 2020. "Malleability of Alcohol Consumption: Evidence from Migrants." Available at SSRN 3569603.

Jacoby, Melissa B. 2014. "Superdelegation and Gatekeeping in Bankruptcy Courts." Temple Law Review, 87: 875.

Kalda, Ankit. 2020. "Peer financial distress and individual leverage." The Review of Financial Studies, 33(7): 3348-3390.

Kluender, Raymond, Neale Mahoney, Francis Wong, and Wesley Yin. 2021. "Medical Debt in the US, 2009-2020." JAMA, 326(3): 250-256.

Livshits, Igor, James MacGee, and Michele Tertilt. 2007. "Consumer bankruptcy: A fresh start." American Economic Review, 97(1): 402-418.

Lupica, Lois R. 2012. "The Consumer Bankruptcy Fee Study: Final Report." American Bankruptcy Institute Law Review, 20(1031): 17.

Mahoney, Neale. 2015. "Bankruptcy as Implicit Health Insurance." American Economic Review, 105(2): 710-46.

Mitman, Kurt. 2016. "Macroeconomic Effects of Bankruptcy and Foreclosure Policies." American Economic Review, 106(8): 2219-55.

NYFed. 2019. “Consumer Credit Panel." New York Federal Reserve Bank.

Pence, Karen M. 2006. "Foreclosing on Opportunity: State Laws and Mortgage Credit." Review of Economics and Statistics, 88(1): 177-182.

Porter, Katherine (Ed.). 2012. Broke: How Debt Bankrupts the Middle Class. Stanford University Press.

Sullivan, Teresa A., Elizabeth Warren, and Jay Lawrence Westbrook. 1994. "Persistence of Local Legal Culture: Twenty Years of Evidence from the Federal Bankruptcy Courts." Harvard Journal of Law \& Public Policy, 17: 801.

Urban Institute. 2019. “Debt in America: An Interactive Map.” Urban Institute. 
Figure 1: Geographic Variation in Financial Distress

(A) Debt in Collections in Past 3 Years (\%)

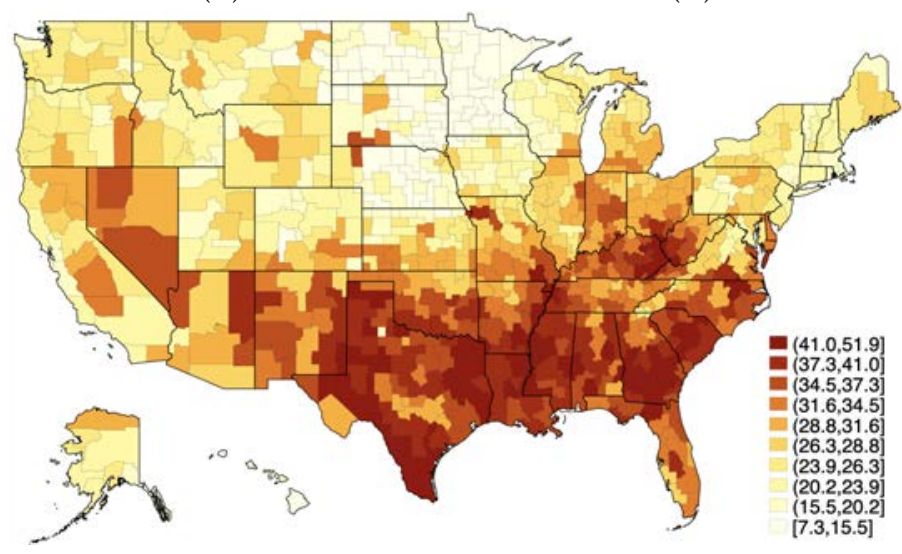

(C) Chapter 7 Filings in Past 3 Years (Per 1,000)
(B) Credit Card Delinquency in Past 3 Years $(\%)$

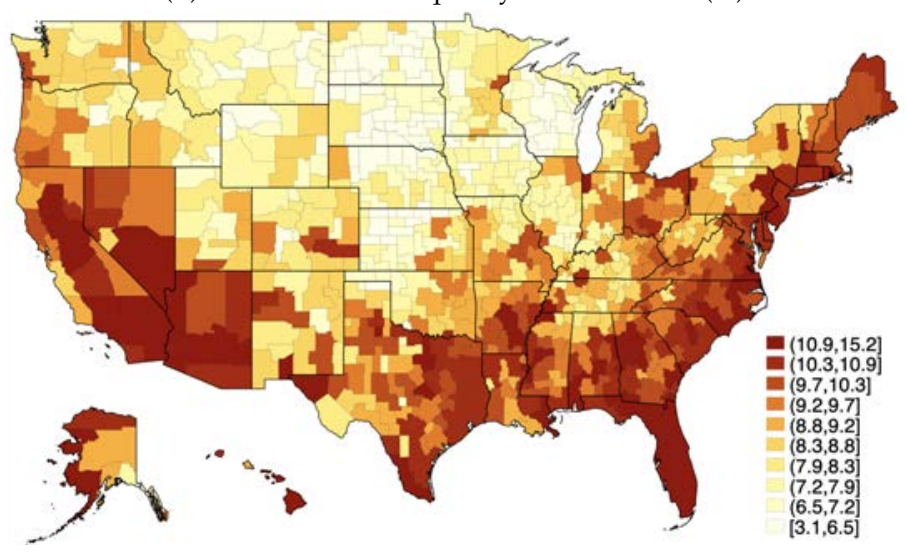

(D) Chapter 13 Filings in Past 3 Years (Per 1,000)

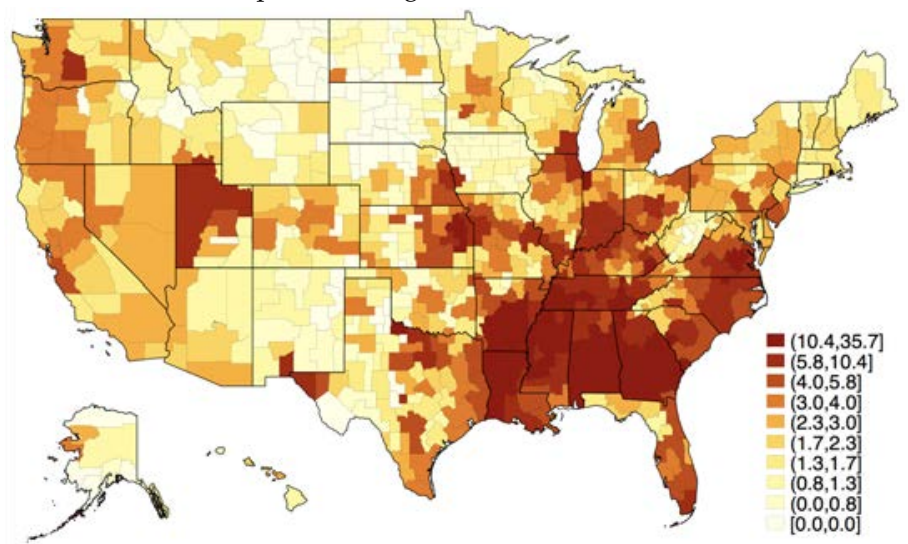

Note: Figure shows CZ-level maps of financial distress. CZ means are constructed using a 10\% random sample of TransUnion credit records from June 2015. Debt in collections is an indicator for 1+ debt in collections in the last 3 years. Credit card delinquency is an indictor for 1+ credit card that is 30+ DPD in the last 3 years. Bankruptcy filings are the number of individuals out of 1,000 who file for Chapter 7 and 13, respectively, in the last 3 years. See Section 2 for more details on variable construction. 


\section{Figure 2: Pre-Move Change in Financial Distress by Size of Move}
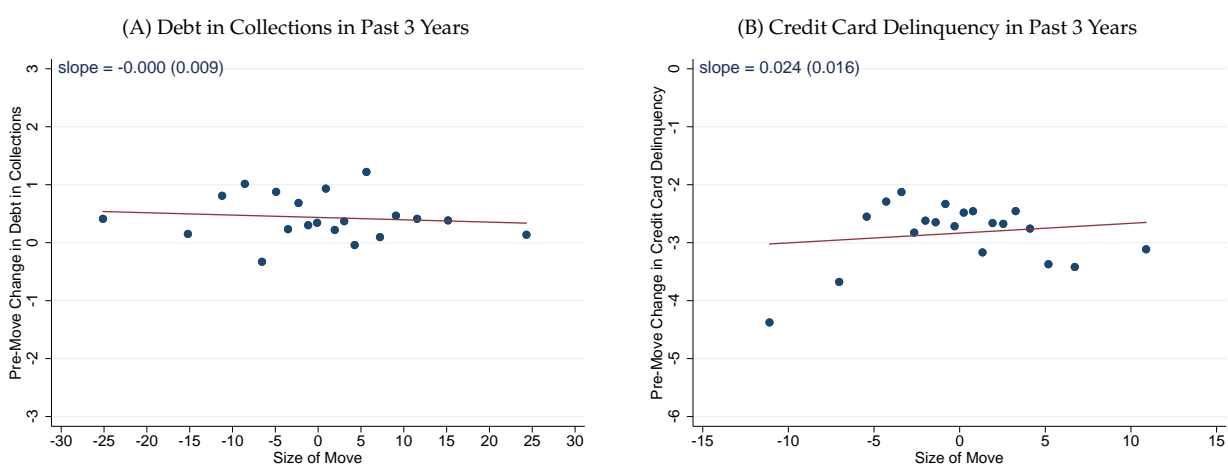

(C) Chapter 7 Filings in Past 3 Years

(D) Chapter 13 Filings in Past 3 Years
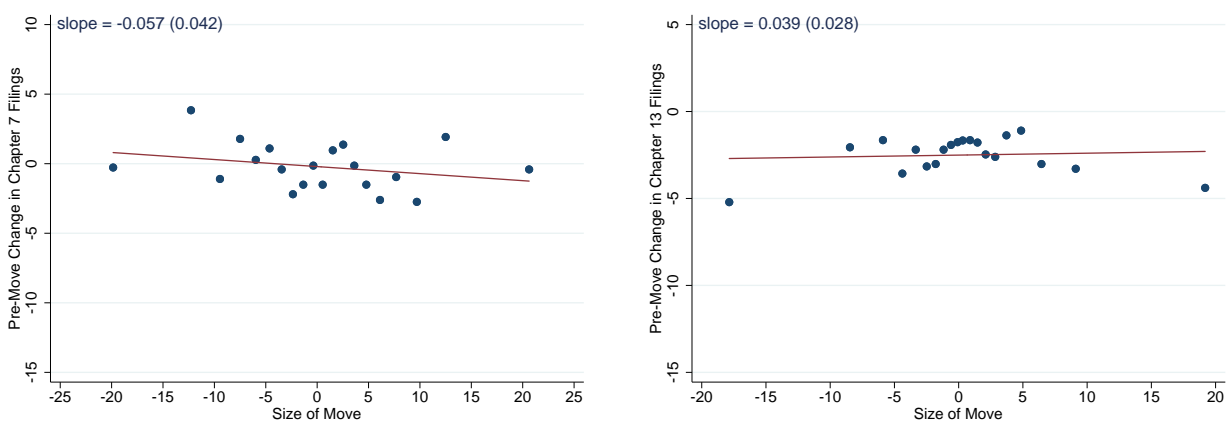

Note: Figure shows binned scatter plots of the pre-move change in the outcome against the size of the move $\hat{\delta}_{i}$. The vertical axis shows average financial distress 1 year pre-move minus average financial distress 3 years pre-move. The horizontal axis shows $\widehat{\delta_{i}}$, the average financial distress between the destination and origin zip codes. The data is split by ventiles of $\widehat{\delta}_{i}$ and each point shows the average in that bin. The plots also show the line of best fit, estimated using the underlying data, and its slope and standard error. 


\section{Figure 3: Pre-Post Change in Financial Distress by Size of Move}

(A) Debt in Collections in Past 3 Years

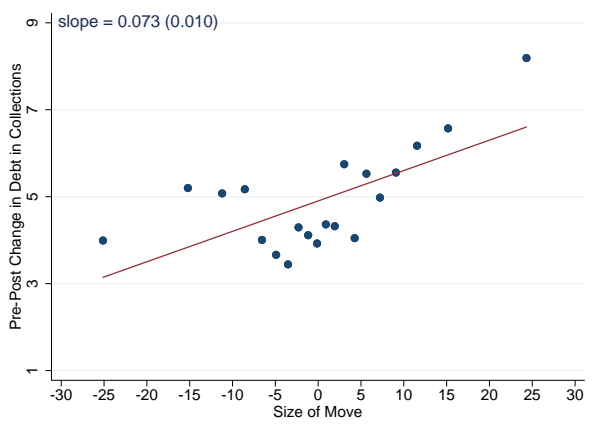

(C) Chapter 7 Filings in Past 3 Years

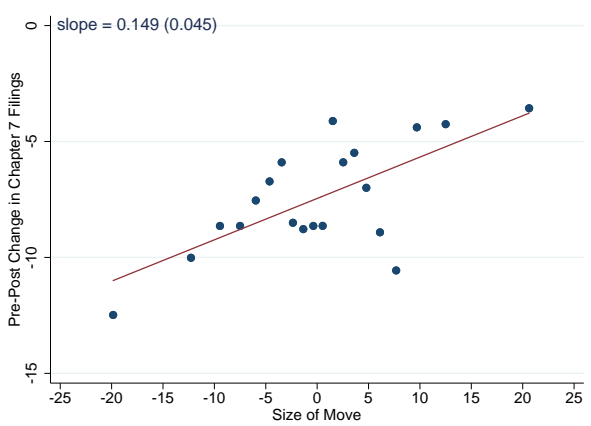

(B) Credit Card Delinquency in Past 3 Years

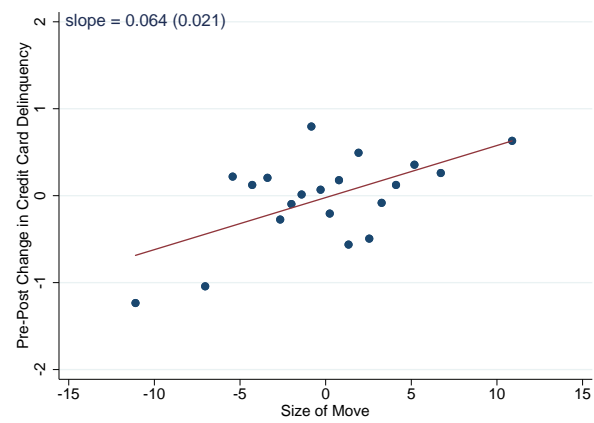

(D) Chapter 13 Filings in Past 3 Years

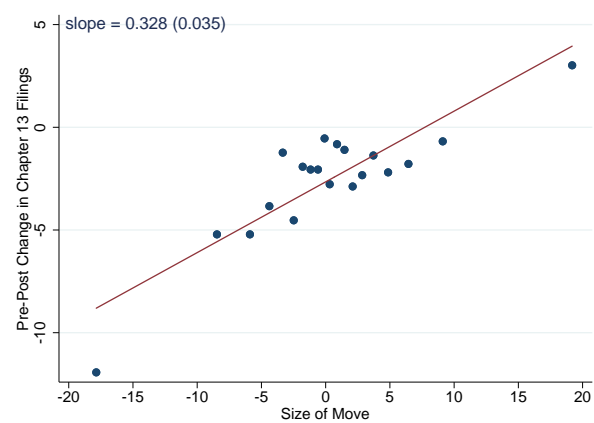

Note: Figure shows binned scatter plots of the pre-post change in the outcome against the size of the move $\hat{\delta}_{i}$. The vertical axis shows average financial distress 3 years post-move minus average financial distress 3 years pre-move. The horizontal axis shows $\widehat{\delta}_{i}$, the average financial distress between the destination and origin zip codes. The data is split by ventiles of $\widehat{\delta}_{i}$ and each point shows the average in that bin. The plots also show the line of best fit, estimated using the underlying data, and its slope and standard error. 


\section{Figure 4: Event-Study Plots}

(A) Debt in Collections in Past 3 Years

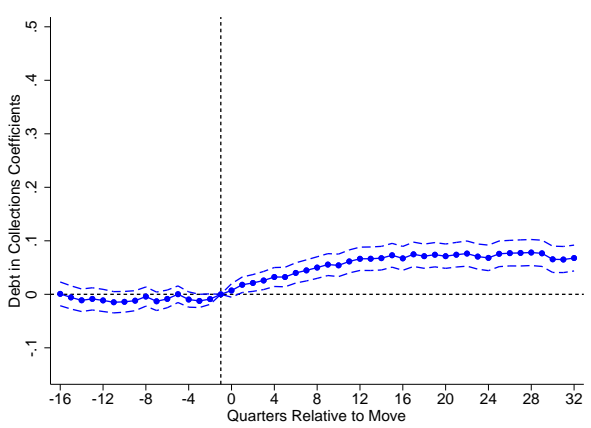

(C) Chapter 7 Filings in Past 3 Years

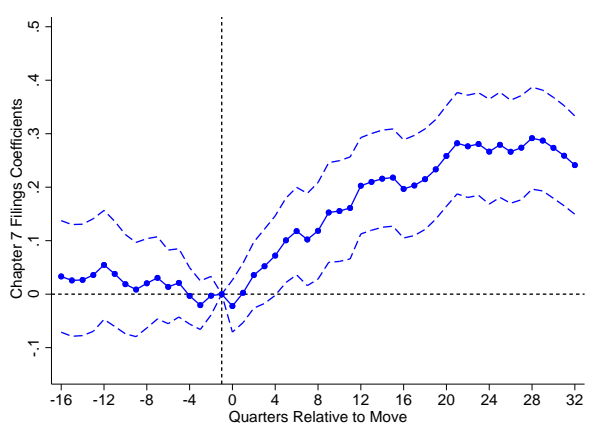

(B) Credit Card Delinquency in Past 3 Years

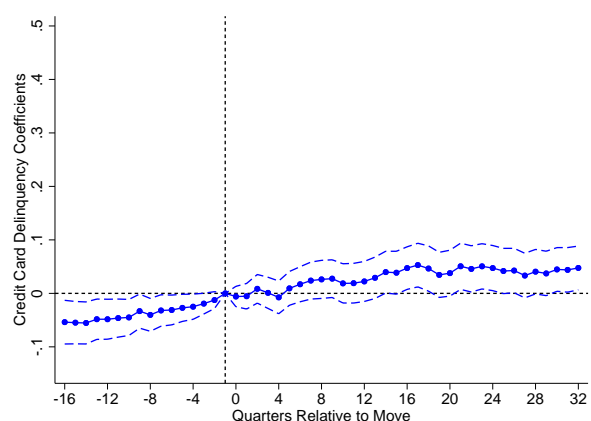

(D) Chapter 13 Filings in Past 3 Years

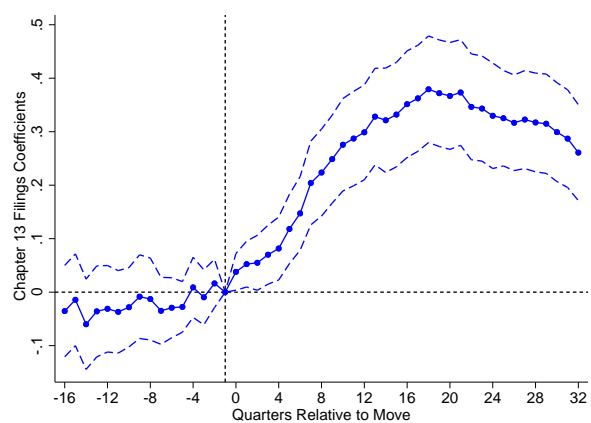

Note: Figure shows place-based effects $\theta_{r}$ from event study regressions of financial distress on the size of the move $\hat{\delta}_{i}$, individual and time fixed effects, and other controls. The dashed lines show $95 \%$ confidence intervals, based on standard errors clustered by origin $\times$ destination $\mathrm{CZ}$. 


\section{Figure 5: Event-Study Plots: Debt in Collections Stock Measures}

(A) Debt in Collections (\%)

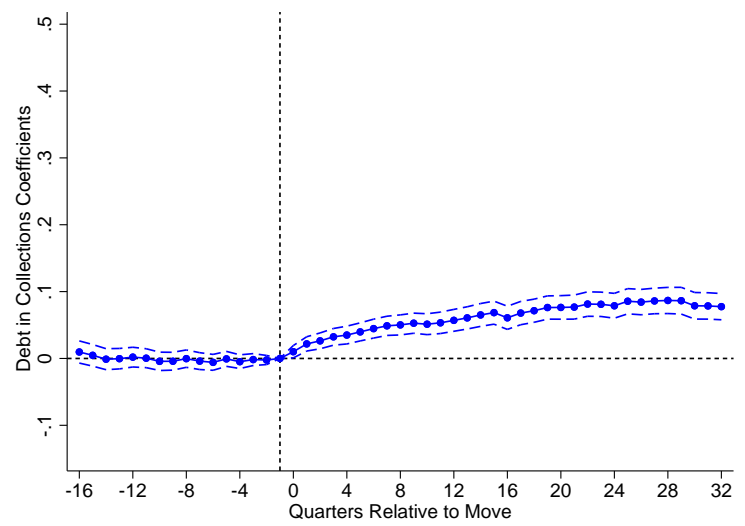

(B) Medical Collections (\%)

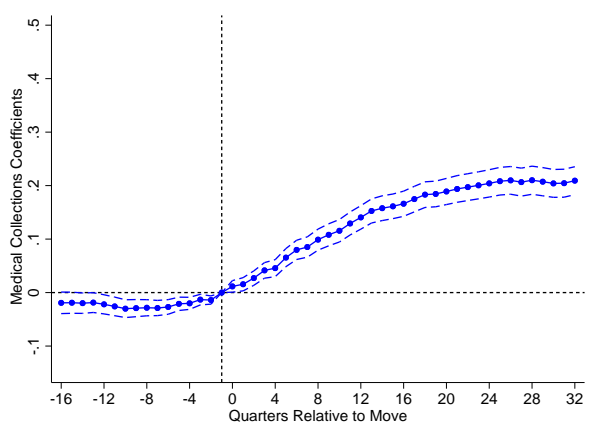

(C) Non-Medical Collections (\%)

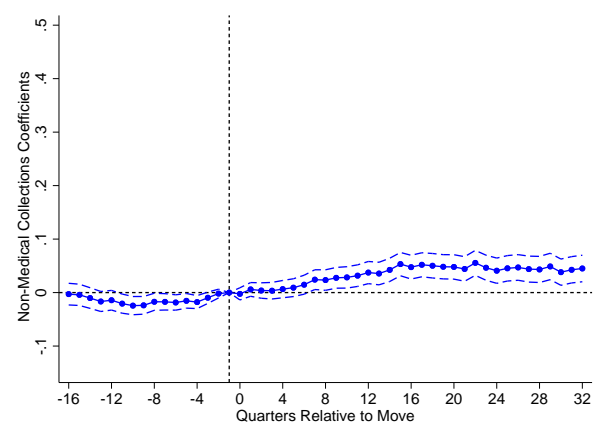

Note: Figures shows place-based effects $\theta_{r}$ from event study regressions of financial distress on the size of the move $\hat{\delta}_{i}$, individual and time fixed effects, and other controls. The dashed lines show $95 \%$ confidence intervals, based on standard errors clustered by origin $\times$ destination $\mathrm{CZ}$. 
Table 1: Financial Distress Measures

\begin{tabular}{|c|c|c|c|c|c|c|c|}
\hline & Mean & Std. Dev. & Median & Pct 75 & Pct 90 & Pct 95 & Pct 99 \\
\hline \multicolumn{8}{|l|}{ Collections - Flow } \\
\hline Debt in collections in past 3 years $(\%)$ & 28.4 & 45.1 & 0 & 100 & 100 & 100 & 100 \\
\hline Balance of collections in past 3 years (\$) & 818.0 & $3,192.7$ & 0 & 237 & 2,000 & 4,121 & 13,386 \\
\hline \multicolumn{8}{|l|}{ Collections - Stock } \\
\hline Debt in collections (\%) & 34.1 & 47.4 & 0 & 100 & 100 & 100 & 100 \\
\hline Medical collections (\%) & 22.1 & 41.5 & 0 & 0 & 100 & 100 & 100 \\
\hline Non-medical collections (\%) & 24.2 & 42.8 & 0 & 0 & 100 & 100 & 100 \\
\hline Collections balance $(\$)$ & $1,350.9$ & $4,843.2$ & 0 & 606 & 3,401 & 6,748 & 21,234 \\
\hline Medical collections balance (\$) & 697.3 & $3,448.4$ & 0 & 0 & 1,245 & 3,178 & 13,770 \\
\hline Non-medical collections balance (\$) & 624.4 & $2,577.0$ & 0 & 0 & 1,445 & 3,218 & 10,993 \\
\hline \multicolumn{8}{|l|}{ Credit Card } \\
\hline Credit card delinquency in past 3 years (\%) & 10.1 & 30.1 & 0 & 0 & 100 & 100 & 100 \\
\hline Credit card delinquency in past 3 years $\left(\%\right.$, cond $\left.{ }^{\prime} 1\right)$ & 14.1 & 34.8 & 0 & 0 & 100 & 100 & 100 \\
\hline \multicolumn{8}{|l|}{ Bankruptcy } \\
\hline Bankruptcy filings in past 3 years (per 1,000) & 14.8 & 120.9 & 0 & 0 & 0 & 0 & 1,000 \\
\hline Chapter 7 filings in past 3 years (per 1,000 ) & 10.5 & 101.8 & 0 & 0 & 0 & 0 & 1,000 \\
\hline Chapter 13 filings in past 3 years (per 1,000) & 4.5 & 67.2 & 0 & 0 & 0 & 0 & 0 \\
\hline $\mathrm{N}$ & $29,398,845$ & & & & & & \\
\hline
\end{tabular}

Note: Table presents summary statistics for measures of financial distress constructed using a $10 \%$ random sample of TransUnion credit records from June 2015. Debt in collections measures are indicators for 1+ debt in collections. We include both flow measures of debt in collections over the past three years and the stock measures of whether the individual has $1+$ debt in collections. Credit card delinquency is an indictor for $1+$ credit card that is 30+ DPD over the past three years. Bankruptcy filings are the number of individuals out of 1,000 who file for any bankruptcy, Chapter 7, and Chapter 13, respectively, in the last 3 years. See Section 2 for more details on variable construction. 
Table 2: Variance Decomposition

\begin{tabular}{lcc}
\hline \hline & Time-series & Cross-section \\
\hline Debt in collections in past 3 years (\%) & 35.19 & 64.81 \\
Debt in collections (\%) & 27.77 & 72.23 \\
Medical collections (\%) & 22.87 & 77.13 \\
Non-medical collections (\%) & 14.04 & 85.96 \\
Credit card delinquency in past 3 years (\%) & 57.37 & 42.63 \\
Chapter 7 filings in past 3 years (per 1,000) & 43.00 & 57.00 \\
Chapter 13 filings in past 3 years (per 1,000) & 10.54 & 89.46 \\
\hline \hline
\end{tabular}

Note: Table presents a decomposition financial distress into its time-series and cross-sectional components, based on a panel dataset of average financial distress for each $C Z \times$ year from 2000-2016. 
Table 3: Geographic Variation in Financial Distress

\begin{tabular}{|c|c|c|c|c|c|c|c|}
\hline & $\begin{array}{c}(1) \\
\text { Mean } \\
\end{array}$ & $\begin{array}{c}(2) \\
\text { Std.Dev. }\end{array}$ & $\begin{array}{c}(3) \\
75 \%- \\
25 \% \\
\end{array}$ & $\begin{array}{c}(4) \\
90 \%- \\
10 \% \\
\end{array}$ & $\begin{array}{c}\text { (5) } \\
\text { Deep } \\
\text { South } \\
\end{array}$ & $\begin{array}{c}(6) \\
\text { Upper } \\
\text { Midwest }\end{array}$ & $\begin{array}{c}(7) \\
\text { Deep South - } \\
\text { Upper Midwest }\end{array}$ \\
\hline \multicolumn{8}{|l|}{ Collections - Flow } \\
\hline Debt in collections in past 3 years (\%) & 28.4 & 7.1 & 11.0 & 18.7 & 37.3 & 19.9 & 17.4 \\
\hline Balance of collections in past 3 years $(\$)$ & 818.0 & 286.4 & 411.9 & 719.3 & $1,117.5$ & 601.3 & 516.2 \\
\hline \multicolumn{8}{|l|}{ Collections - Stock } \\
\hline Debt in collections (\%) & 34.1 & 7.9 & 11.5 & 20.8 & 43.5 & 23.8 & 19.8 \\
\hline Medical collections ( $\%$ ) & 22.1 & 8.1 & 11.5 & 22.5 & 31.6 & 14.4 & 17.2 \\
\hline Non-medical collections (\%) & 24.2 & 5.2 & 7.1 & 14.1 & 29.1 & 17.4 & 11.7 \\
\hline Collections balance (\$) & $1,350.9$ & 461.4 & 580.4 & $1,160.5$ & $1,723.2$ & 987.5 & 735.7 \\
\hline Medical collections balance (\$) & 697.3 & 373.4 & 500.8 & 962.0 & $1,064.8$ & 541.9 & 522.9 \\
\hline Non-medical collections balance (\$) & 624.4 & 188.7 & 303.4 & 483.8 & 627.0 & 423.0 & 204.0 \\
\hline \multicolumn{8}{|l|}{ Credit Card } \\
\hline Credit card delinquency in past 3 years (\%) & 10.1 & 1.5 & 2.0 & 3.4 & 10.7 & 7.2 & 3.5 \\
\hline Credit card delinquency in past 3 years ( $\%$, cond $\left.{ }^{\prime} 1\right)$ & 14.2 & 2.6 & 3.5 & 6.7 & 17.1 & 9.3 & 7.7 \\
\hline \multicolumn{8}{|l|}{ Bankruptcy } \\
\hline Bankruptcy filings in past 3 years (per 1,000) & 14.8 & 6.4 & 8.7 & 17.8 & 19.8 & 14.5 & 5.3 \\
\hline Chapter 7 filings in past 3 years (per 1,000) & 10.5 & 4.6 & 7.5 & 12.1 & 9.2 & 11.9 & -2.6 \\
\hline Chapter 13 filings in past 3 years (per 1,000 ) & 4.5 & 4.1 & 2.9 & 7.7 & 10.8 & 2.8 & 8.1 \\
\hline
\end{tabular}

Note: Table presents statistics on CZ-level measures of financial distress. CZ means are constructed using a 10\% random sample of TransUnion credit records from June 2015. Summary statistics are calculated using the CZ level data, with CZs weighted by the number of individual-level observations in each CZ so means are representative of the underlying individual-level data. The Deep South is defined as Alabama, Arkansas, Georgia, Louisiana, Mississippi, and South Carolina and Upper Midwest as Iowa, Minnesota, North Dakota, South Dakota, Wisconsin, and the upper peninsula of Michigan. See Table 1 note for more details on the financial distress measures. 
Table 4: Event-Study Estimates

\begin{tabular}{|c|c|c|c|c|c|}
\hline \multirow[b]{2}{*}{ Financial distress measures } & \multicolumn{5}{|c|}{$\begin{array}{l}\text { Fraction converged to outcome } \\
\text { at destination } 4 \text { years post move }\end{array}$} \\
\hline & $\begin{array}{c}(1) \\
\text { All movers }\end{array}$ & $\begin{array}{c}(2) \\
\text { Same origin }\end{array}$ & $\begin{array}{c}(3) \\
\text { Same destination }\end{array}$ & $\begin{array}{c}(4) \\
\text { Zip } \times \text { age level }\end{array}$ & $\begin{array}{c}(5) \\
\text { County level } \\
\end{array}$ \\
\hline Debt in collections 3 years & $\begin{array}{c}0.0681 \\
(0.0122)\end{array}$ & $\begin{array}{c}0.0358 \\
(0.0123)\end{array}$ & $\begin{array}{c}0.0487 \\
(0.0125)\end{array}$ & $\begin{array}{c}0.0622 \\
(0.0105)\end{array}$ & $\begin{array}{c}0.1615 \\
(0.0173)\end{array}$ \\
\hline Debt in collections & $\begin{array}{c}0.0788 \\
(0.0095)\end{array}$ & $\begin{array}{c}0.0536 \\
(0.0095)\end{array}$ & $\begin{array}{c}0.0611 \\
(0.0097)\end{array}$ & $\begin{array}{c}0.0659 \\
(0.0081)\end{array}$ & $\begin{array}{c}0.1539 \\
(0.0141)\end{array}$ \\
\hline Medical collections & $\begin{array}{c}0.2042 \\
(0.0130)\end{array}$ & $\begin{array}{c}0.1291 \\
(0.0131)\end{array}$ & $\begin{array}{c}0.1908 \\
(0.0133)\end{array}$ & $\begin{array}{c}0.1575 \\
(0.0110)\end{array}$ & $\begin{array}{c}0.3036 \\
(0.0164)\end{array}$ \\
\hline Non-medical collections & $\begin{array}{c}0.0409 \\
(0.0120)\end{array}$ & $\begin{array}{c}0.0213 \\
(0.0122)\end{array}$ & $\begin{array}{c}0.0337 \\
(0.0123)\end{array}$ & $\begin{array}{c}0.0490 \\
(0.0103)\end{array}$ & $\begin{array}{c}0.0956 \\
(0.0187)\end{array}$ \\
\hline Credit card delinquency 3 years & $\begin{array}{c}0.0473 \\
(0.0215)\end{array}$ & $\begin{array}{c}0.0681 \\
(0.0215)\end{array}$ & $\begin{array}{c}0.0149 \\
(0.0213)\end{array}$ & $\begin{array}{c}0.0326 \\
(0.0157)\end{array}$ & $\begin{array}{c}0.0710 \\
(0.0376)\end{array}$ \\
\hline Chapter 7 filings 3 years & $\begin{array}{c}0.2665 \\
(0.0500)\end{array}$ & $\begin{array}{c}0.2088 \\
(0.0501)\end{array}$ & $\begin{array}{c}0.2212 \\
(0.0509)\end{array}$ & $\begin{array}{c}0.0863 \\
(0.0325)\end{array}$ & $\begin{array}{c}0.5068 \\
(0.0897)\end{array}$ \\
\hline Chapter 13 filings 3 years & $\begin{array}{c}0.3298 \\
(0.0503)\end{array}$ & $\begin{array}{c}0.3578 \\
(0.0522)\end{array}$ & $\begin{array}{c}0.2095 \\
(0.0535)\end{array}$ & $\begin{array}{c}0.1097 \\
(0.0422)\end{array}$ & $\begin{array}{c}0.4940 \\
(0.0625)\end{array}$ \\
\hline
\end{tabular}

Note: Table shows place-based effects $\theta_{r}$ at 6 years (24 quarters) after the move from event study regressions of financial distress on the size of the move $\hat{\delta}_{i}$, individual and time fixed effects, and other controls. Standard errors, clustered by origin $\times$ destination $C Z$, are shown in parentheses. Column (1) shows the baseline specification. In column (2), we isolate variation from moves "from the same place" by including fully interacted origin $\mathrm{CZ} \times$ event time fixed effects. In column (3), we isolate variation from moves "to the same place" by including fully interacted destination $\mathrm{CZ} \times$ event time fixed effects. In columns (4) and (5), we show alternative specifications where we construct $\hat{\delta}_{i}$ using non-movers in the movers' origin and destination zip code $\times 10$ year age-bin, and using non-movers in the movers' origin and destination county. 


\section{What Determines Consumer Financial Distress? Place- and Person-Based Factors

\author{
Online Appendix
}

\section{A Variable Definitions}

Debt in collections: We use the line-item information from the collection segment. We rely on the collection origination date to focus on individuals with debt in collections in the past three years. Because collection accounts are not automatically removed from credit reports when they are paid, we drop accounts that have been charged off or paid in full. We rely on the Manner of Payment (MOP) code to separate accounts that are in collection (9B), charged off (9) or paid in full (9P). Our collection measure only includes 9B. We also drop accounts with original balance smaller than $\$ 100$ to avoid small-dollar nuisance accounts. Accounts with original balances smaller than $\$ 100$ are similarly ignored by FICO Score $8 .{ }^{33}$ Across unpaid collection accounts, around $2 \%$ are disputed by customers with code ("AID"). Dropping these accounts has negligible impact on the fraction of individuals with debt in collections, and so we do not make this adjustment. We rely on the Legislative Prohibited Code to construct measures for whether an individual has medical and nonmedical debts in collections.

As explained in the main text, we are unable to construct flow measures separately for medical and non-medical debt in collections due to data limitations. Prior to 2009, TransUnion only reports aggregated medical and non medical debt in collections in the individual level data without any information on origination dates. While the line-item collections data contained origination dates, we cannot identify whether those collection accounts are related to medical debt.

Collections balances: To measure the amount of debt in collections, we compute the total collection balance amount of all collections, medical collections, and non-medical collections owned by each individual. We construct both a stock measure of the total collection balance and a flow measure of the balance for unpaid collections opened during the past 3 years. Again, we only include collection accounts not yet paid in full with an original balance greater than $\$ 100$.

Credit card delinquency: We use the line-item information from the trade segment. We rely on months since the most recent credit card delinquency (30+ DPD) in the individual level data to focus on individuals with delinquency over the past three years. To exclude individuals who quickly payback their credit card debt, we also require that these

\footnotetext{
${ }^{33}$ See https:/ / www.myfico.com/credit-education/credit-scores/fico-score-versions.
} 
individuals are currently delinquent. We use the line-item information from the trade segment to construct an indicator of whether an individual has at least one credit card that is in delinquency. The delinquency status includes accounts that are 30 days or more past due (30+ PDP), charged off, or in collections. We identify the status of credit card accounts using their MOP codes. MOP codes of 2, 3, 4, and 5 indicate that the credit card account is $30 \mathrm{DPD}, 60 \mathrm{DPD}, 90 \mathrm{DPD}$, and 120+ DPD, respectively. MOP code 7 is for wage earner or similar plan. MOP codes starting with number 8 indicate that the account is currently a repossession or was a repossession but paid in full, although this code is very rare. MOP codes starting with number 9 indicate that the account is currently in collection, charged off, or was a collection but paid in full.

We construct this credit card delinquency measures for all individuals with a credit report and conditional on those with a credit card.

Bankruptcy: We use the line-item information from the public record segments. We use public record type code to identify bankruptcy filings and the chosen chapter (i.e. 7 vs 13). The public record segment also includes the date of filing, so we can restrict to filings in the past 3 years to focus on relatively recent distress conditions.

\section{B Two-Way Fixed Effects}

As we discuss in Section 4, we examine the sensitivity of the place versus person decompositions to a two-way fixed effects specification. Compared to the event study, the two-way fixed effects model relaxes the assumptions that there is minimal noise in $\widehat{\delta}_{i}$ and that any heterogeneity in place effects is orthogonal to the size of the move.

As before, let $i$ indicate individuals, $t$ indicate time measured in quarters, and $r$ indicate event time. For a given outcome $y_{i t}$, we recover $\mathrm{CZ}$ place-based effects with the regression

$$
y_{i t}=\alpha_{i}+\alpha_{y}+\alpha_{q}+\alpha_{r}+\gamma_{j}+x_{i t} \beta+\epsilon_{i t}
$$

where $\alpha_{i}$ are individual fixed effects, $\alpha_{y}$ are calendar-year fixed effects, $\alpha_{q}$ are calendarquarter fixed effects, $\alpha_{r}$ are event-time fixed effects, and $x_{i t}$ are controls for 10-year age bins.

The coefficients of interest are the CZ-level fixed effects, $\gamma_{j}$, and can be interpreted as the causal effect of residing in $\mathrm{CZ} j$ on the measure of financial distress. The $\mathrm{CZ}$ fixed effects are identified off individuals who move across CZs in our sample. The identifying assumption is that moves across CZs are uncorrelated with changes in the outcome.

As in our baseline event study specification, we restrict the sample to individuals who we observe for the entire sample window and who are between 30 and 80 years of age, inclusive, in the last period. We further restrict the sample to individuals who did not move at all (non-movers) or moved only once across CZs (movers) between 2000 and 2016. As with the baseline event study, we drop individuals who moved after 2008. To isolate 
the pre- and post-move periods, we also drop the quarter of the move. Because we have more non-movers than movers (roughly a 14 to 1 ratio), we down-weight non-movers such that movers and non-movers have the same aggregate weight in our regressions. The results are very similar if we do not down-weight non-movers. The resulting sample contains 340,485 movers and 4,674,848 non-movers for a total of 5,015,333 individuals. It is larger than the event-study sample because we do not restrict ourselves to movers we can observe from 4 years before to 8 years after the move.

Following Finkelstein, Gentzkow and Williams (2016), we use the estimates from the two-way fixed effects model to calculate the share of the difference in outcomes between two regions due to place. Let $R$ and $R^{\prime}$ denote two regions of interest. The share due to place is given by

$$
S_{\text {place }}\left(R, R^{\prime}\right)=\frac{\gamma_{R}-\gamma_{R^{\prime}}}{\bar{y}_{R}-\bar{y}_{R^{\prime}}}
$$

where $\gamma_{R}$ is the average of the CZ-level place effects, $\gamma_{j}$, in region $R, \bar{y}_{R}$ is the average of the outcome, $\bar{y}_{j^{\prime}}$, in region $R$, and $\gamma_{R^{\prime}}$ and $\bar{y}_{R^{\prime}}$ are analogously defined for region $R^{\prime}{ }^{34}$

Appendix Table A5 shows the results of this decomposition. Column 1 decomposes differences in outcomes between CZs with financial distress above versus below the median; columns 2 through 4 decompose differences in outcomes between CZs with financial distress in the top versus bottom $25 \%, 10 \%$ and $5 \%$ of CZs; and column 5 decomposes differences in outcomes between the Deep South and Upper Midwest. Rows show the average difference in the outcomes, the average amount attributable to place, and the share of the difference attributable to place. Standard errors for the place share, calculated by drawing 50 samples of individuals with replacement, are shown in parentheses.

As in the event studies, the most prominent takeaway is that the share of variation explained by place is much larger for bankruptcy than for the non-bankruptcy outcomes. The share of variation explained by place is very similar across different sets of regions that we consider. The exception is the decomposition of Chapter 7 bankruptcy rates between the Deep South and Upper Midwest where the place effect is very noisy. This is a natural consequence of the fact that the absolute difference in Chapter 7 filing rates between the Deep South and Upper Midwest is quite small. The precise estimates for the share of variation explained by place are, on average, slightly larger than those from the baseline event study model and are more similar to those from the event study model where $\widehat{\delta}_{i}$ is constructed at the county level.

\footnotetext{
${ }^{34}$ We calculate $\gamma_{R}$ weighting $\gamma_{j}$ by the number of observations in each CZ. We calculate $\bar{y}_{j}$ by first averaging across all individuals in $\mathrm{CZ} j$ at time $t$, and then taking a simple average across time for that $\mathrm{CZ}$. This is the same way we compute the size of the move $\widehat{\delta}_{i}$. Our results are very similar when we take a pooled average across individuals and time in a single step.
} 


\section{Correlates of Place-Based Effects}

We examine correlates of our place-based effects in two steps, following the methodology in Finkelstein, Gentzkow and Williams (2016). First, because a number of the correlates vary at the state level (e.g., bankruptcy exemptions), we recover state-level place-based effects from two-way fixed effects models. The sample and specification are identical to that described in Appendix Section B, except that we replace CZ-level fixed effects with fixed effects for each state. Second, we project the state-level fixed effects on state-level legal factors (e.g., measures of the generosity of bankruptcy laws, wage garnishment levels), measures of state-level credit supply (e.g., credit score-adjusted credit limits, bank branches), and state-level economic factors (e.g., median income, house values, employment).

We focus our analysis on the state fixed effects based on the medical debt in collections and bankruptcy outcome variables. These are the outcomes where we find economically significant place-based effects, and where there is the potential to detect meaningful correlations. For these outcomes, we project the state-level place-based effects, $\widehat{\gamma}_{s}$, on state-level legal, credit supply, and economic factors.

For legal factors, we consider median seizable assets, wage garnishment levels, Chapter 7 fees, and Chapter 13 fees. Median seizable assets are a state-level measure of the assets above the Chapter 7 bankruptcy exemptions in that state for the median household from a nationally representative distribution, and are taken from Mahoney (2015). Wage garnishment is the percentage of a borrower's disposable income that can be withheld to pay back creditors, which we obtain from nolo.com. ${ }^{35}$ Chapter 7 and Chapter 13 bankruptcy fees are taken from Lupica (2012). To construct state-level measures, we aggregate the judicial district level fees to the state level, weighting by number of observations in our sample, and then we average fees before and after the Bankruptcy Abuse Prevention and Consumer Production Act (BAPCPA), weighting by number of years that our sample falls into the pre- and post-BAPCPA periods.

To measure credit supply, we construct three measures. We construct a measure of the average credit score-adjusted credit limit in the state. Specifically, to eliminate demand effects, we calculate the weighted average credit limit, where the weights are determined so that each state has the same distribution of credit scores (based on 10 point bins) as the national distribution. This weighted average measures the credit limit that a national representative consumer would obtain in this state. We also proxy for credit supply with the number of bank branches per squared mile and the fraction of bank branches from national banks, both based on 2014 FDIC data.

For economic factors, we use state-level measures of median income, income inequality based on the Gini coefficient, the percentage who own a house, median house value, percent who own a vehicle, the percentage with a bachelors degree or more, the percent-

\footnotetext{
${ }^{35}$ The federal limit for wage garnishment is $25 \%$, with some states imposing a lower limit. These limits usually apply for debts other than child support, taxes, and student loans.
} 
age employed, and the percentage with health insurance. All of these variables are constructed from the 2011-2015 5-year sample of the American Community Survey (ACS). We also use a state-level measure of for-profit hospitals, defined as the share of for-profit hospitals, from the 2014 Provider of Services (POS) file provided by the Centers for Medicare \& Medicaid Services (CMS).

To conduct the analysis, we standardize all variables to have a mean of zero and a standard deviation of one. Then, following Finkelstein, Gentzkow and Williams (2016), we examine the correlation between the normalized place-based effects and covariates using two approaches. First, for a given outcome, we estimate separate bivariate regressions of the place-based effects on each covariate. The coefficient from these regressions is the Pearson correlation coefficient. It takes on values between -1 and +1 and its square is the $r^{2}$ of the regression. Second, we report coefficients from a post-Lasso multivariate regression. For a given outcome, we run a Lasso regression of the place effects on the full set of covariates, with the penalty level chosen by a 4 -fold cross-validation to minimize the mean squared error. Then, for that outcome, we run an OLS regression on the set of covariates chosen by the Lasso regression.

Figures A15 to A17 examine correlates with the medical debt, Chapter 7 bankruptcy and Chapter 13 bankruptcy place effects. In each figure, the left panel shows the coefficients from the separate bivariate regressions and the right panel shows the coefficients from the multivariate regression with the covariates chosen by a Lasso regression. The results are hard to interpret. While there are correlations that are consistent with existing theories, there are also patterns that suggest important omitted variables. For instance, the strong correlation between wage garnishment and Chapter 7 bankruptcy place effects is consistent with theories that wage garnishment "pushes" people into bankruptcy. On the other hand, the fact that there is a correlation between for-profit hospitals and the Chapter 13 filing place effects, but not the Chapter 7 filings place effects, strikes us as spurious. In our view, the results are due to the fact that places with more for-profit hospitals, which are typically in the Deep South, also have distinctive legal cultures which drive the correlations.

To potentially improve interpretation, we conduct additional analysis of the bankruptcy place effects that allows us to separately examine the extensive margin and the chapter of filing margin. Figure A18 shows results for a combined bankruptcy outcome, which captures the extensive margin decision. In the bivariate regressions, wage garnishment is associated with high bankruptcy place effects, while Chapter 7 filing fees are associated with lower bankruptcy place effects. The local economic factors have mixed effects. This is consistent with the fairly weak, inverse-U-shaped cross-sectional relationship between bankruptcy rates and zip code income. ${ }^{36}$ Figure A19 and A20 show results for the Chapter 7 and Chapter 13 place effects, including the combined bankruptcy place effect as an ad-

\footnotetext{
${ }^{36}$ See Appendix Figure A21.
} 
ditional covariate, so that the resulting partial correlations can be interpreted as the effects on the chapter of filing. As in the prior analysis, the results are hard to interpret. 
Figure A1: Decay Rates of Collections and Credit Card Delinquencies

(A) Debt in Collections

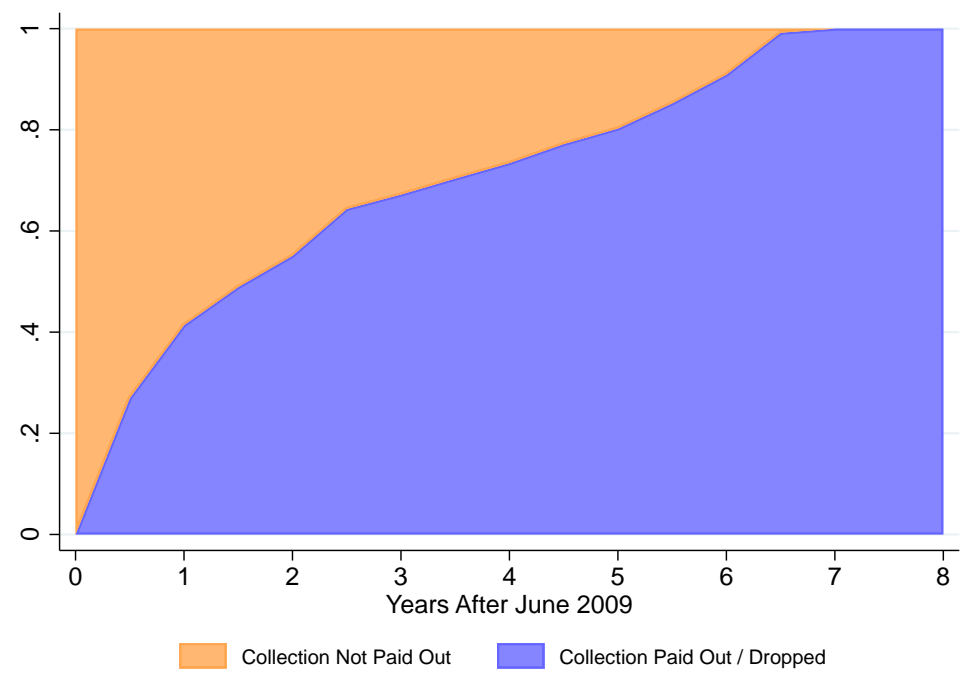

(B) Credit Card Delinquency

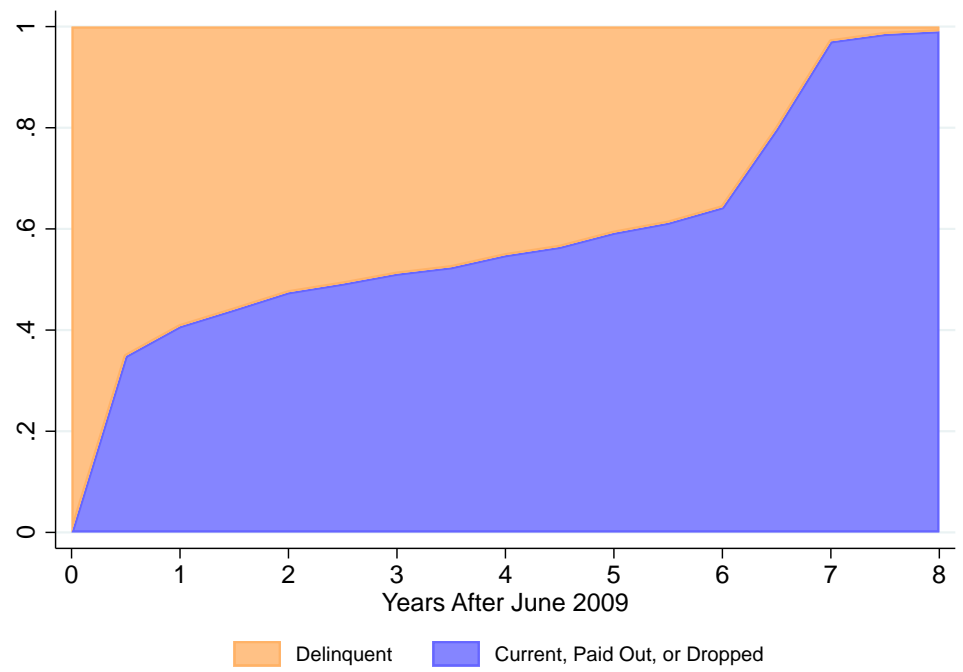

Note: Figure shows the evolution of collection and delinquent credit card accounts in TransUnion data. Starting from June 2009, we focus on debt in collection accounts opened over the past 6 months in Panel (A) and credit card trade accounts that became delinquent over the past 6 months in Panel (B). Each panel shows the fraction of collections not paid out and credit card accounts still non current over the next eight years. 
Figure A2: Geographic Variation in Collection Stock Measures

(A) Debt in Collections (\%)

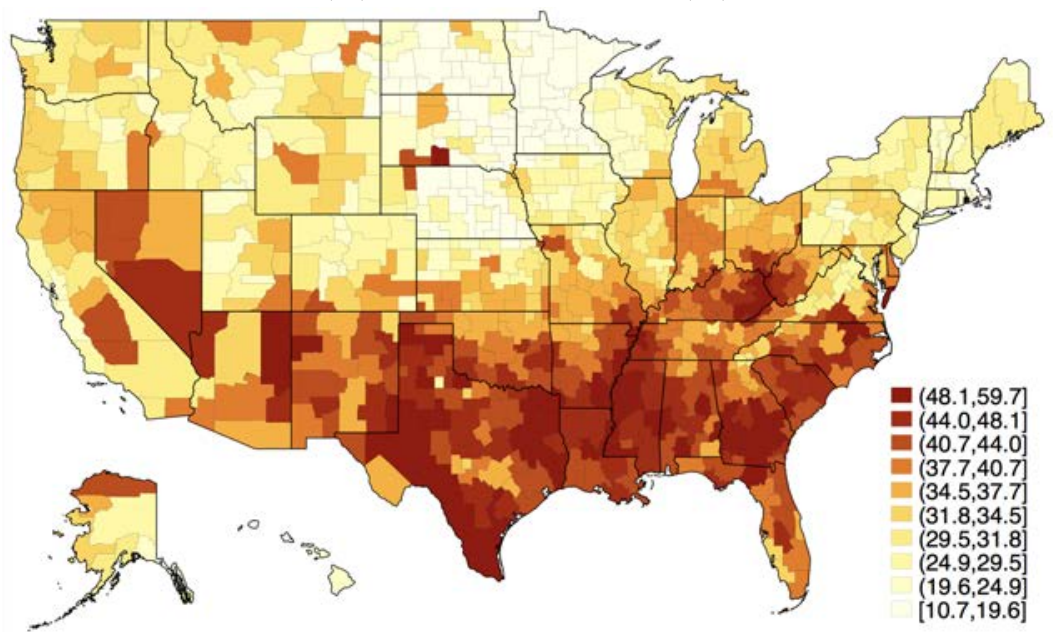

(B) Medical Collections (\%)

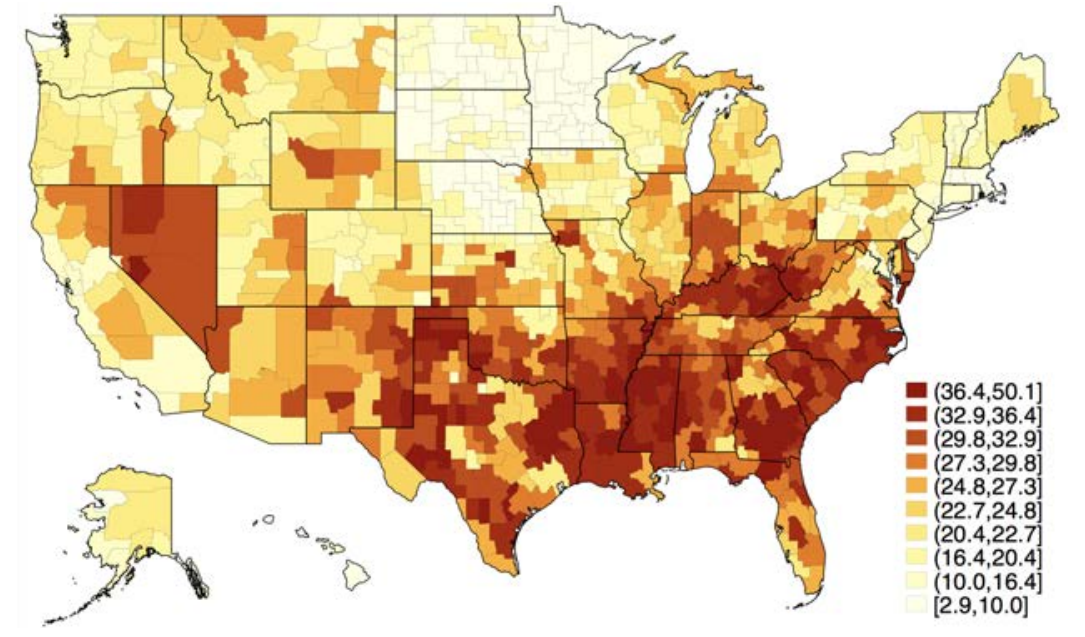

(C) Non-Medical Collections (\%)

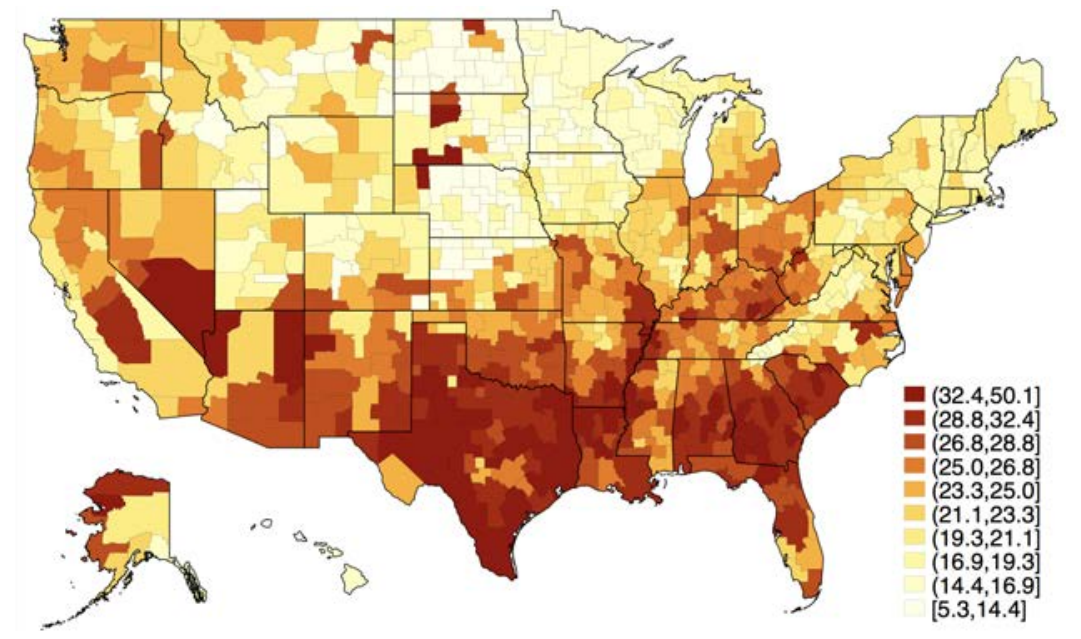

Note: Figure shows maps based on data aggregated to the CZ level. CZ means are constructed using a $10 \%$ random sample of TransUnion credit records from June 2015. Debt in collections is an indicator for 1+debt in collections in the last 3 years. Medical collections is an indicator for $1+$ medical debt in collections.

Non-medical collections is an indicator for 1+ non-medical debt in collections. See Section 2 for more details on variable construction. 
Figure A3: Geographic Variation in Collections Balances

(A) Balance of Collection in Past 3 years $(\$)$

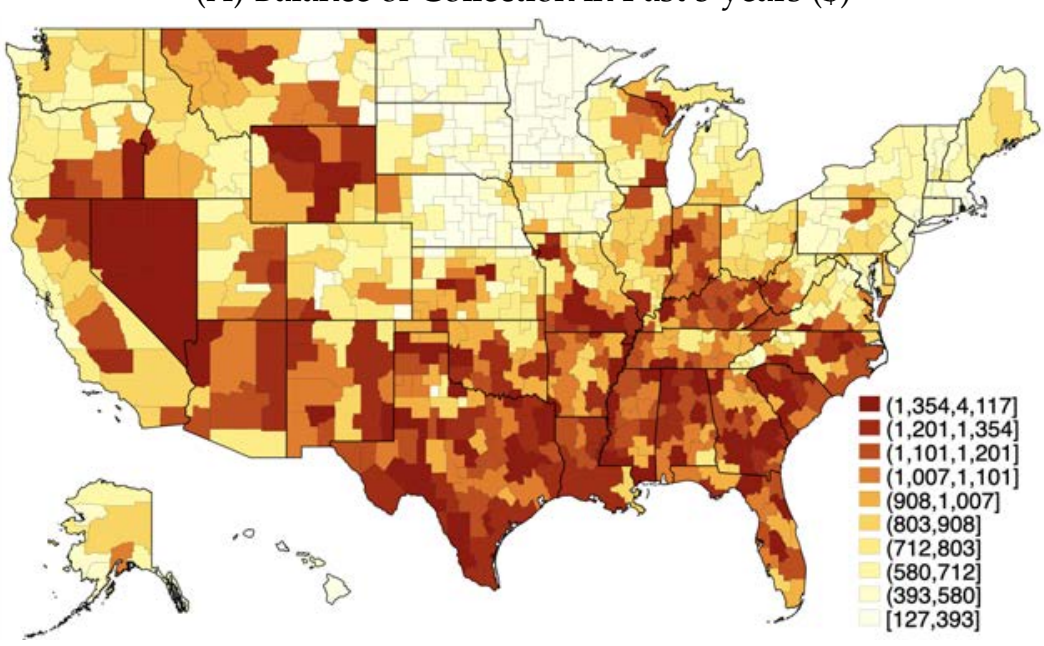

(C) Medical Collection Balance (\$)

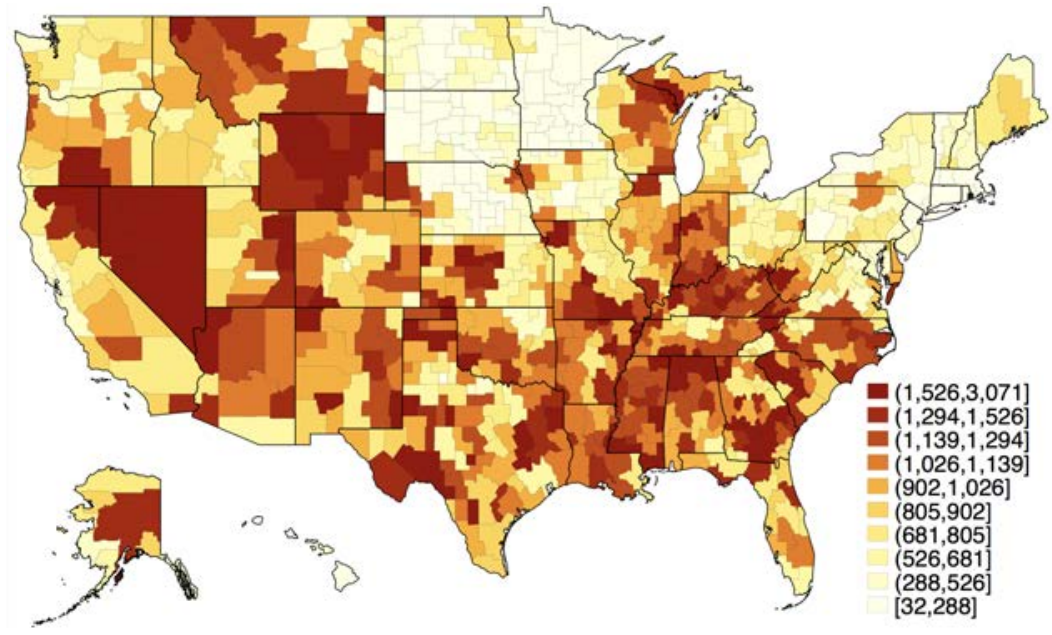

(B) Collection Balance $(\$)$

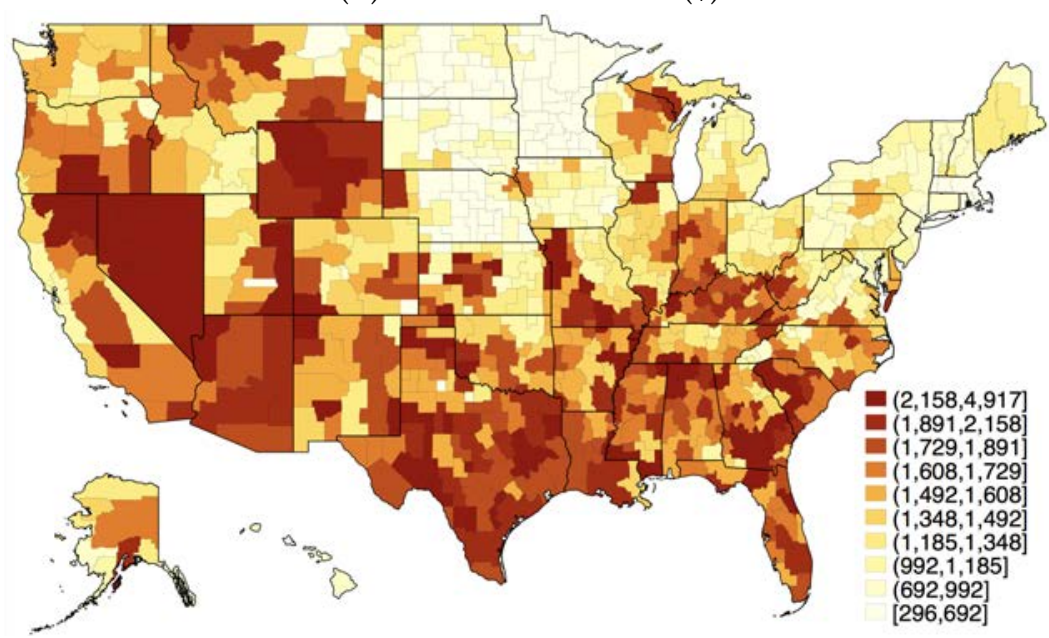

(D) Non-Medical Collection Balance (\$)

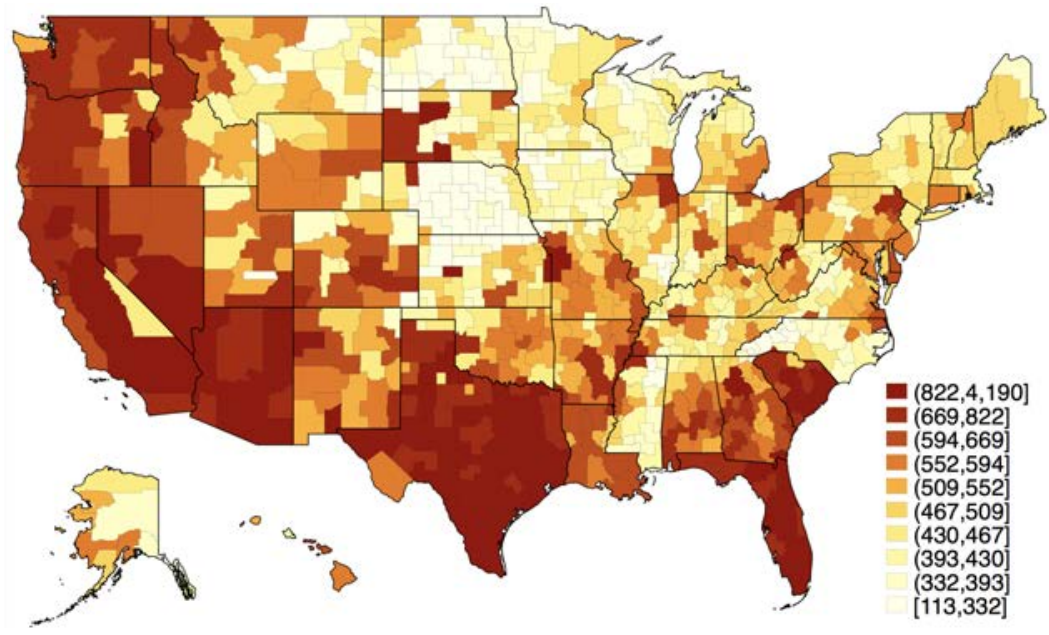

Note: Figure shows maps based on data aggregated to the CZ level. CZ means are constructed using a 10\% random sample of TransUnion credit records from June 2015. Balance of collection in past 3 years is the average balance of debt in collections opened during the past 3 years. Collections balance is the average balance of debt in collections. Medical and non-medical collections balances are the average balances of medical and non-medical debt in collections. See Section 2 for more details on variable construction. 
Figure A4: Geographic Variation in Percent with Credit Cards and Credit Reports

(A) Percent with Credit Card (\%)

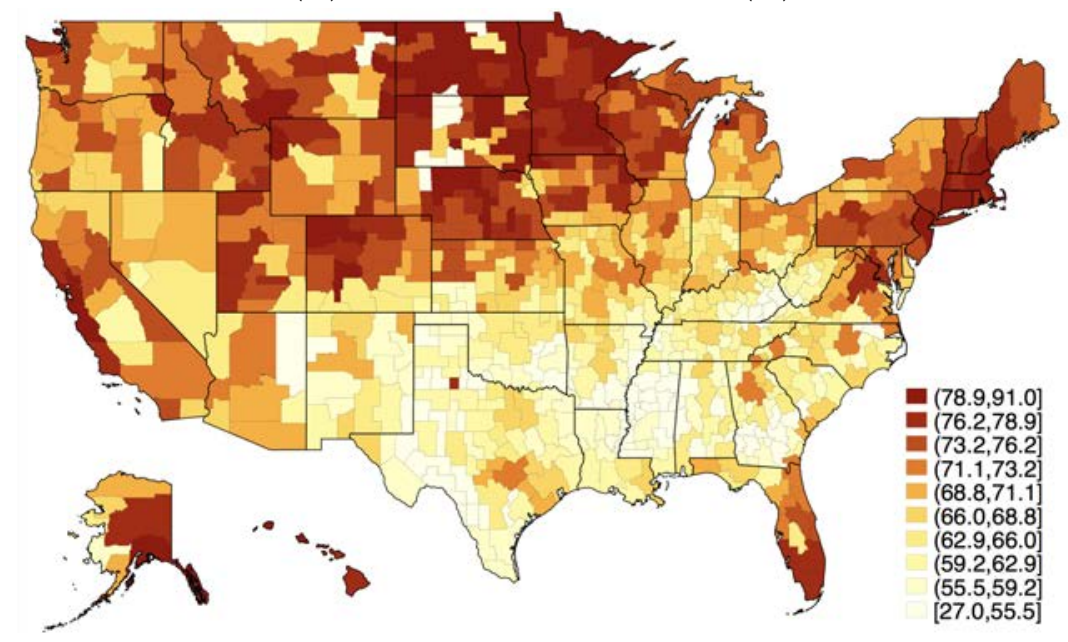

(B) Percent of Population with Credit Report (\%)

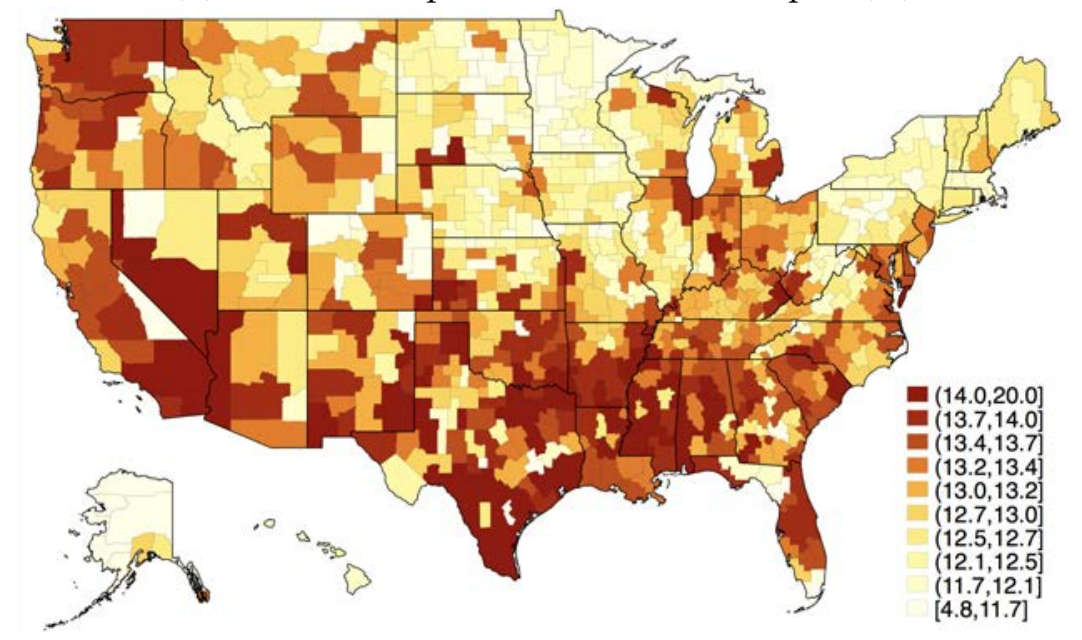

(C) Percent of Population with Credit Report But No Trade Account (\%)

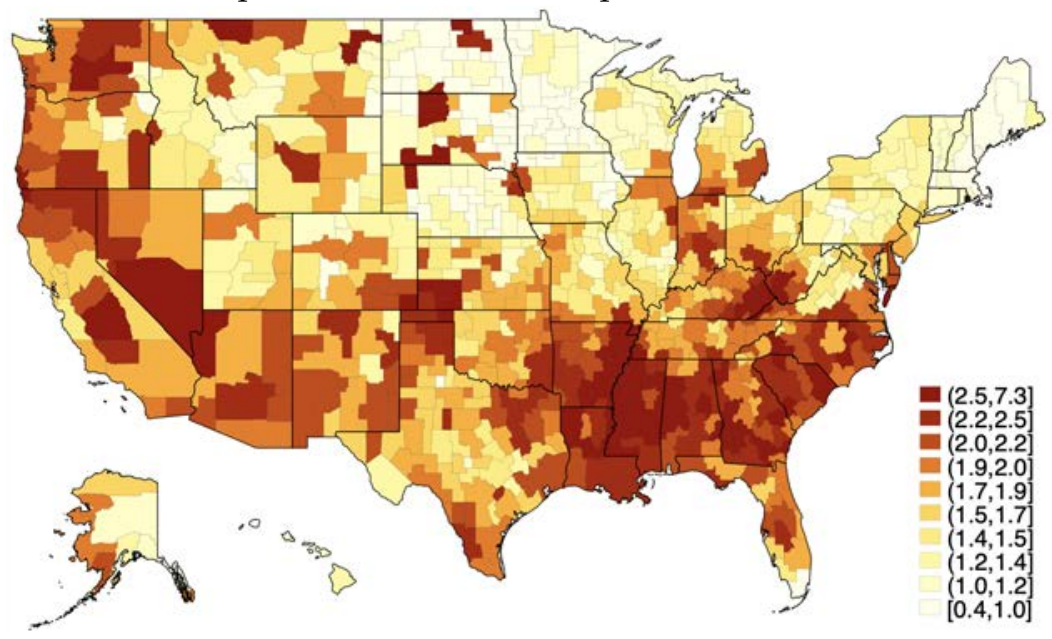

Note: Figure shows maps based on data aggregated to the CZ level. Panel A shows the percent of individuals with a credit card in our credit report data. Panel B shows the ratio of observations in our credit report data to the total population between 20 and 80 reported in the 2015 American Community Survey. Panel $\mathrm{C}$ shows the ratio of observations in our credit report data without valid trade accounts to total population between 20 and 80 . The credit report data 46 Pe constructed using a $10 \%$ random sample of TransUnion credit records from June 2015, aggregated to the CZ level. 
Figure A5: Geographic Variation in Delinquency and Bankruptcy Filings

(A) Credit Card Delinquency (\%)

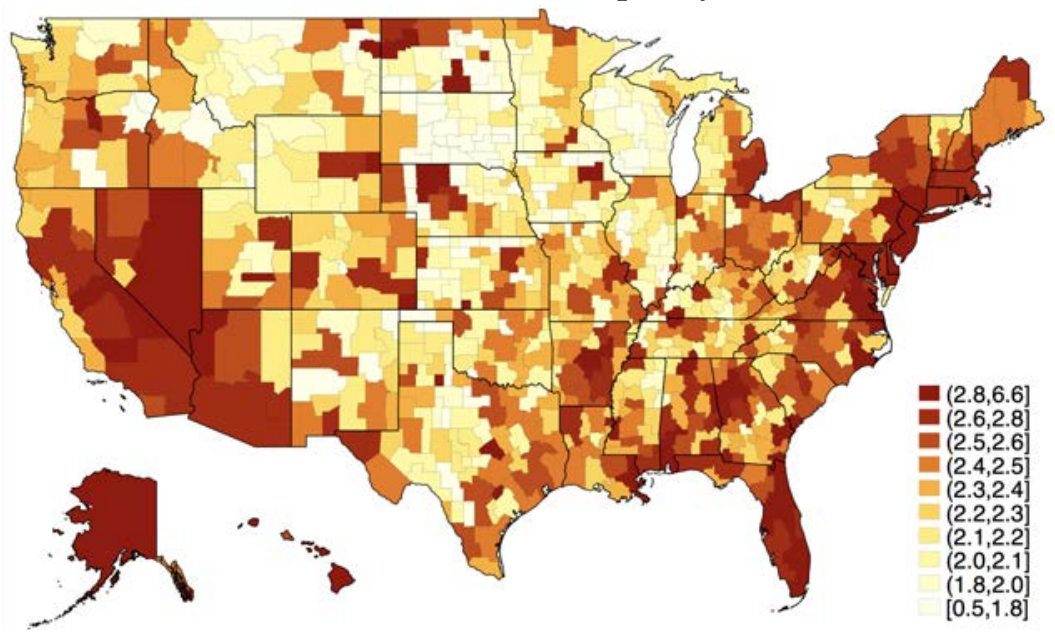

(B) Bankruptcy Filings in Past 3 Years (per 1,000)

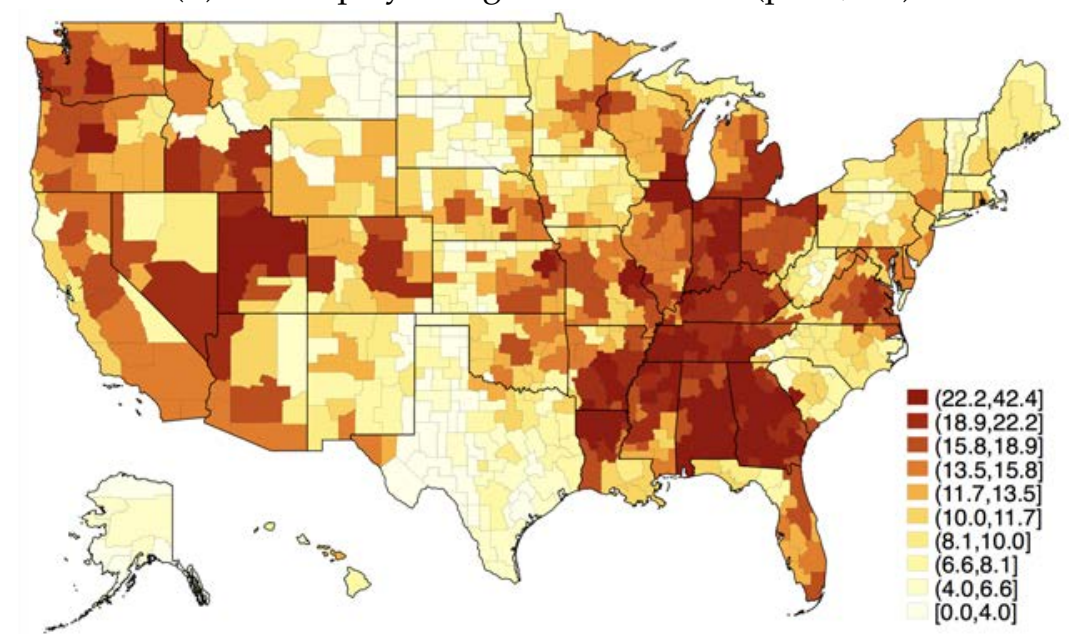

Note: Figure shows maps based on data aggregated to the CZ level. CZ means are constructed using a $10 \%$ random sample of TransUnion credit records from June 2015. Credit card delinquency is an indicator for $1+$ credit card (30+DPD but not charged off or in collections). 


\section{Figure A6: Rank Stability in Financial Distress}

(A) Debt in Collections in Past 3 Years (\%)

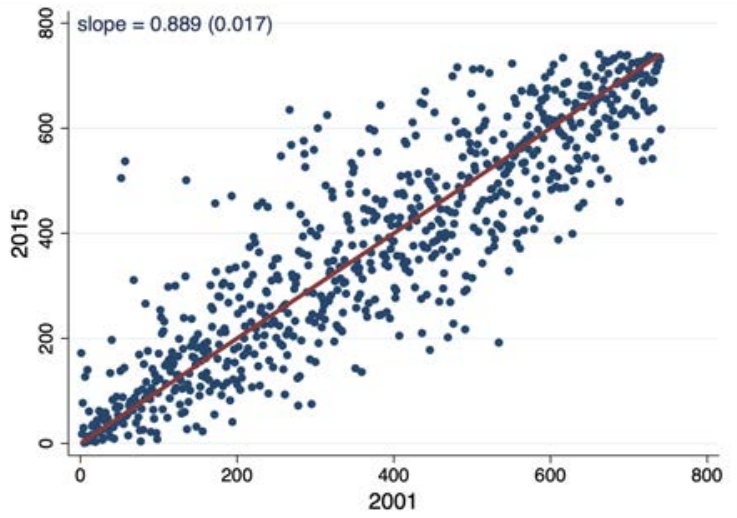

(C) Chapter 7 Filings in Past 3 Years (Per 1,000)

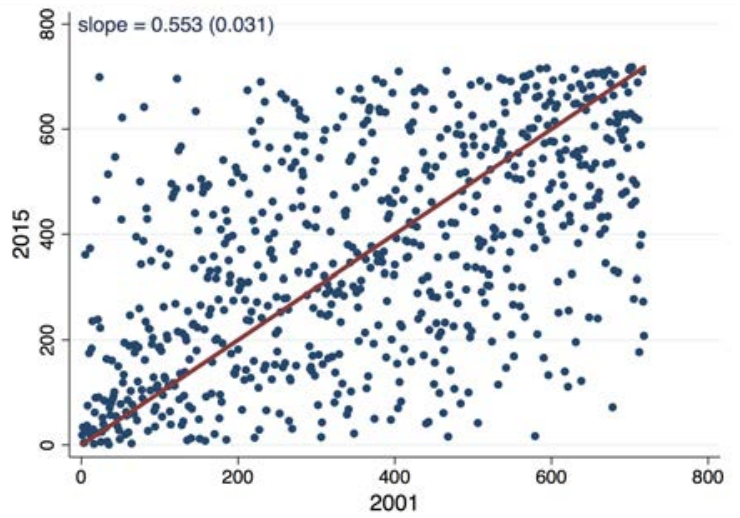

(B) Credit Card Delinquency in Past 3 Years (\%)

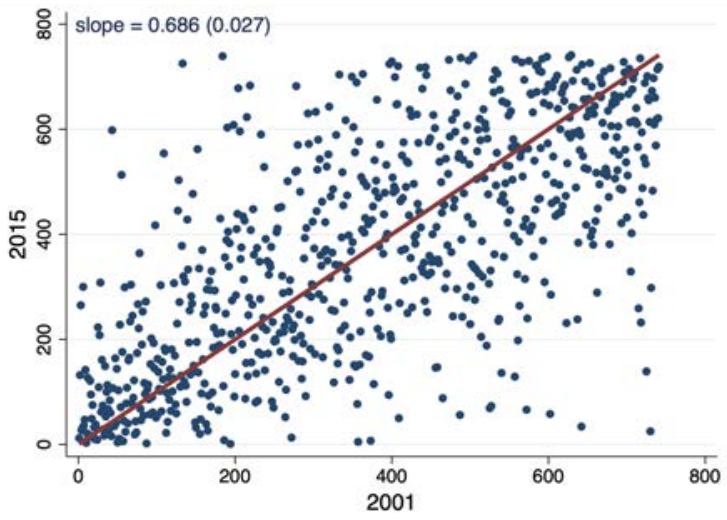

(D) Chapter 13 Filings in Past 3 Years (Per 1,000)

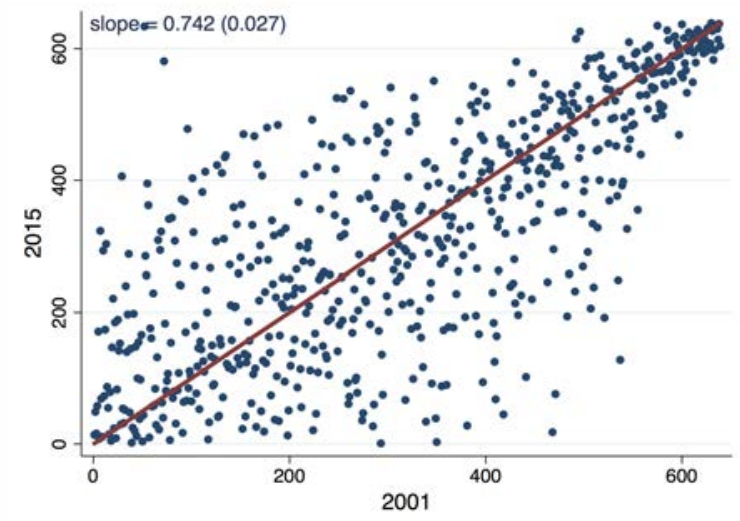

Note: Figure shows scatter plots of the ordinal ranking of CZs in 2015 versus 2001 for our financial distress measures. The 45 degree line is shown in red. 


\section{Figure A7: Stability in Financial Distress}

(A) Debt in Collections in Past 3 Years (\%)

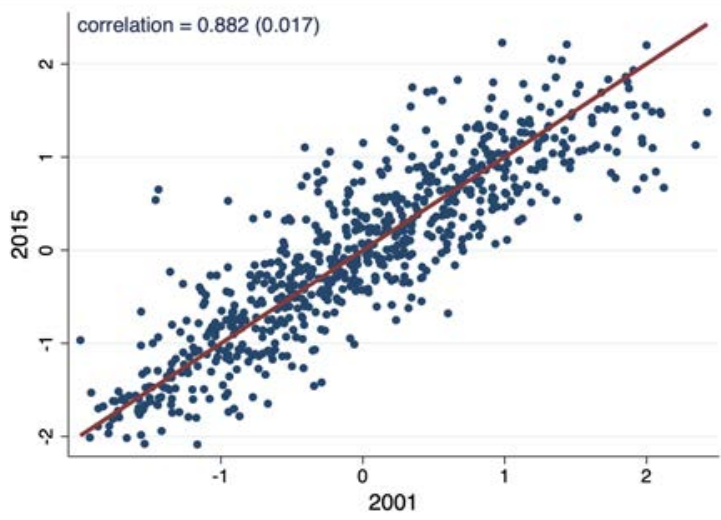

(C) Chapter 7 Filings in Past 3 Years (Per 1,000)

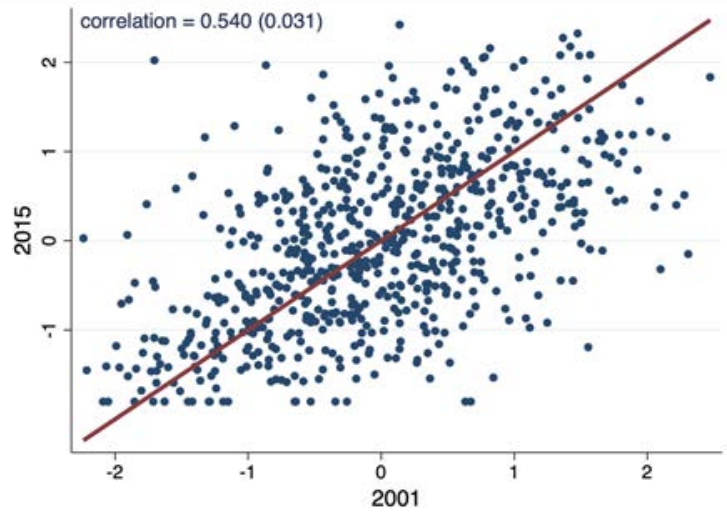

(B) Credit Card Delinquency in Past 3 Years (\%)

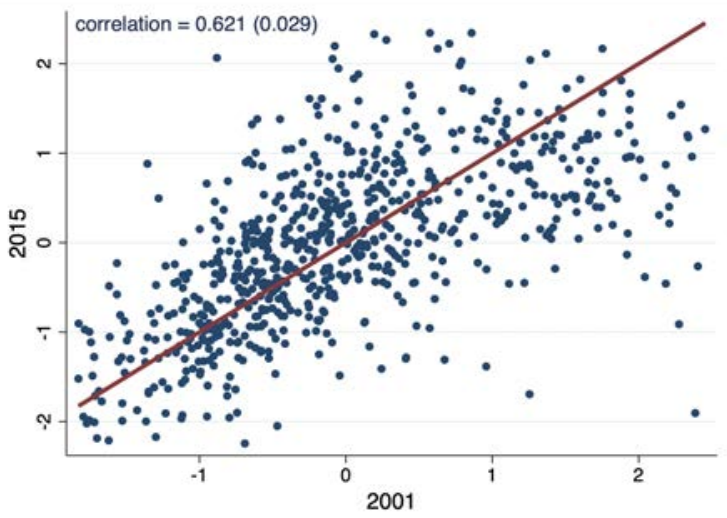

(D) Chapter 13 Filings in Past 3 Years (Per 1,000)

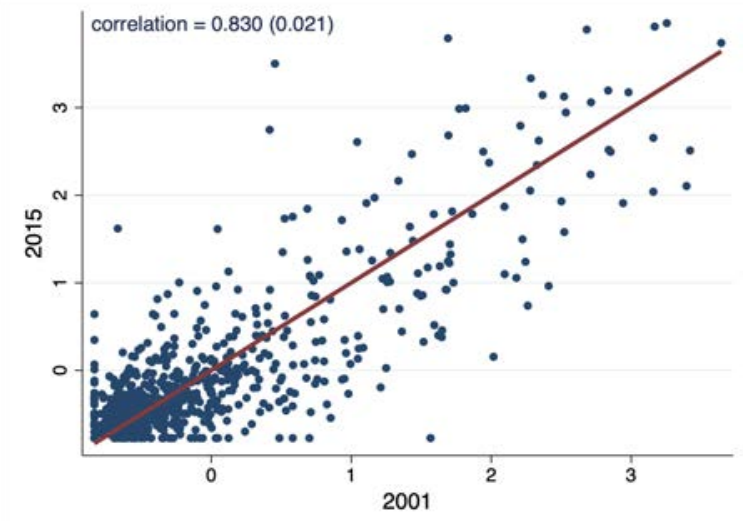

Note: Figure shows scatter plots of average financial distress measures of CZs in 2015 versus 2001. Financial distress measures are normalized by the mean and standard deviation across CZs in their respective years. Correlation coefficients based on the full sample are reported at the top left corner, while the scatter plots are Winsorized at 1 st and 99th percentile. The 45 degree line is shown in red. 
Figure A8: Distribution of Observations and Movers by Commuting Zones

(A) TransUnion Observations (in thousands)

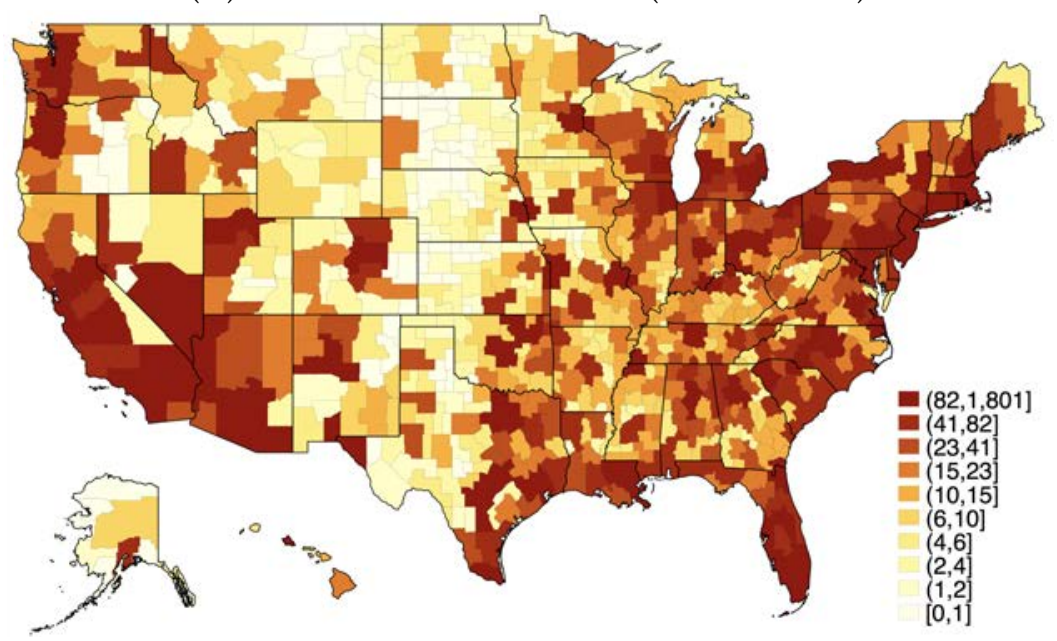

(B) Origin Commuting Zones of Movers

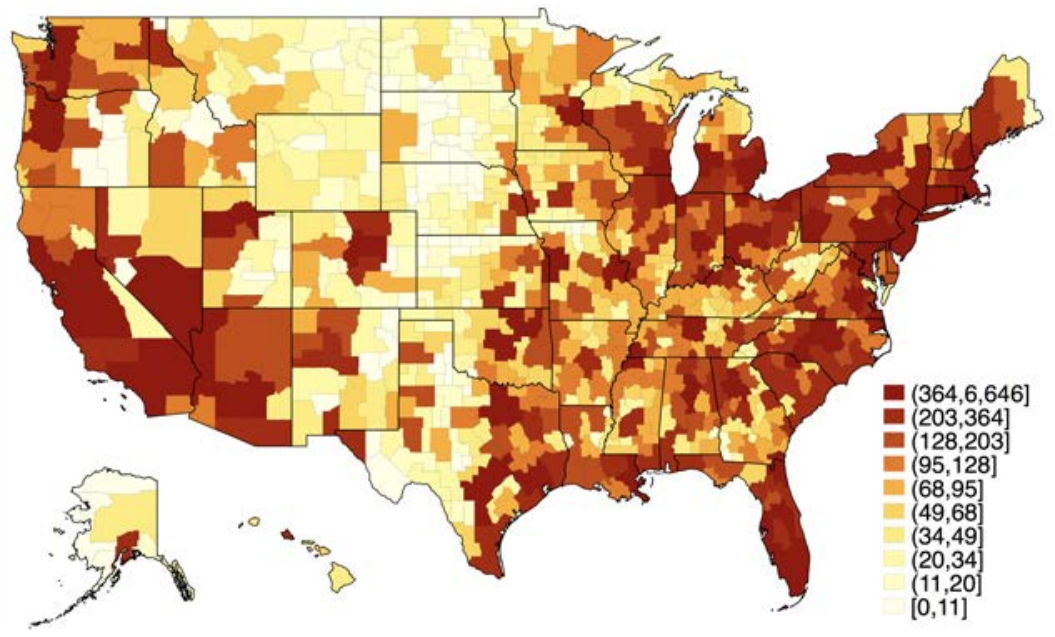

(C) Destination Commuting Zones of Movers

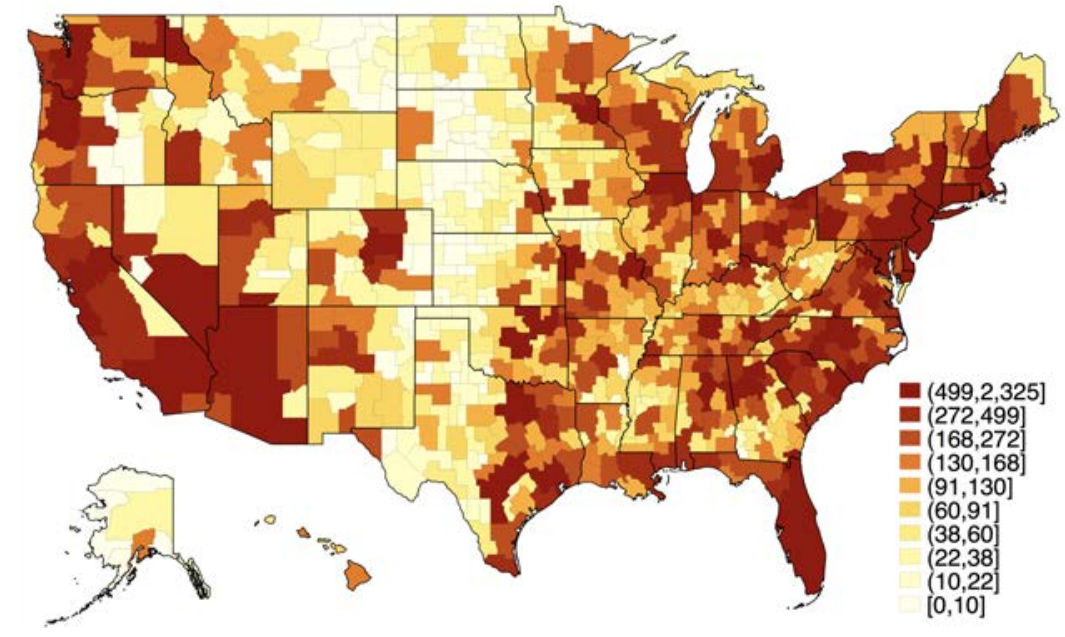

Note: Figure shows distributions of observations across CZs. Panel A displays number of observations (in thousands) in each CZ from the 10\% random sample of TransUnion credit records in June 2015. Panels B and $\mathrm{C}$ display the number of movers in their origin and destination CZs. See Section 4 for further discussion of the sample restrictions for movers. 
Figure A9: Histogram of Size of Move $\widehat{\delta}_{i}$ at Zip Code Level
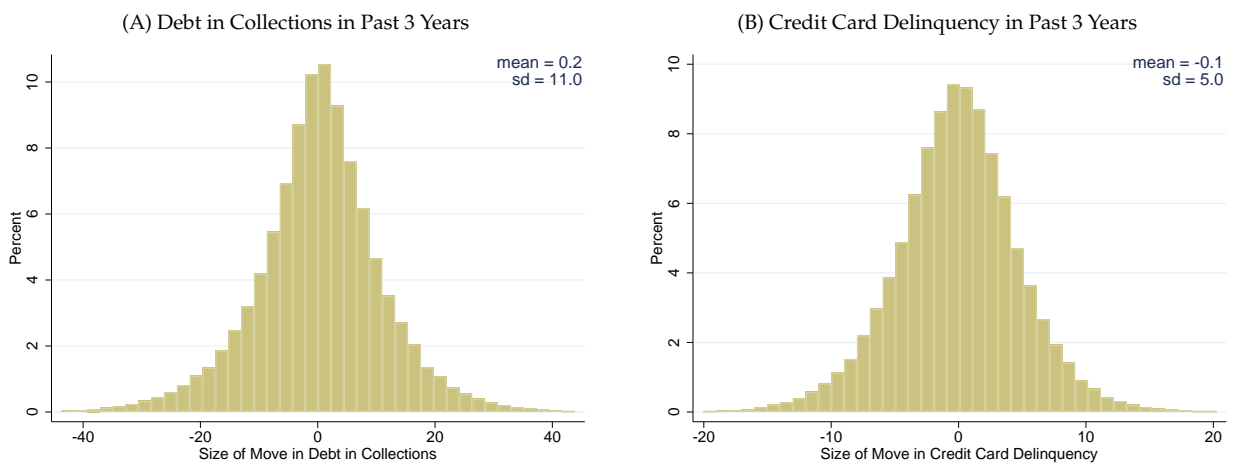

(C) Chapter 7 Filings in Past 3 Years

(D) Chapter 13 Filings in Past 3 Years
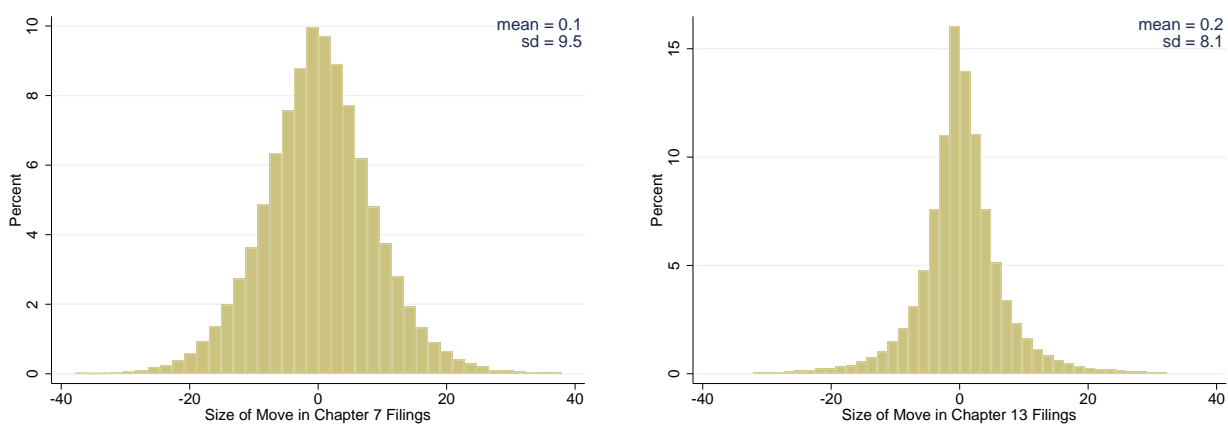

Note: Figure shows histogram of size of move $\widehat{\delta}_{i}$ computed at zip code level. We keep $\widehat{\delta}_{i}$ that are within \pm 4 standard deviations from the mean. 
Figure A10: Histogram of Size of Move $\widehat{\delta}_{i}$ at Zip Code $\times 10$-Year Age Bin Level
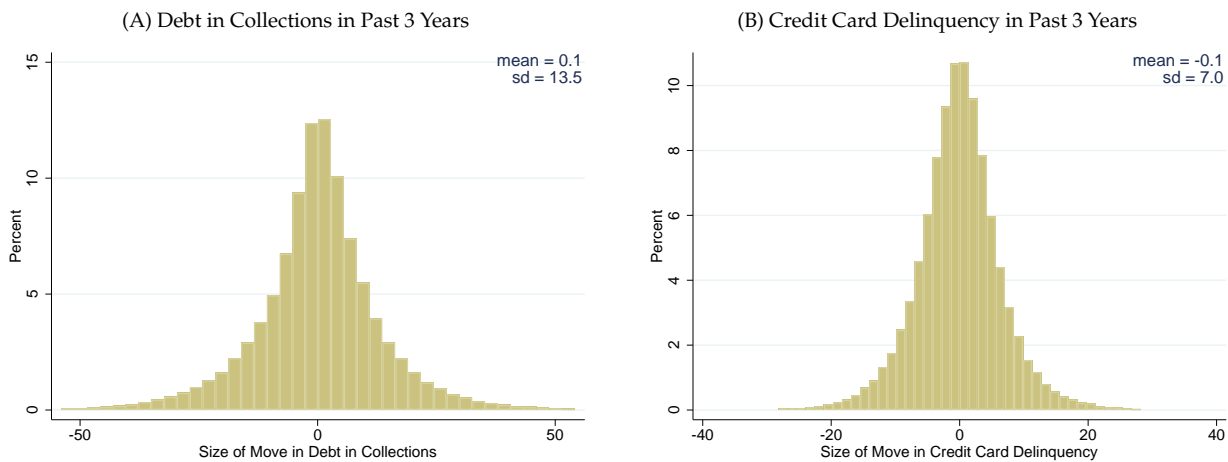

(C) Chapter 7 Filings in Past 3 Years

(D) Chapter 13 Filings in Past 3 Years
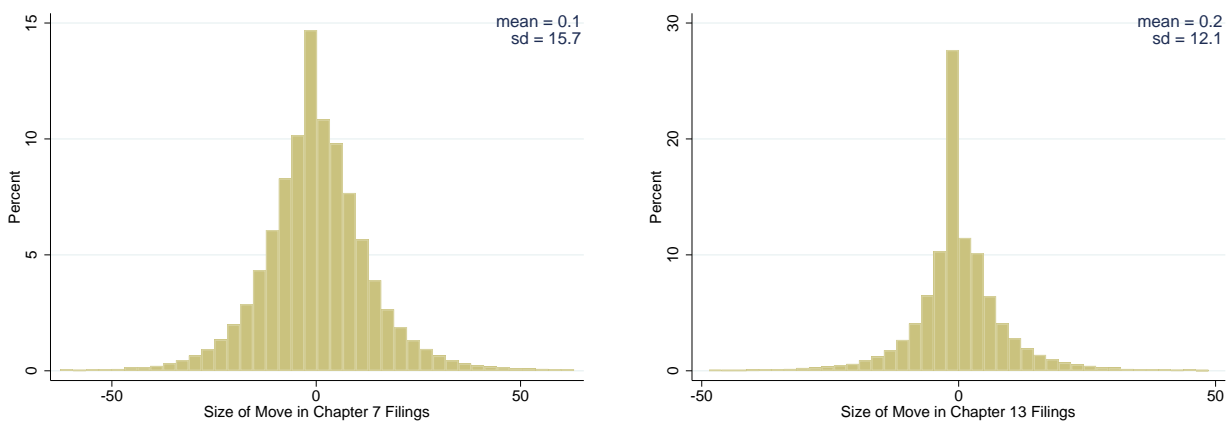

Note: Figure shows histogram of size of move $\widehat{\delta}_{i}$ computed at zip code $\times 10$-year age bin level. We keep $\widehat{\delta}_{i}$ that are within \pm 4 standard deviations from the mean. 
Figure A11: Histogram of Size of Move $\widehat{\delta}_{i}$ at County Level
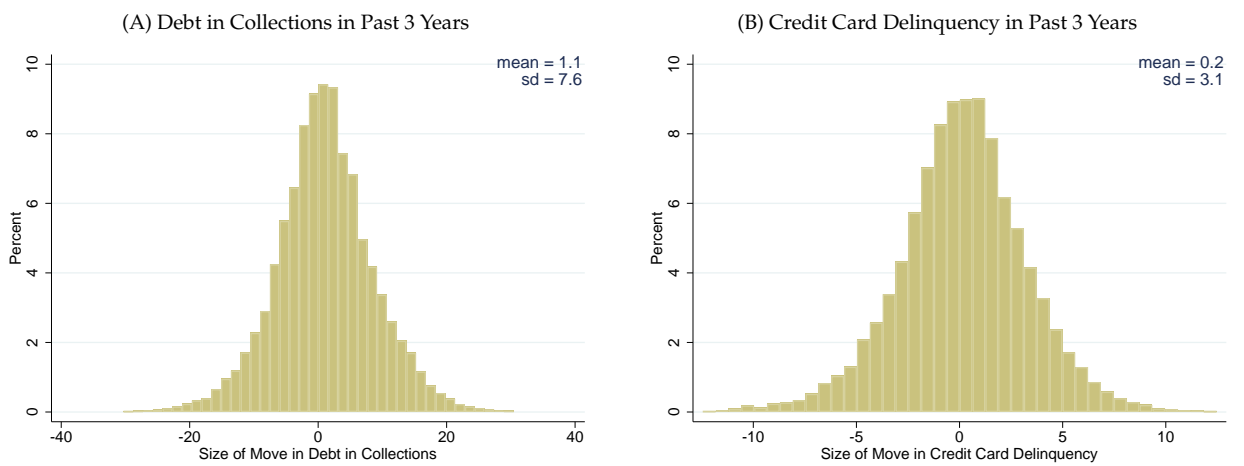

(C) Chapter 7 Filings in Past 3 Years

(D) Chapter 13 Filings in Past 3 Years
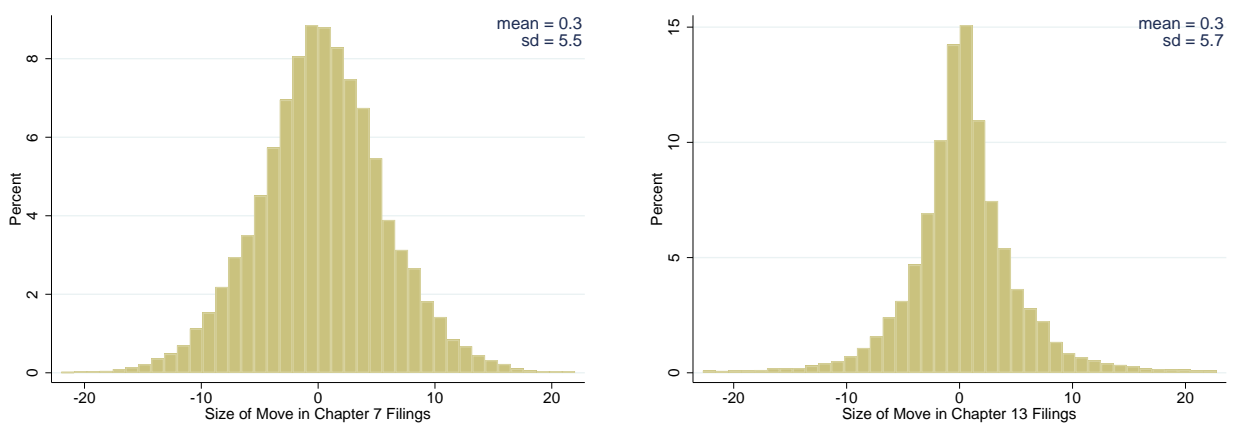

Note: Figure shows histogram of size of move $\widehat{\delta}_{i}$ computed at county level. We keep $\widehat{\delta}_{i}$ that are within \pm 4 standard deviations from the mean. 


\section{Figure A12: Event-Study Plots: Within and Across State Movers}

(A) Chapter 7 Filings in Past 3 Years, Same State (\%)

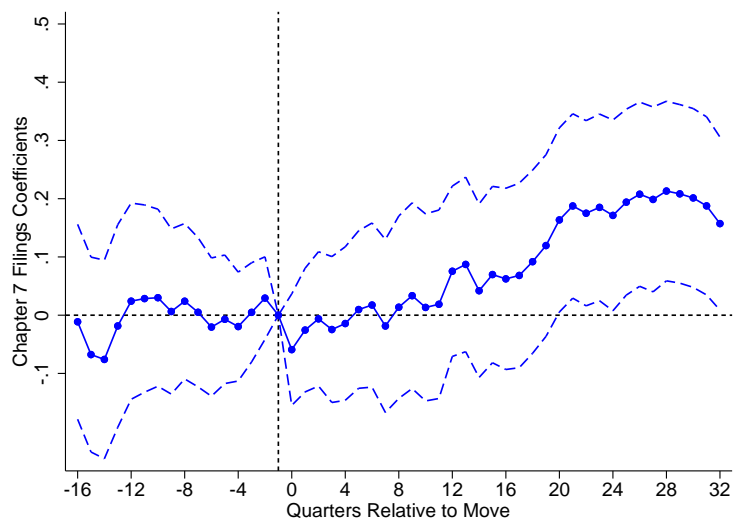

(C) Chapter 7 Filings in Past 3 Years, Cross State

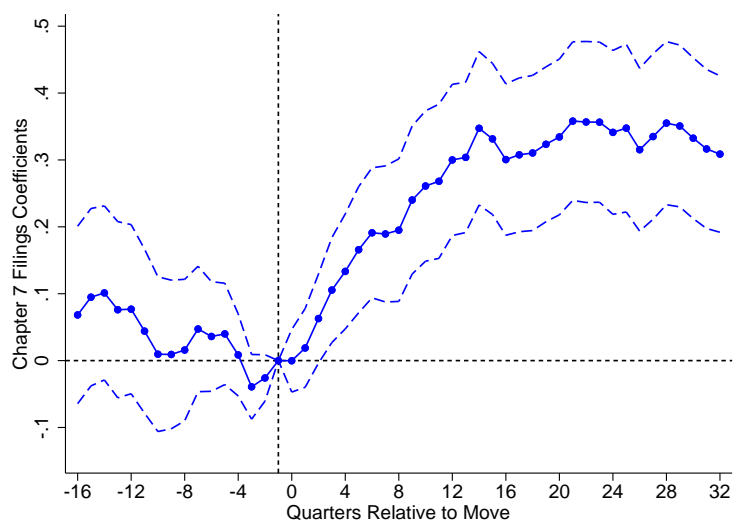

(B) Chapter 13 Filings in Past 3 Years, Same State

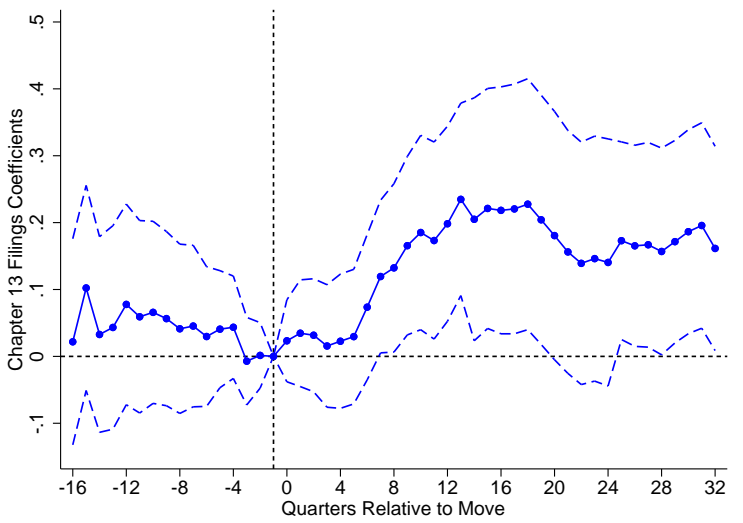

(D) Chapter 13 Filings in Past 3 Years, Cross State)

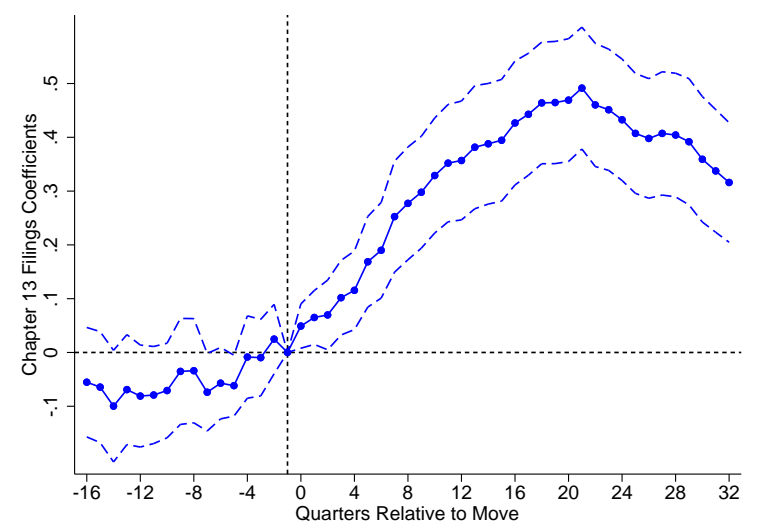

Note: Figures shows place-based effects $\theta_{r}$ from event-study regressions of financial distress on the size of the move $\widehat{\delta_{i, t}}$, individual and time fixed effects, and other controls. Top panels restrict to the subsample of movers within the same state. Bottom panels restrict to the subsample of movers across states. The dashed lines show $95 \%$ confidence intervals, based on standard errors clustered by origin $\times$ destination CZ. 


\section{Figure A13: Event-Study Plots: Pre-Move Credit Score}

(A) Chapter 7 Filings in Past 3 Years, Low Score (\%)

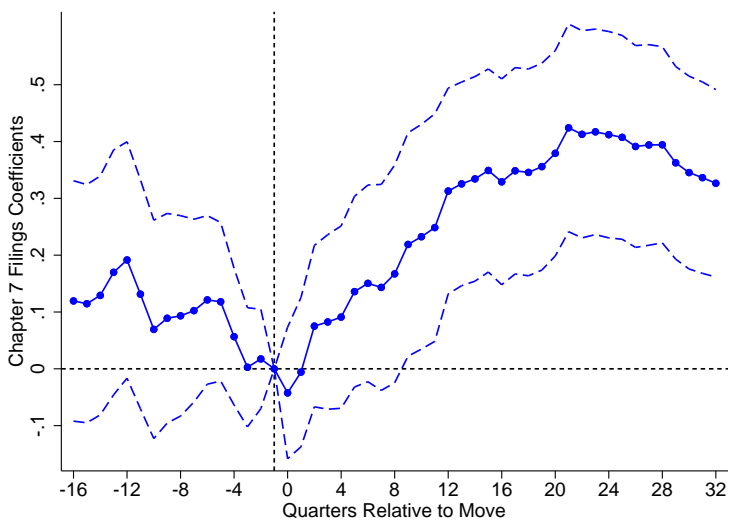

(C) Chapter 7 Filings in Past 3 Years, Mid Score

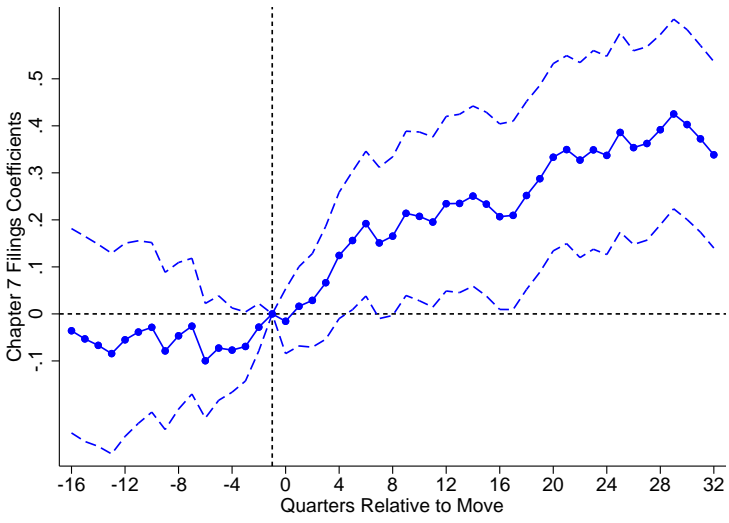

(E) Chapter 7 Filings in Past 3 Years, High Score

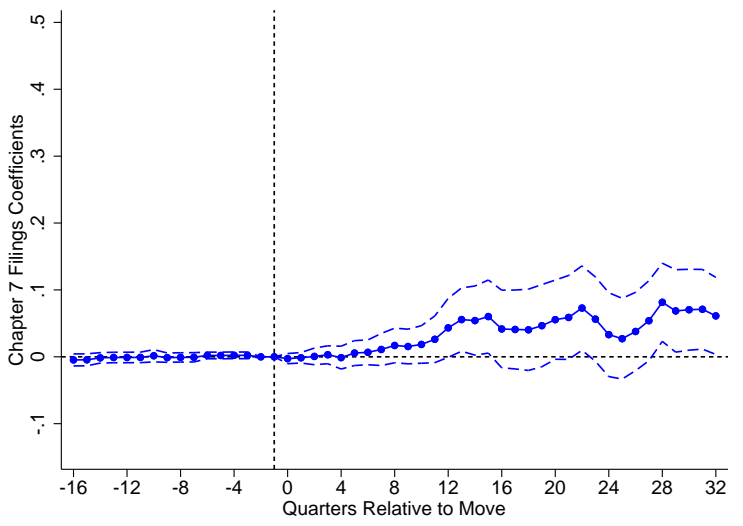

(B) Chapter 13 Filings in Past 3 Years, Low Score

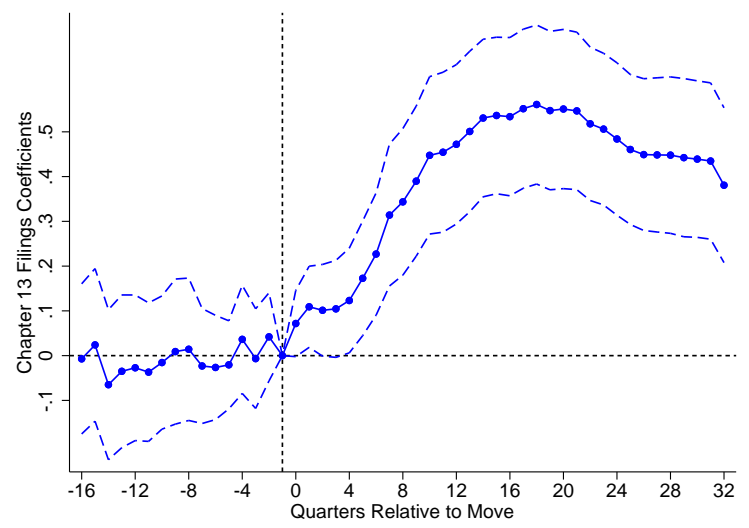

(D) Chapter 13 Filings in Past 3 Years, Mid Score)

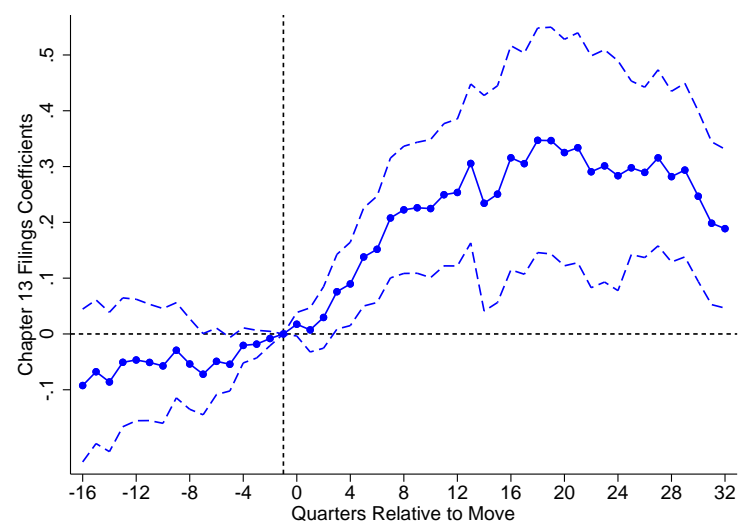

(F) Chapter 13 Filings in Past 3 Years, High Score)

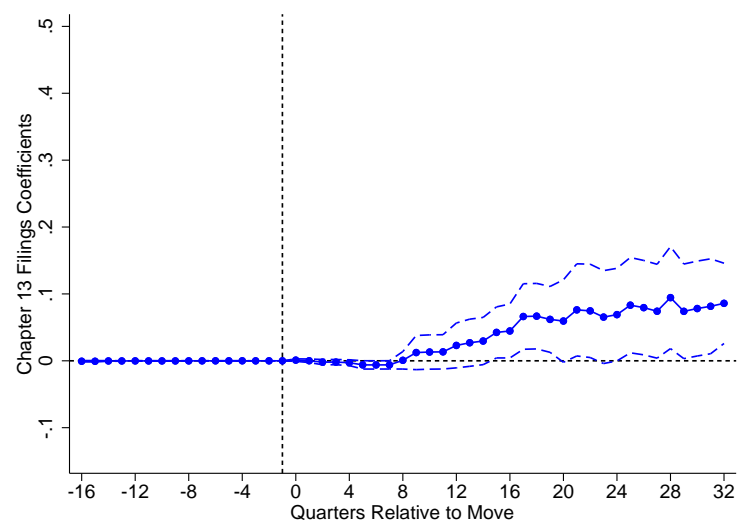

Note: Figures shows place-based effects $\theta_{r}$ from event-study regressions of financial distress on the size of the move $\widehat{\delta_{i, t}}$, individual and time fixed effects, and other controls. Top panels restrict movers with credit score below 620 the quarter prior to move. Middle panels restrict to movers with credit score between 620 and 765 the quarter prior to move. Bottom panels restrict to movers with credit score above 765 the quarter prior to move. The dashed lines show $95 \%$ confidence intervals, based on standard errors clustered by origin $\times$ destination $\mathrm{CZ}$. 


\section{Figure A14: Event-Study Plots: Sensitivity to BAPCPA}

(A) Chapter 7 Filings in Past 3 Years (Per 1,000) (\%)

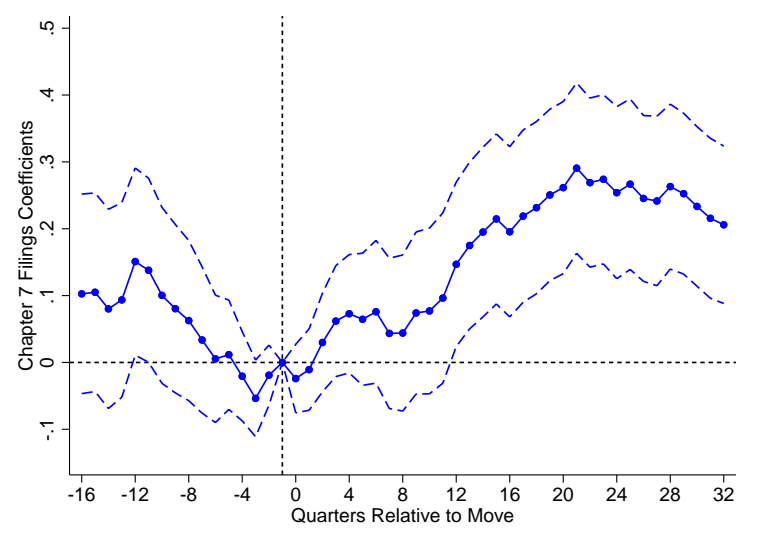

(B) Chapter 13 Filings in Past 3 Years (Per 1,000)

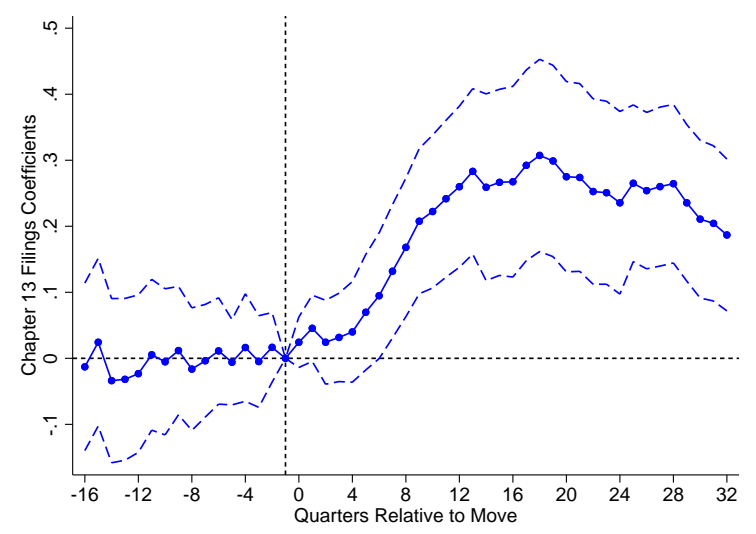

Note: Figures shows place-based effects $\theta_{r}$ from event-study regressions of financial distress on the size of the move $\widehat{\delta_{i, t}}$, individual and time fixed effects, and other controls, where we allow the size of the move to vary before and after the 2005 bankruptcy reform (BAPCPA). Specifically, we define the pre-BAPCPA size of the move using average outcomes for non-movers in the pre-BAPCA period and the post-move size of the move using average outcomes for non-movers in the post-BAPCA period. The dashed lines show $95 \%$ confidence intervals, based on standard errors clustered by origin $\times$ destination CZ. 
Figure A15: Correlates of Place Effects: Medical Debt in Collections
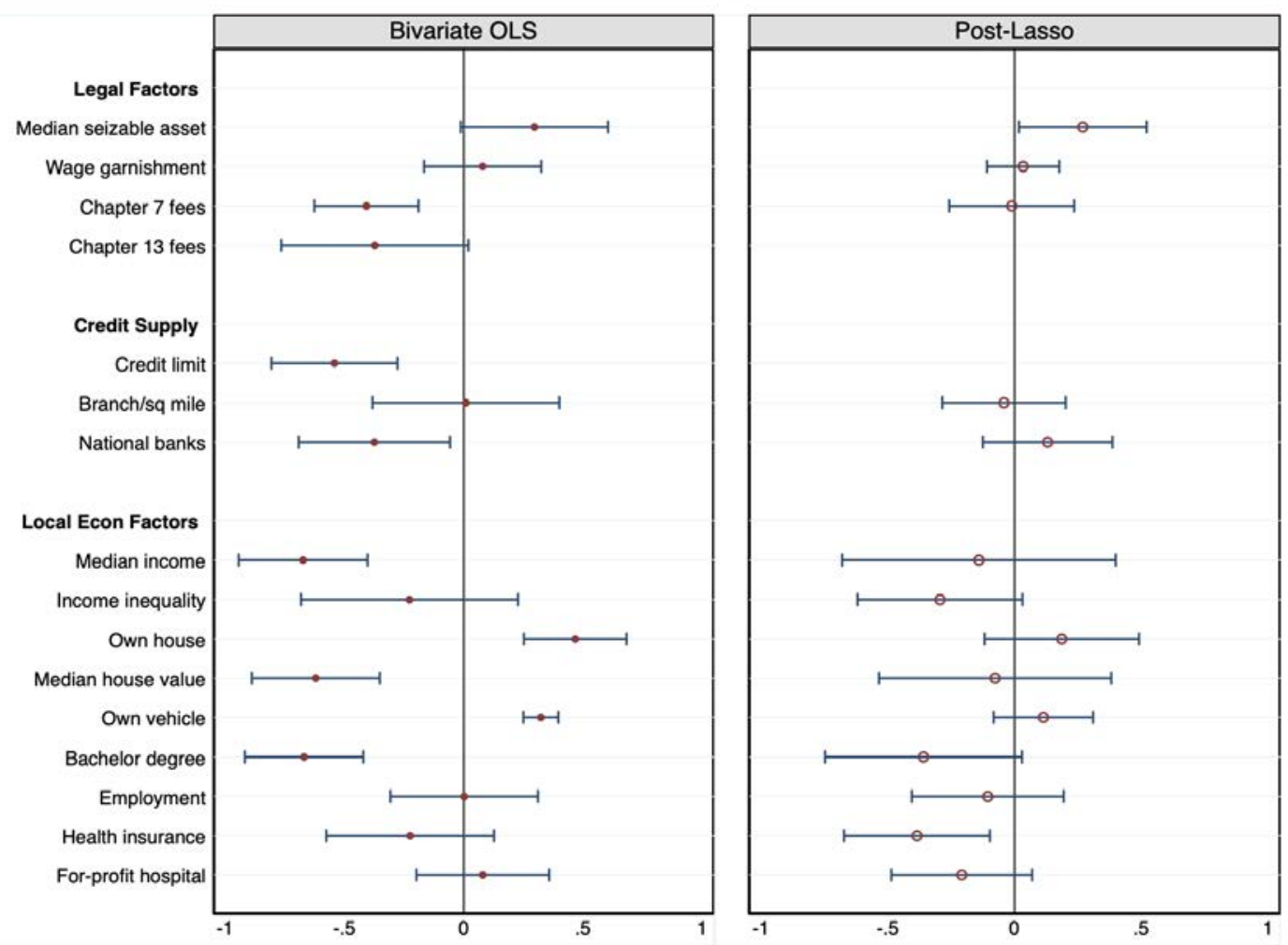

Note: Figure shows bivariate OLS regression coefficients (left panel) and post-Lasso multivariate regression coefficients (right panel) of the place effect of medical debt in collections. The dependent variable and all covariates have been standardized to have a mean of zero and a standard deviation of one. To obtain the post-Lasso estimates, we first run a Lasso regression on the full set of covariates, with the penalty level chosen by a 4-fold cross-validation to minimize mean squared error. We then run an OLS regression on the set of covariates chosen by the Lasso regression. 


\section{Figure A16: Correlates of Place Effects: Chapter 7 Filings}

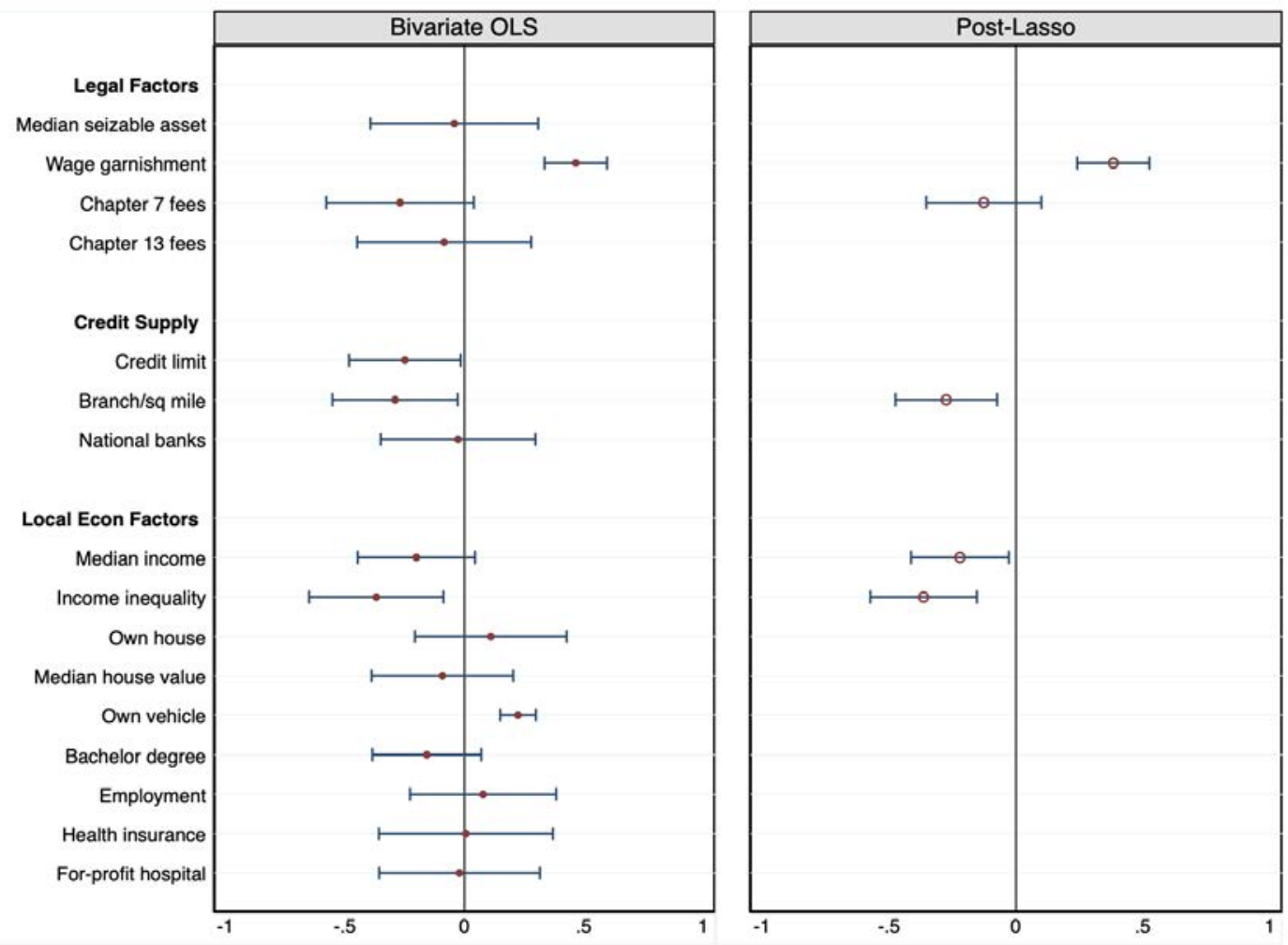

Note: Figure shows bivariate OLS regression coefficients (left panel) and post-Lasso multivariate regression coefficients (right panel) of the place effect of Chapter 7 bankruptcy filings in the past three years. The dependent variable and all covariates have been standardized to have a mean of zero and a standard deviation of one. To obtain the post-Lasso estimates, we first run a Lasso regression on the full set of covariates, with the penalty level chosen by a 4-fold cross-validation to minimize mean squared error. We then run an OLS regression on the set of covariates chosen by the Lasso regression. 


\section{Figure A17: Correlates of Place Effects: Chapter 13 Filings}

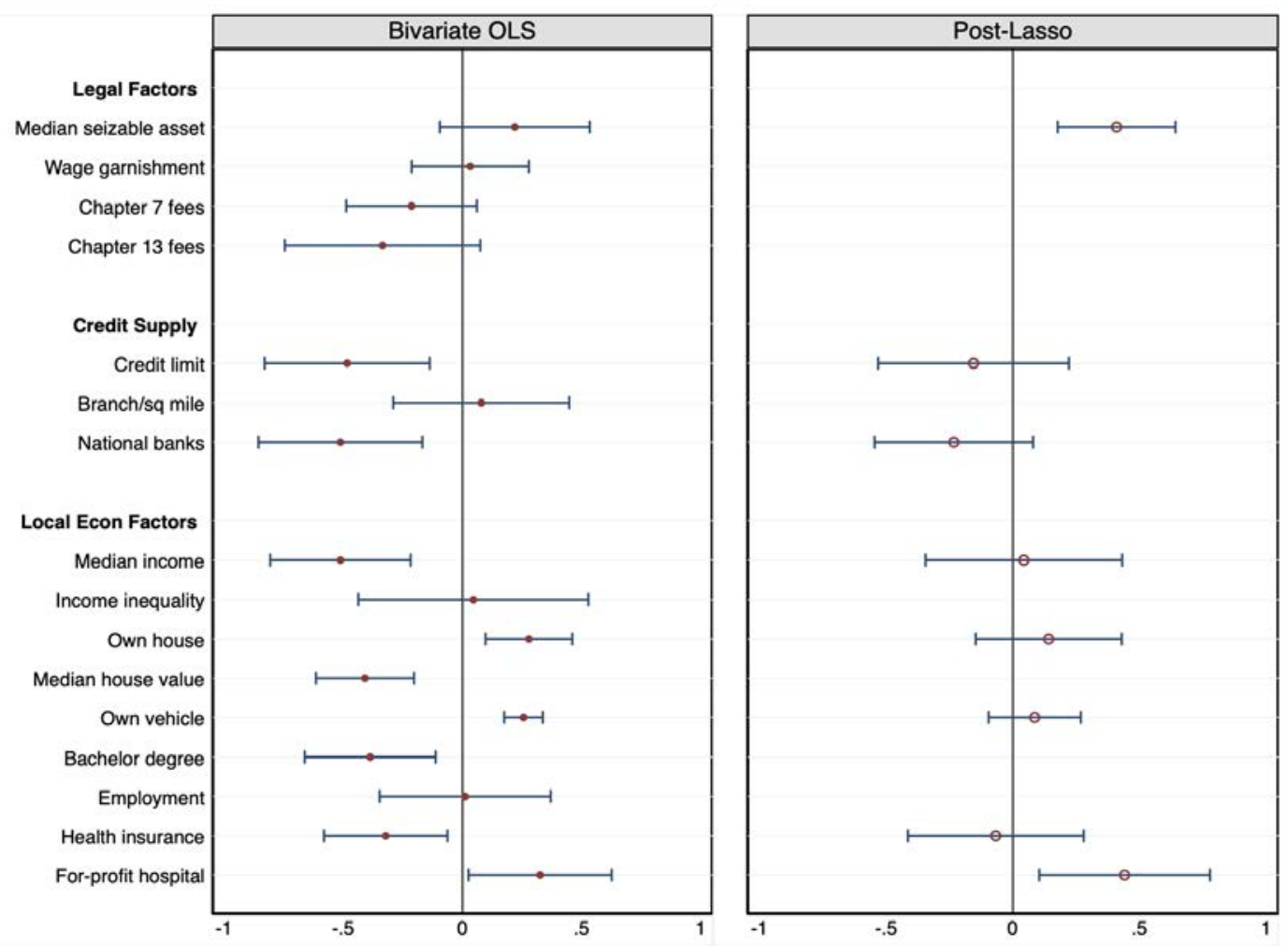

Note: Figure shows bivariate OLS regression coefficients (left panel) and post-Lasso multivariate regression coefficients (right panel) of the place effect of Chapter 13 bankruptcy filings in the past three years. The dependent variable and all covariates have been standardized to have a mean of zero and a standard deviation of one. To obtain the post-Lasso estimates, we first run a Lasso regression on the full set of covariates, with the penalty level chosen by a 4-fold cross-validation to minimize mean squared error. We then run an OLS regression on the set of covariates chosen by the Lasso regression. 


\section{Figure A18: Correlates of Place Effects: Combined Bankruptcy Filings}
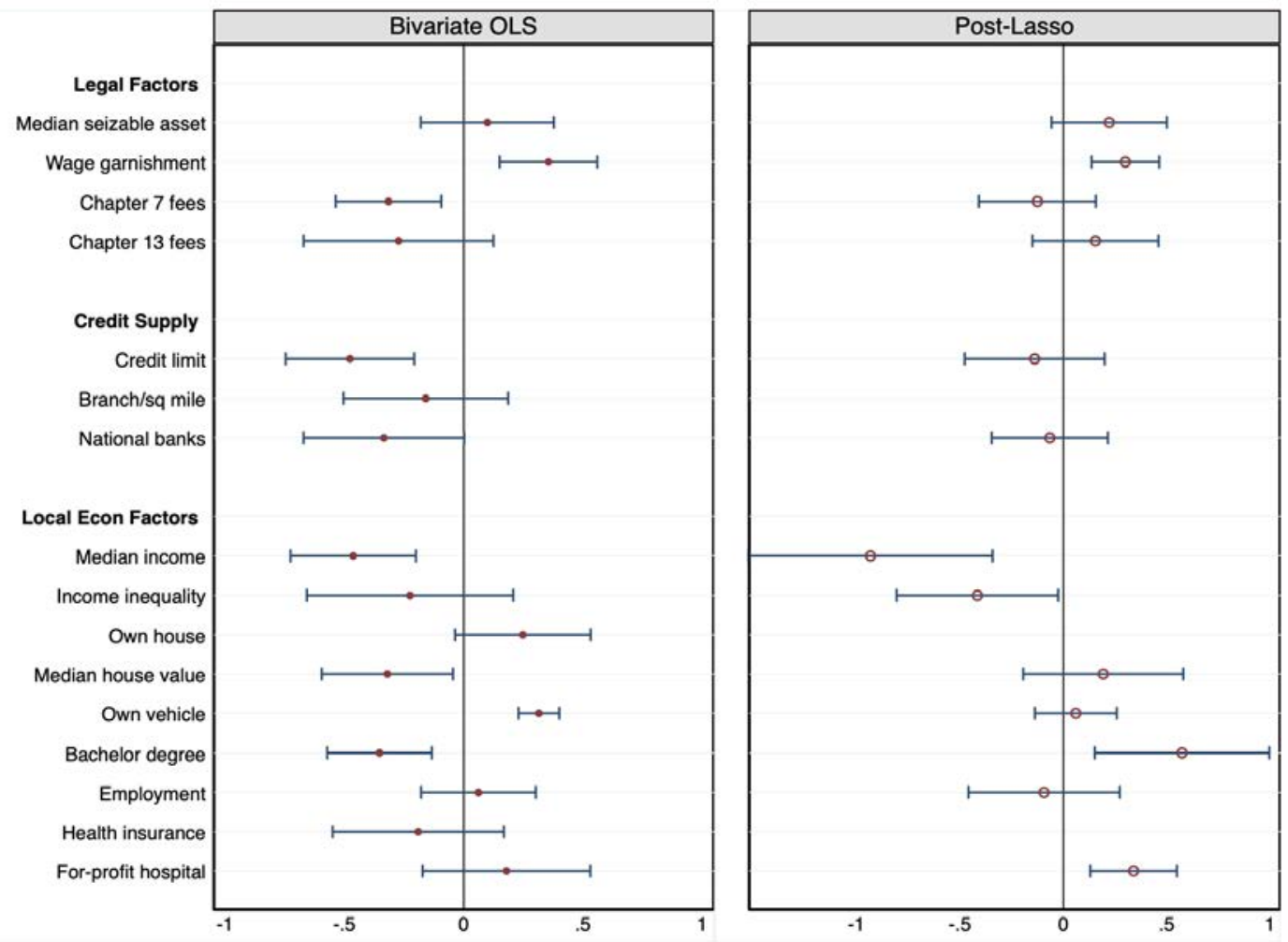

Note: Figure shows bivariate OLS regression coefficients (left panel) and post-Lasso multivariate regression coefficients (right panel) of the place effect of any bankruptcy filings in the past three years. The dependent variable and all covariates have been standardized to have a mean of zero and a standard deviation of one. To obtain the post-Lasso estimates, we first run a Lasso regression on the full set of covariates, with the penalty level chosen by a 4-fold cross-validation to minimize mean squared error. We then run an OLS regression on the set of covariates chosen by the Lasso regression. 
Figure A19: Correlates of Place Effects: Chapter 7 Filings Controlling for Combined Filings
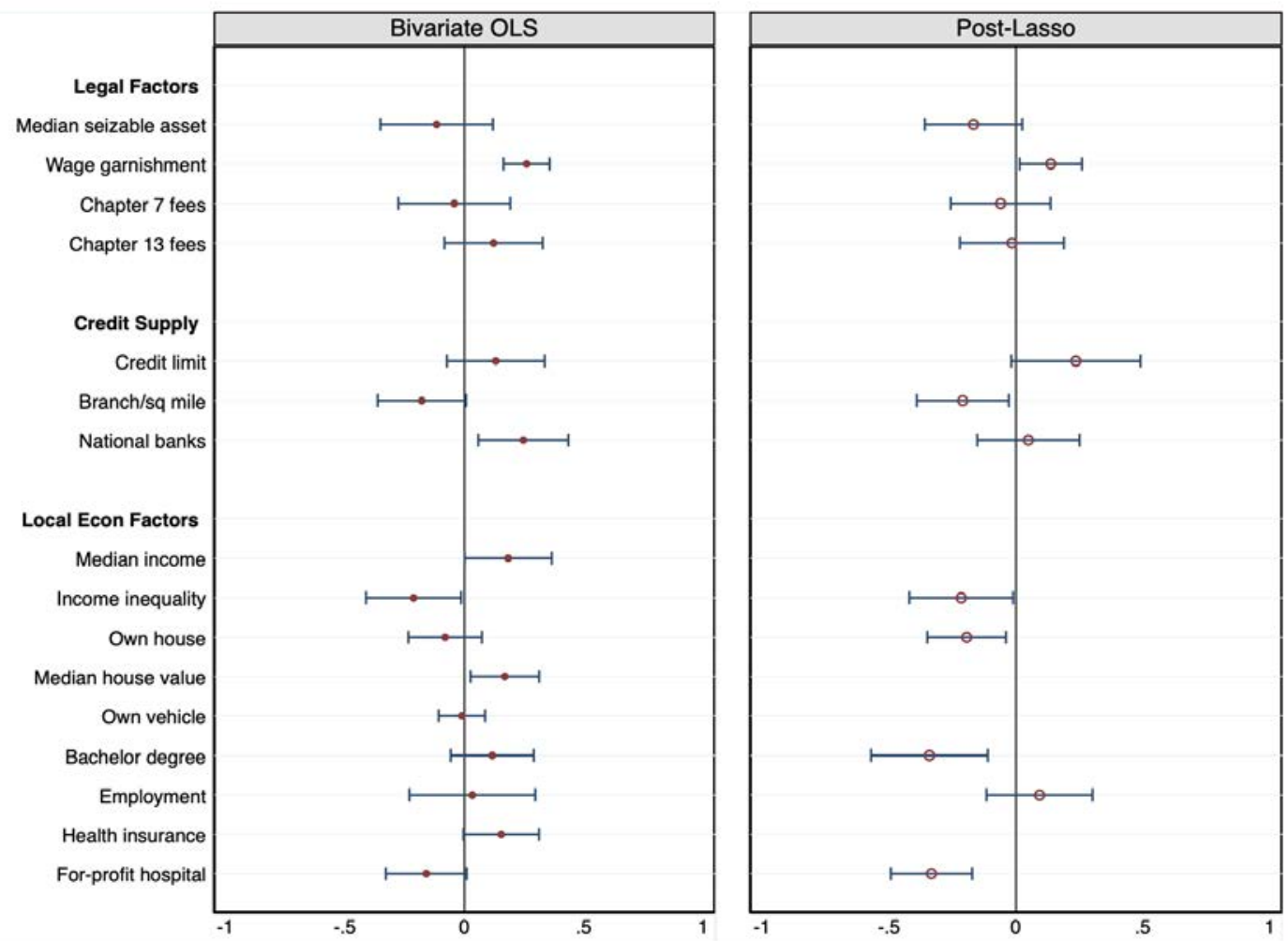

Note: Figure shows bivariate OLS regression coefficients after partialling out combined bankruptcy filings (left panel) and post-Lasso multivariate regression coefficients (right panel) of the place effect of Chapter 7 bankruptcy filings in the past three years. The dependent variable and all covariates have been standardized to have a mean of zero and a standard deviation of one. To obtain the post-Lasso estimates, we first run a Lasso regression on the full set of covariates including combined bankruptcy filings, with the penalty level chosen by a 4-fold cross-validation to minimize mean squared error. We then run an OLS regression on the set of covariates chosen by the Lasso regression. 


\section{Figure A20: Correlates of Place Effects: Chapter 13 Filings Controlling for Com- bined Filings}
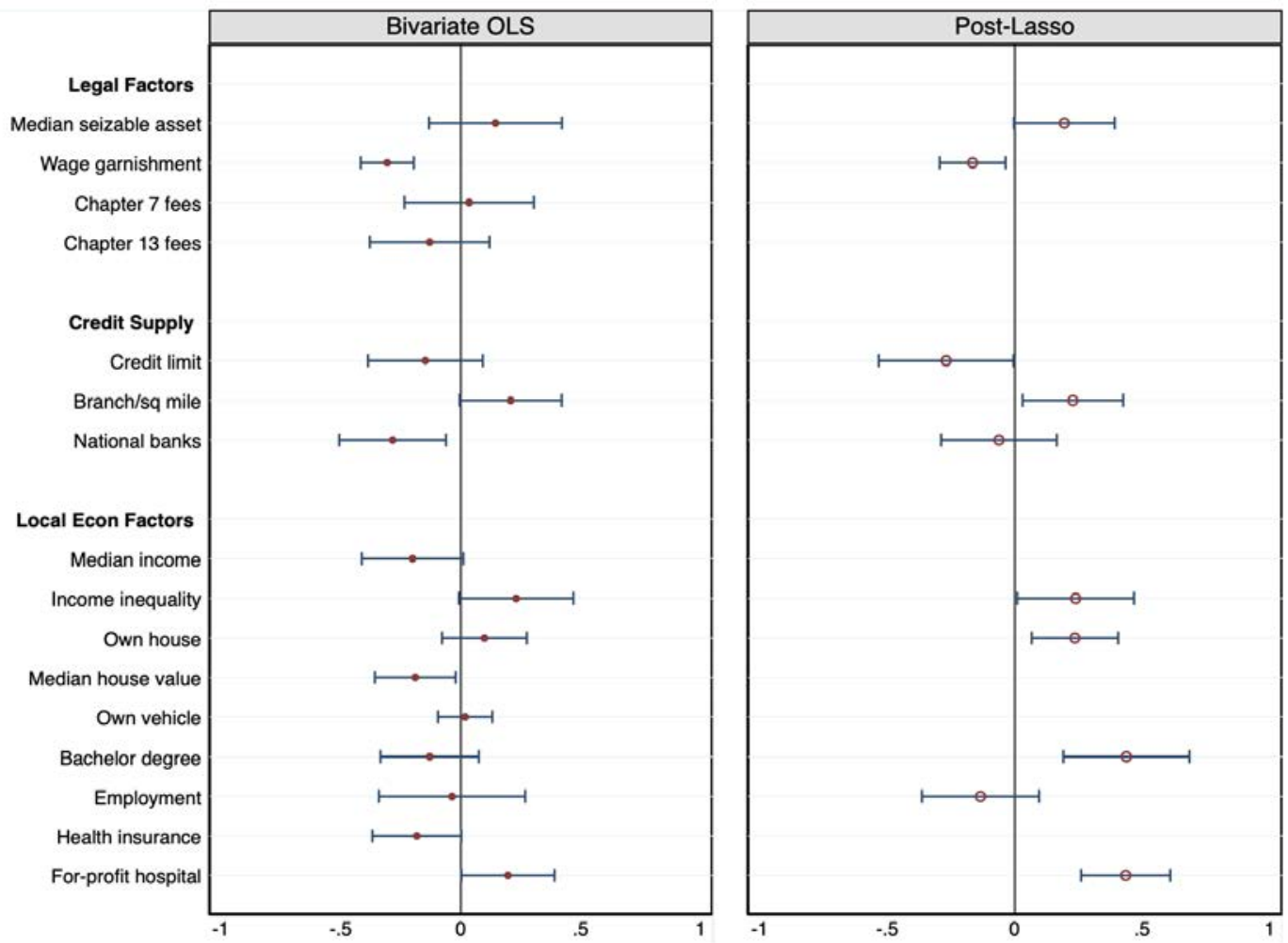

Note: Figure shows bivariate OLS regression coefficients after partialling out combined bankruptcy filings (left panel) and post-Lasso multivariate regression coefficients (right panel) of the place effect of Chapter 13 bankruptcy filings in the past three years. The dependent variable and all covariates have been standardized to have a mean of zero and a standard deviation of one. To obtain the post-Lasso estimates, we first run a Lasso regression on the full set of covariates including combined bankruptcy filings, with the penalty level chosen by a 4-fold cross-validation to minimize mean squared error. We then run an OLS regression on the set of covariates chosen by the Lasso regression. 


\section{Figure A21: Bankruptcy Filings across Income}

(A) Chapter 7 Filings (\%)

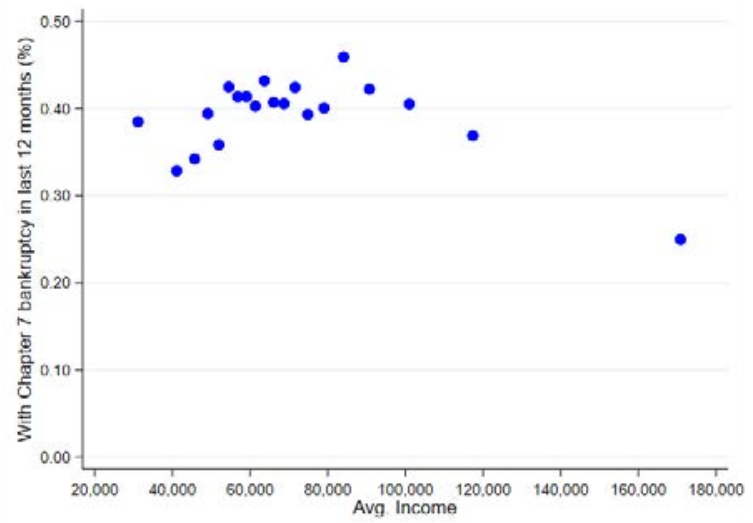

(B) Chapter 13 Filings

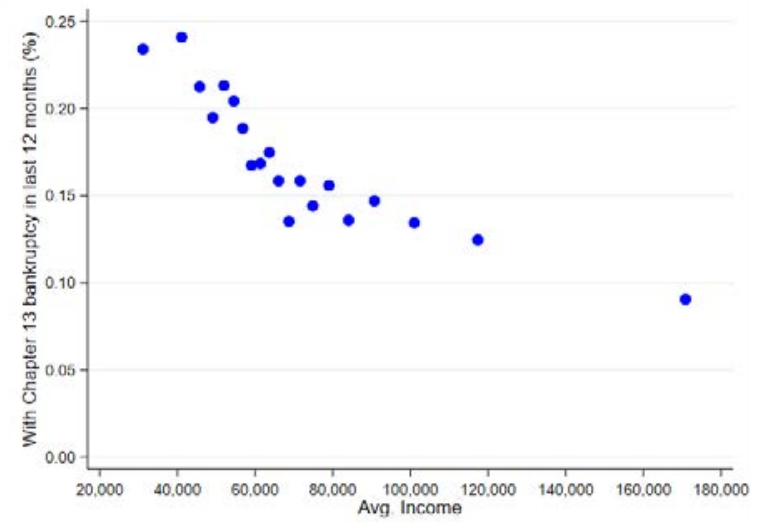

(C) Combined Filings

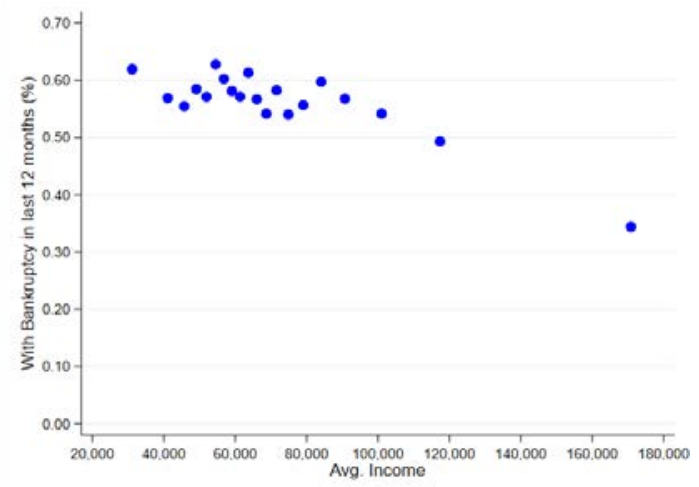

Note: Binned scatter plots show the relationship between bankruptcy filing and average income at zip code level. The y-axis corresponds to the fraction of individuals who filed for Chapter 7,13, or any bankruptcy in the past 12 months, constructed using pooled 10\% random samples of TransUnion credit records from June 2009-2016. The x-axis corresponds to average income at zip code level from 2013-2017 5-year ACS. 
Table A1: Breakdown of Collection Accounts

\begin{tabular}{lccc}
\hline Creditor Types & \% Current Balance & \% Number of Accounts & Average Balance \\
\hline Retail & 3.856 & 4.336 & 899.8 \\
Medical/Health Care & 51.869 & 58.678 & 894.8 \\
Oil Company & 0.004 & 0.008 & 576.9 \\
Government & 1.385 & 2.237 & 626.6 \\
Personal Service & 0.445 & 0.403 & $1,118.5$ \\
Insurance & 0.367 & 1.149 & 322.9 \\
Educational & 3.996 & 0.823 & $4,912.1$ \\
Banking & 3.904 & 1.232 & $3,207.6$ \\
Rental/Leasing & 4.391 & 1.934 & $2,298.1$ \\
Utilities & 3.278 & 5.746 & 577.4 \\
Cable/Cellular & 7.313 & 10.964 & 675.0 \\
Financial & 4.620 & 2.862 & $1,633.2$ \\
Credit Union & 0.182 & 0.066 & $2,801.0$ \\
Automotive & 0.299 & 0.082 & $3,670.1$ \\
Check Guarantee & 0.019 & 0.037 & 528.5 \\
NA & 14.073 & 9.443 & $1,508.3$ \\
\hline
\end{tabular}

Note: Table shows a break down of collection accounts as of June 2015 in TransUnion by creditor types. 
Table A2: Frequency of Moves

\begin{tabular}{lcccccc}
\hline & 2005 & 2005 & 2005 & 2015 & 2015 & 2015 \\
Pct of population (\%) & TU & CPS & ACS & TU & CPS & ACS \\
\hline$\quad$ From 1 year ago & & & & & & \\
Any move &. & 13.19 & 16.12 &. & 11.07 & 14.55 \\
Across zipcode & 13.23 &. &. & 8.82 &. &. \\
Across county & 7.60 & 5.48 &. & 4.71 & 3.87 &. \\
Across State & 4.07 & 2.65 & 2.61 & 2.19 & 1.68 & 2.42 \\
$\quad$ & & & & & & \\
$\quad$ From 5 years ago & & & & & & \\
Any move &. & 38.28 &. &. & 32.73 &. \\
Across zipcode & 35.56 &. &. & 25.56 &. &. \\
Across county & 19.83 &. &. & 14.39 &. &. \\
Across State & 9.59 & 8.25 &. & 6.98 & 5.69 &. \\
\hline
\end{tabular}

Note: Table shows the frequencies of moves during the last 1 and 5 years in the TransUnion, CPS, and ACS data. In the CPS and ACS, we restrict the analysis to persons between 20 and 80 years old to match the sample restrictions in the TransUnion data. Missing cells indicate that the measure is not available. 
Table A3: Number of Non-Movers Used to Construct $\hat{\delta}_{i}$

\begin{tabular}{lcccccccccc}
\hline \hline No. Non-Movers & Mean & Pct 1 & Pct 5 & Pct 10 & Pct 25 & Pct 50 & Pct 75 & Pct 90 & Pct 95 & Pct 99 \\
\hline Zip & 3,795 & 100 & 353 & 671 & 1,631 & 3,224 & 5,320 & 7,528 & 9,185 & 12,989 \\
Zip $\times$ age bin & 956 & 34 & 90 & 156 & 357 & 748 & 1,308 & 1,969 & 2,501 & 3,842 \\
County & 71,162 & 1,601 & 3,664 & 5,799 & 12,762 & 37,224 & 91,388 & 172,316 & 238,733 & 549,968 \\
\hline \hline
\end{tabular}

Note: Table shows summary statistics of the number of non-movers used to construct different versions of $\hat{\delta}_{i}$. The statistics pool across origins and destinations and are weighed by the number of movers so that they are representative for our sample. For example, the mean should be interpreted as the average number of non-movers in each mover's origin or destination. 
Table A4: Event-Study Estimates: Larger Sample

\begin{tabular}{|c|c|c|c|c|c|}
\hline \multirow[b]{2}{*}{ Financial distress measures } & \multicolumn{5}{|c|}{$\begin{array}{l}\text { Fraction converged to outcome } \\
\text { at destination } 4 \text { years post move }\end{array}$} \\
\hline & $\begin{array}{c}(1) \\
\text { All movers }\end{array}$ & $\begin{array}{c}(2) \\
\text { Same origin }\end{array}$ & $\begin{array}{c}(3) \\
\text { Same destination }\end{array}$ & $\begin{array}{c}(4) \\
\text { Zip } \times \text { age level }\end{array}$ & $\begin{array}{c}(5) \\
\text { County level } \\
\end{array}$ \\
\hline Debt in collections 3 years & $\begin{array}{c}0.0673 \\
(0.0114)\end{array}$ & $\begin{array}{c}0.0549 \\
(0.0116)\end{array}$ & $\begin{array}{c}0.0457 \\
(0.0119)\end{array}$ & $\begin{array}{c}0.0584 \\
(0.0099)\end{array}$ & $\begin{array}{c}0.1364 \\
(0.0156)\end{array}$ \\
\hline Debt in collections & $\begin{array}{c}0.0605 \\
(0.0068)\end{array}$ & $\begin{array}{c}0.0458 \\
(0.0069)\end{array}$ & $\begin{array}{c}0.0491 \\
(0.0070)\end{array}$ & $\begin{array}{c}0.0517 \\
(0.0059)\end{array}$ & $\begin{array}{c}0.1059 \\
(0.0091)\end{array}$ \\
\hline Medical collections & $\begin{array}{c}0.1510 \\
(0.0090)\end{array}$ & $\begin{array}{c}0.1114 \\
(0.0092)\end{array}$ & $\begin{array}{c}0.1426 \\
(0.0091)\end{array}$ & $\begin{array}{c}0.1144 \\
(0.0076)\end{array}$ & $\begin{array}{c}0.1993 \\
(0.0113)\end{array}$ \\
\hline Non-medical collections & $\begin{array}{c}0.0467 \\
(0.0086)\end{array}$ & $\begin{array}{c}0.0372 \\
(0.0087)\end{array}$ & $\begin{array}{c}0.0414 \\
(0.0089)\end{array}$ & $\begin{array}{c}0.0432 \\
(0.0074)\end{array}$ & $\begin{array}{c}0.0730 \\
(0.0120)\end{array}$ \\
\hline Credit card delinquency 3 years & $\begin{array}{c}0.0464 \\
(0.0203)\end{array}$ & $\begin{array}{c}0.0698 \\
(0.0204)\end{array}$ & $\begin{array}{c}0.0152 \\
(0.0204)\end{array}$ & $\begin{array}{c}0.0291 \\
(0.0151)\end{array}$ & $\begin{array}{c}0.0617 \\
(0.0331)\end{array}$ \\
\hline Chapter 7 filings 3 years & $\begin{array}{c}0.1735 \\
(0.0352)\end{array}$ & $\begin{array}{c}0.1137 \\
(0.0360)\end{array}$ & $\begin{array}{c}0.1745 \\
(0.0363)\end{array}$ & $\begin{array}{c}0.0441 \\
(0.0234)\end{array}$ & $\begin{array}{c}0.3845 \\
(0.0602)\end{array}$ \\
\hline Chapter 13 filings 3 years & $\begin{array}{c}0.2611 \\
(0.0361)\end{array}$ & $\begin{array}{c}0.3171 \\
(0.0372)\end{array}$ & $\begin{array}{c}0.1581 \\
(0.0391)\end{array}$ & $\begin{array}{c}0.1433 \\
(0.0261)\end{array}$ & $\begin{array}{c}0.3382 \\
(0.0489)\end{array}$ \\
\hline
\end{tabular}

Note: Table shows place-based effects $\theta_{r}$ at 4 years (16 quarters) after the move from event study regressions of financial distress on the size of the move $\hat{\delta}_{i}$, individual and time fixed effects, and other controls. We include a larger sample of individuals who moved across CZs between 2004 and 2012. Standard errors, clustered by origin $\times$ destination $C Z$, are shown in parentheses. Column (1) shows the baseline specification. In column (2), we isolate variation from moves "from the same place" by including fully interacted origin CZ $\times$ event time fixed effects. In column (3), we isolate variation from moves "to the same place" by including fully interacted destination $\mathrm{CZ} \times$ event time fixed effects. In columns (4) and (5), we show alternative specifications where we construct $\hat{\delta}_{i}$ using non-movers in the movers' origin and destination zip code $\times 10$ year age-bin, and using non-movers in the movers' origin and destination county. 
Table A5: Place Effects From Two-Way Fixed Effects Model

\begin{tabular}{|c|c|c|c|c|c|}
\hline & $\begin{array}{c}1) \\
\text { Above / } \\
\text { below } \\
\text { median }\end{array}$ & $\begin{array}{c}(2) \\
\text { Top \& } \\
\text { bottom } \\
25 \%\end{array}$ & $\begin{array}{c}(3) \\
\text { Top \& } \\
\text { bottom } \\
10 \%\end{array}$ & $\begin{array}{c}(4) \\
\text { Top \& } \\
\text { bottom } \\
5 \%\end{array}$ & $\begin{array}{c}\text { (5) } \\
\text { Deep South } \\
\text { vs } \\
\text { Upper Midwest }\end{array}$ \\
\hline \multicolumn{6}{|l|}{ Debt in collections 3 years } \\
\hline Overall & 11.32 & 18.59 & 27.35 & 32.70 & 14.10 \\
\hline Place & 2.02 & 3.10 & 4.52 & 6.23 & 1.23 \\
\hline \multirow[t]{2}{*}{ Share of difference due to place } & 17.82 & 16.67 & 16.53 & 19.05 & 8.70 \\
\hline & $(1.20)$ & $(1.07)$ & (1.19) & $(1.68)$ & (1.93) \\
\hline \multicolumn{6}{|l|}{ Debt in collections } \\
\hline Overall & 13.48 & 22.03 & 31.93 & 38.81 & 16.89 \\
\hline Place & 2.22 & 3.26 & 5.78 & 6.73 & 1.46 \\
\hline \multirow[t]{2}{*}{ Share of difference due to place } & 16.48 & 14.78 & 18.12 & 17.35 & 8.66 \\
\hline & $(1.15)$ & $(1.02)$ & $(1.22)$ & (1.59) & $(1.87)$ \\
\hline \multicolumn{6}{|l|}{ Medical collections } \\
\hline Overall & 12.38 & 19.51 & 28.05 & 32.60 & 12.90 \\
\hline Place & 2.87 & 3.80 & 6.60 & 7.75 & 1.23 \\
\hline \multirow[t]{2}{*}{ Share of difference due to place } & 23.21 & 19.48 & 23.52 & 23.77 & 9.55 \\
\hline & $(1.21)$ & $(1.31)$ & $(1.70)$ & $(2.08)$ & $(2.65)$ \\
\hline \multicolumn{6}{|l|}{ Non-medical collections } \\
\hline Overall & 9.97 & 16.48 & 24.71 & 29.74 & 11.96 \\
\hline Place & 1.30 & 1.98 & 3.03 & 4.31 & 0.38 \\
\hline \multirow[t]{2}{*}{ Share of difference due to place } & 13.03 & 11.99 & 12.26 & 14.49 & 3.18 \\
\hline & (1.63) & $(1.56)$ & $(1.90)$ & (1.85) & $(2.81)$ \\
\hline \multicolumn{6}{|l|}{ Credit card delinquency 3 years } \\
\hline Overall & 3.10 & 5.83 & 8.97 & 10.67 & 5.01 \\
\hline Place & 0.70 & 1.20 & 1.91 & 1.76 & 0.71 \\
\hline \multirow{2}{*}{ Share of difference due to place } & 22.47 & 20.53 & 21.30 & 16.50 & 14.19 \\
\hline & $(2.83)$ & $(3.16)$ & $(4.04)$ & $(5.32)$ & $(5.56)$ \\
\hline \multicolumn{6}{|l|}{ Chapter 7 filings 3 years } \\
\hline Overall & 7.00 & 12.63 & 18.81 & 24.95 & -1.11 \\
\hline Place & 3.06 & 4.93 & 8.11 & 13.53 & -1.08 \\
\hline \multirow[t]{2}{*}{ Share of difference due to place } & 43.72 & 39.00 & 43.09 & 54.23 & 97.49 \\
\hline & (5.39) & $(5.02)$ & $(6.29)$ & (13.96) & $(131.86)$ \\
\hline \multicolumn{6}{|l|}{ Chapter 13 filings 3 years } \\
\hline Overall & 4.53 & 9.03 & 18.07 & 24.15 & 9.02 \\
\hline Place & 2.31 & 4.40 & 7.81 & 9.33 & 2.99 \\
\hline \multirow[t]{2}{*}{ Share of difference due to place } & 50.99 & 48.71 & 43.23 & 38.63 & 33.13 \\
\hline & $(3.82)$ & $(4.67)$ & (5.64) & $(5.80)$ & (8.04) \\
\hline
\end{tabular}

Note: Table shows place effects from a two-way fixed effects model (Equation 2). Column (1) decomposes differences in outcomes between CZs with financial distress above versus below the median; columns (2) through (4) decompose differences in outcomes between CZs with financial distress in the top versus bottom $25 \%, 10 \%$ and $5 \%$ of CZs; column (5) decomposes differences in outcomes between the Deep South and Upper Midwest. For each financial distress measure, rows show the average difference in the outcomes, the average amount attributable to place, and the share of the difference attributable to place. Standard errors for the place share, calculated by drawing 50 samples of individuals with replacement, are shown in parentheses. 
Table A6: Event-Study Estimates: Heterogeneity

\begin{tabular}{|c|c|c|c|c|c|}
\hline \multirow[b]{2}{*}{ Financial distress measures } & \multicolumn{5}{|c|}{$\begin{array}{l}\text { Fraction converged to outcome } \\
\text { at destination } 6 \text { years post move }\end{array}$} \\
\hline & $\begin{array}{l}(1) \\
\text { All movers }\end{array}$ & $\begin{array}{c}(2) \\
\text { Positive moves }\end{array}$ & $\begin{array}{c}\text { (3) } \\
\text { Negative moves }\end{array}$ & $\begin{array}{c}(4) \\
\text { Move }<40 \\
\end{array}$ & $\begin{array}{c}(5) \\
\text { Move } \geq 40\end{array}$ \\
\hline Debt in collections 3 years & $\begin{array}{c}0.0681 \\
(0.0122)\end{array}$ & $\begin{array}{c}0.0482 \\
(0.0246)\end{array}$ & $\begin{array}{c}0.0453 \\
(0.0248)\end{array}$ & $\begin{array}{c}0.0766 \\
(0.0249)\end{array}$ & $\begin{array}{c}0.0684 \\
(0.0135)\end{array}$ \\
\hline Debt in collections & $\begin{array}{c}0.0788 \\
(0.0095)\end{array}$ & $\begin{array}{c}0.0645 \\
(0.0191)\end{array}$ & $\begin{array}{c}0.0574 \\
(0.0200)\end{array}$ & $\begin{array}{c}0.0759 \\
(0.0190)\end{array}$ & $\begin{array}{c}0.0810 \\
(0.0109)\end{array}$ \\
\hline Medical collections & $\begin{array}{c}0.2042 \\
(0.0130)\end{array}$ & $\begin{array}{c}0.2099 \\
(0.0248)\end{array}$ & $\begin{array}{c}0.1173 \\
(0.0269)\end{array}$ & $\begin{array}{c}0.2336 \\
(0.0260)\end{array}$ & $\begin{array}{c}0.1955 \\
(0.0140)\end{array}$ \\
\hline Non-medical collections & $\begin{array}{c}0.0409 \\
(0.0120)\end{array}$ & $\begin{array}{l}-0.0846 \\
(0.0260)\end{array}$ & $\begin{array}{c}0.1405 \\
(0.0240)\end{array}$ & $\begin{array}{c}0.0173 \\
(0.0250)\end{array}$ & $\begin{array}{c}0.0485 \\
(0.0136)\end{array}$ \\
\hline Credit card delinquency 3 years & $\begin{array}{c}0.0473 \\
(0.0215)\end{array}$ & $\begin{array}{c}0.1060 \\
(0.0456)\end{array}$ & $\begin{array}{l}-0.0071 \\
(0.0470)\end{array}$ & $\begin{array}{c}0.1205 \\
(0.0447)\end{array}$ & $\begin{array}{c}0.0321 \\
(0.0239)\end{array}$ \\
\hline Chapter 7 filings 3 years & $\begin{array}{c}0.2665 \\
(0.0500)\end{array}$ & $\begin{array}{c}0.2276 \\
(0.0934)\end{array}$ & $\begin{array}{c}0.2423 \\
(0.1004)\end{array}$ & $\begin{array}{c}0.2383 \\
(0.0982)\end{array}$ & $\begin{array}{c}0.2777 \\
(0.0577)\end{array}$ \\
\hline Chapter 13 filings 3 years & $\begin{array}{c}0.3298 \\
(0.0503)\end{array}$ & $\begin{array}{c}0.4518 \\
(0.0756)\end{array}$ & $\begin{array}{c}0.1944 \\
(0.1198)\end{array}$ & $\begin{array}{c}0.3924 \\
(0.0903)\end{array}$ & $\begin{array}{c}0.3050 \\
(0.0624)\end{array}$ \\
\hline
\end{tabular}

Note: Table shows place-based effects $\theta_{r}$ at 6 years (24 quarters) after the move from event study regressions of financial distress on the size of the move $\hat{\delta}_{i}$, individual and time fixed effects, and other controls. Standard errors, clustered by origin $\times$ destination $C Z$, are shown in parentheses. Column (1) shows the baseline specification. In columns (2) and (3), we report estimates from regressions estimated separately on positive moves to places with higher financial distress $\left(\hat{\delta}_{i}>0\right)$ and negative moves to places with lower financial distress $\left(\hat{\delta}_{i}<0\right)$. In columns (4) and (5), we report estimates from regressions separately on individuals who moved when they are less than 40-year-old and individuals who moved at age greater or equal to 40-year-old. 